\title{
Geophysical and Lithologic Logs of Coal Test Holes Drilled During 1980 \\ In the Plerce Reservoir and Bengough Hill Quadrangles, Albany County, Wyoming
}

\author{
by \\ Dan E. Hansen, Jean N. Weaver, \\ Margaret Stamm E11is, and Courteney Williamson
}

Open-File Report 82- 315

1982

This report is preliminary and has not been reviewed for conformity with U.S. Geological Survey editorial standards. 
Introduction- 1

Geologic Setting- 2

Summary- 3

References- 9

Lithologic and Geophysical Logs- 10

\section{ILLUSTRATIONS}

Figure 1. Sketch map showing approximate locations of dri11 sites, Rock Creek coal field, Wyoming- 6

2-3 Drill-hole location maps, Albany County, Wyoming:

2. Central part of Pierce Reservoir-Bengough $\mathrm{H} 111$ Quadrangles- 7

3. Southeast part of Pierce Reservoir Quadrangle-- 8 TABLE

Table 1. Summary of information for 19 drill holes in the Pierce Reservolr and Bengough Hill Quadrangles, Albany County, Wyoming- 
GEOPHYSICAL AND LITHOLOGIC LOGS OF COAL TEST HOLES DRILLED DURING 1980 IN THE PIERCE

RESERVOIR AND BENGOUGH HILL QUADRANGLES, ALBANY COUNTY, WYOMING

by

\author{
Dan E. Hansen, Jean N. Weaver, \\ Margaret Stamm Ellis, and Courteney Williamson
}

Introduction

The U. S. Geological Survey drilled and logged 19 test holes in the Rock Creek coal field, Albany County, Wyoming as part of the Coal Exploratory Program. The holes were drilled on Federal lands in the Pierce Reservoir and Bengough Hill quadrangles, T. 19 N., R. 77 (see fig. 1). Information for these holes is summarized in table 1 and more precise drill hole locations are shown by individual area maps (figures $2-3$ ). The holes were arilled chiefly to facilitate correlation of coal beds and associated strata and to evaluate the quality, thickness, and lateral extent of the coal beds. This report on 1980 drilling supplements a report on 1978 and 1979 drilling in these quadrangles (see Hansen, 1980).

Rotary holes were drilled by a U. S. Geological Survey truck-mounted drill using 5-1/8 inch tricone bits. Rotary pilot holes were drilled for all the designated core holes. The core was recovered using a 15-foot-1ong core barrel with a core diameter of 2.8 inch and a diamond bit size of $5-1 / 8$ inch. Recovery of core was greater than 90 percent. Drilling fluids used were air, air-water biodegradable foam, and mud. The holes were filled with heavy mud upon completion and a surface plug of cement placed therein. Drill sites were then reclaimed.

Three of the holes had to be abandoned because of drilling problems, but 
a11 were offset a short distance and completed. These three holes, PR 9, PR 10, and PR 16, were first drilled with air, but heavy water flows caused drilling problems and the offsets were drilled using heavy mud.

A general suite of logs consisting of natural gamma ray, gamma gamma (density), and resistivity were run. A caliper $10 g$ was run in five of the holes. The density $\log$ was not run in holes $\mathrm{BH}-21$ because of instrument malfunctions and a subsequent hole collapse. Geophysical logging was done by Geoscience Associates, Denver, Colorado.

Geophysical logs in this report were photographically reduced to 20 percent of the original size. The reduced vertical scale is about 1 inch to 50 feet. All measurements on the geophysical logs are in feet, but depth in meters and feet are shown with the logs.

Lithologic logs are based on field examination of drill-hole cuttings collected at 5-foot intervals and field examination of the cores. Lithologic interpretations are adjusted to the geophysical logs.

\section{Geologic Setting}

The coal beds that were drilled occur chiefly in the basal part of the Upper Cretaceous Medicine Bow Formation, which outcrops on the northwest side of the Laramie basin. The formation, 0-300 feet thick, consists of finegrained sandstones, shales, siltstones, and coals that were deposited in fresh to brackish water environments marginal to a marine shoreline. This means the coal beds and sedimentary strata were probably deposited as associated infill and swamp-marsh deposits of the relatively small bays and lagoons that had formed on the landward side of the ocean beach and other shore deposits. As a consequence, the coal beds are generally very lenticular.

Overlying the Medicine Bow Formation at a disconformity, the Hanna Formation, 0-400 feet thick, of Paleocene age consists chiefly of coarse- 
grained and conglomeratic sandstones, silty shales, and a few thin, local coal beds and associated carbonaceous shales. The Hanna Formation was deposited in a fluvial environment as channel-fill deposits, overbank strata, and a few thin backswamp deposits (coal beds).

Where the coal beds lie, the regional dip is about seven degrees southeast into the Laramie basin. However, the basin is rimmed on this northwest side by structures in which the dips become locally steep and the strike of the rock outcrops varies widely.

\section{Summary}

The coal beds that were penetrated by the drill holes and that lie at the base of the Upper Cretaceous Medicine Bow Formation in the Rock Creek coal field, northwestern Laramie basin, occur chiefly as three coal zones. The coal beds vary locally in thickness and some appear to have a very limited areal extent. The basal coal bed, however, occurs throughout most of the area drilled. This coal bed is as thick as 22 feet Coal quality data is lacking, the coals probably range from subbituminous to bituminous in rank. Coal cores from this drilling program have been submitted for analysis. 
Table 1.--Summary of information for 19 drill holes in the Bengough and Pierce Reservoir quadrangles, Albany County, Wyoming

\begin{tabular}{|c|c|c|c|c|}
\hline $\begin{array}{l}\text { Drill } \\
\text { hole }\end{array}$ & Location & Quadrangle & $\begin{array}{l}\text { Depth } \\
\text { drilled }(f t)\end{array}$ & $\begin{array}{l}\text { Depth } \\
\text { logged }(f t)\end{array}$ \\
\hline $\mathrm{PR}-8$ & $\begin{array}{l}\text { SW SW SW Sec. } 2 \text {, } \\
\text { T. } 19 \mathrm{~N}_{.}, \mathrm{R} \cdot 77 \mathrm{~W} .\end{array}$ & $\begin{array}{l}\text { Pierce } \\
\text { Reservoir }\end{array}$ & 455 & 450 \\
\hline PR-9-B ** & $\begin{array}{l}\text { SW SW NW Sec.2, } \\
\text { T. } 19 \mathrm{~N} ., \text { R. } 77 \mathrm{~W} .\end{array}$ & $\begin{array}{l}\text { Pierce } \\
\text { Reservoir }\end{array}$ & 335 & 330 \\
\hline PR-10-B ** & $\begin{array}{l}\text { NW NW NW Sec. } 2 \text {, } \\
\text { T 19N., R. } 77 \mathrm{~W} .\end{array}$ & $\begin{array}{l}\text { Pierce } \\
\text { Reservoir }\end{array}$ & 195 & 191 \\
\hline$P R-11$ & $\begin{array}{l}\text { NE NE NE Sec 2, } \\
\text { T. 19N., R. } 77 \mathrm{~W} .\end{array}$ & $\begin{array}{l}\text { Pierce } \\
\text { Reservoir }\end{array}$ & 515 & 501 \\
\hline$P R-12$ & $\begin{array}{l}\text { NE NE SE Sec. } 2 \text {, } \\
\text { T. } 19 \mathrm{~N}_{.}, \text {R. } 77 \mathrm{~W} .\end{array}$ & $\begin{array}{l}\text { Pierce } \\
\text { Reservoir }\end{array}$ & 455 & 452 \\
\hline$P R-13$ & $\begin{array}{l}\text { SE NE NE Sec. } 4 \text {, } \\
\text { T. } 19 \mathrm{~N}_{.}, \mathrm{R}_{\bullet} 77 \mathrm{~W} .\end{array}$ & $\begin{array}{l}\text { Pierce } \\
\text { Reservoir }\end{array}$ & 135 & 97 \\
\hline$P R-14$ & $\begin{array}{l}\text { NE NE SE Sec. } 4 \text {, } \\
\text { T. } 19 \mathrm{~N}_{.}, \text {R. } 77 \mathrm{~W} .\end{array}$ & $\begin{array}{l}\text { Pierce } \\
\text { Reservoir }\end{array}$ & 55 & 50 \\
\hline$P R-14-C *$ & $\begin{array}{l}\text { NE NE SE, Sec. } 4 \text {, } \\
\text { T. } 19 \mathrm{~N}_{.}, \mathrm{R}_{0} 77 \mathrm{~W} .\end{array}$ & $\begin{array}{l}\text { Pierce } \\
\text { Reservoir }\end{array}$ & 55 & 40 \\
\hline$P R-15$ & $\begin{array}{l}\text { SW SE SE Sec. } 4 \text {, } \\
\text { T. } 19 \mathrm{~N}_{\bullet}, \text { R. } 77 \mathrm{~W} .\end{array}$ & $\begin{array}{l}\text { Pierce } \\
\text { Reservoir }\end{array}$ & 115 & 112 \\
\hline$P R-15-C *$ & $\begin{array}{l}\text { SW SE SE Sec. 4, } \\
\text { T. } 19 \mathrm{~N} ., \text { R. } 77 \mathrm{~W} .\end{array}$ & $\begin{array}{l}\text { Pierce } \\
\text { Reservoir }\end{array}$ & 51 & 48 \\
\hline$P R-16-B \quad * *$ & $\begin{array}{l}\text { NW NW SW Sec. } 10 \text {, } \\
\text { T. } 19 \mathrm{~N} ., \text { R. } 77 \mathrm{~W} .\end{array}$ & $\begin{array}{l}\text { Pierce } \\
\text { Reservoir }\end{array}$ & 475 & 471 \\
\hline$P R-17$ & $\begin{array}{l}\text { SW SW SW Sec. } 10 \text {, } \\
\text { T. } 19 \mathrm{~N} ., \text { R. } 77 \mathrm{~W} .\end{array}$ & $\begin{array}{l}\text { Pierce } \\
\text { Reservoir }\end{array}$ & 555 & 530 \\
\hline$P R-18$ & $\begin{array}{l}\text { SE SE SE Sec. 10, } \\
\text { T. 19N., R. } 77 \mathrm{~W} .\end{array}$ & $\begin{array}{l}\text { Pierce } \\
\text { Reservoir }\end{array}$ & 605 & 598 \\
\hline PR-19 & $\begin{array}{l}\text { NE NE SE Sec. } 8 \\
\text { T. } 19 \mathrm{~N}_{.}, \text {R. } 77 \mathrm{~W} .\end{array}$ & $\begin{array}{l}\text { Pierce } \\
\text { Reservoir }\end{array}$ & 130 & 130 \\
\hline$P R-19-C *$ & $\begin{array}{l}\text { NE NE SE Sec. } 8 \\
\text { T. } 19 \mathrm{~N} ., \text { R. } 77 \mathrm{~W} .\end{array}$ & $\begin{array}{l}\text { Pierce } \\
\text { Reservoir }\end{array}$ & 165 & 130 \\
\hline
\end{tabular}


Table 1.--Summary of information for $19 \mathrm{drill}$ holes in the Bengough and Pierce Reservoir quadrangles, Albany County, Wyoming--Continued

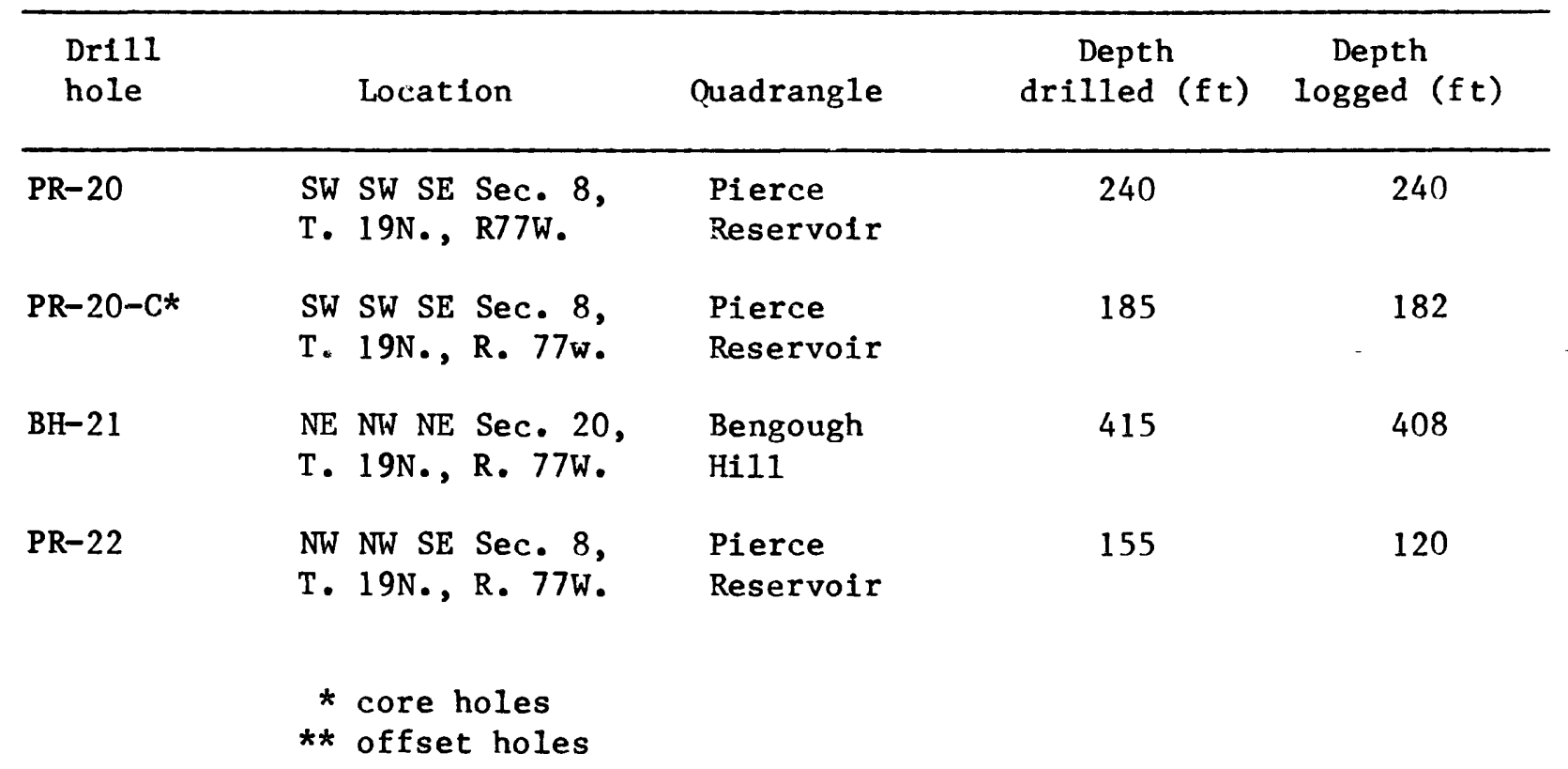




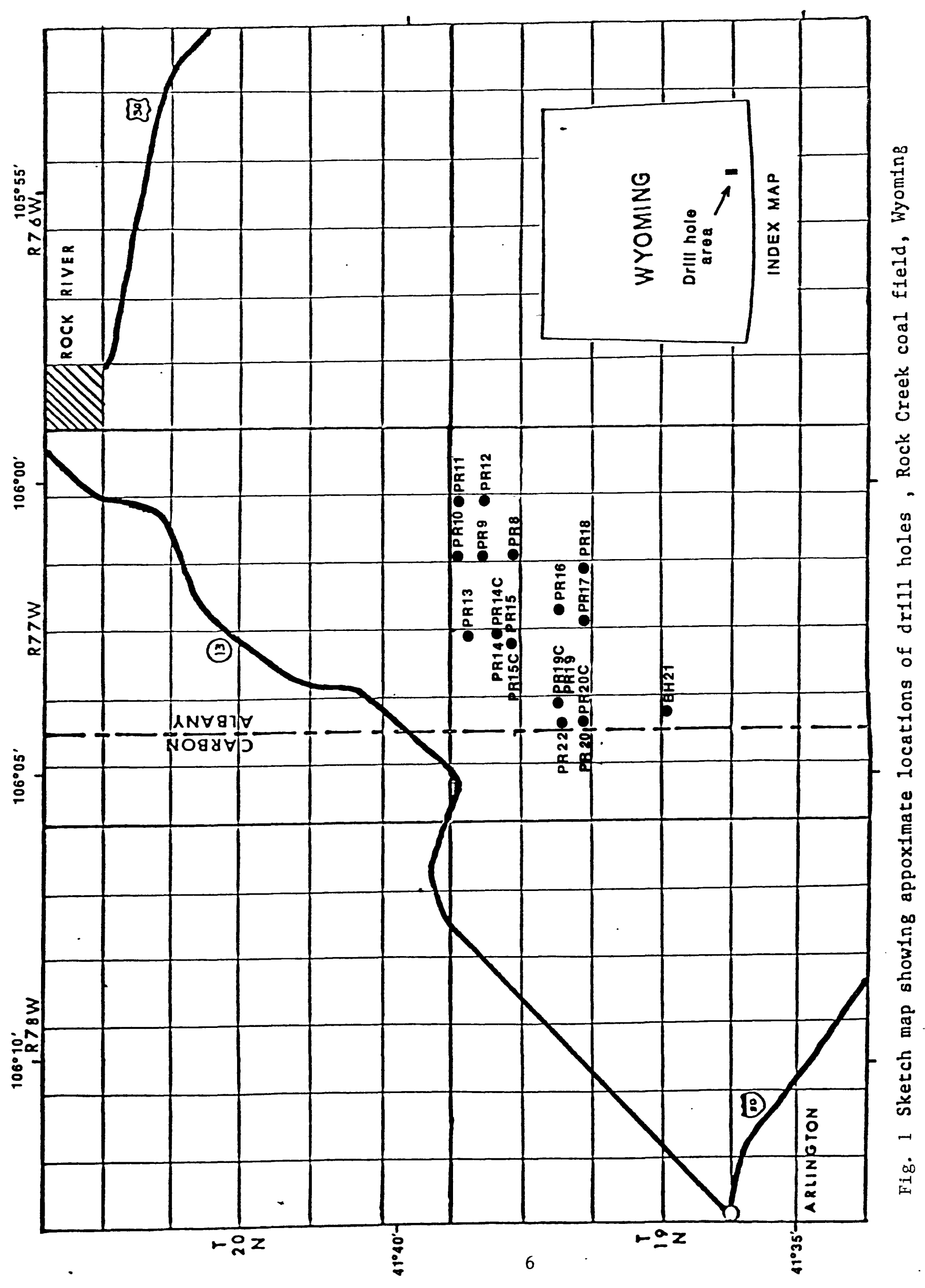




\section{Pierce Reservoir and Bengough Hill Quads.}

\section{Carbon and Albany Co. Wyoming}

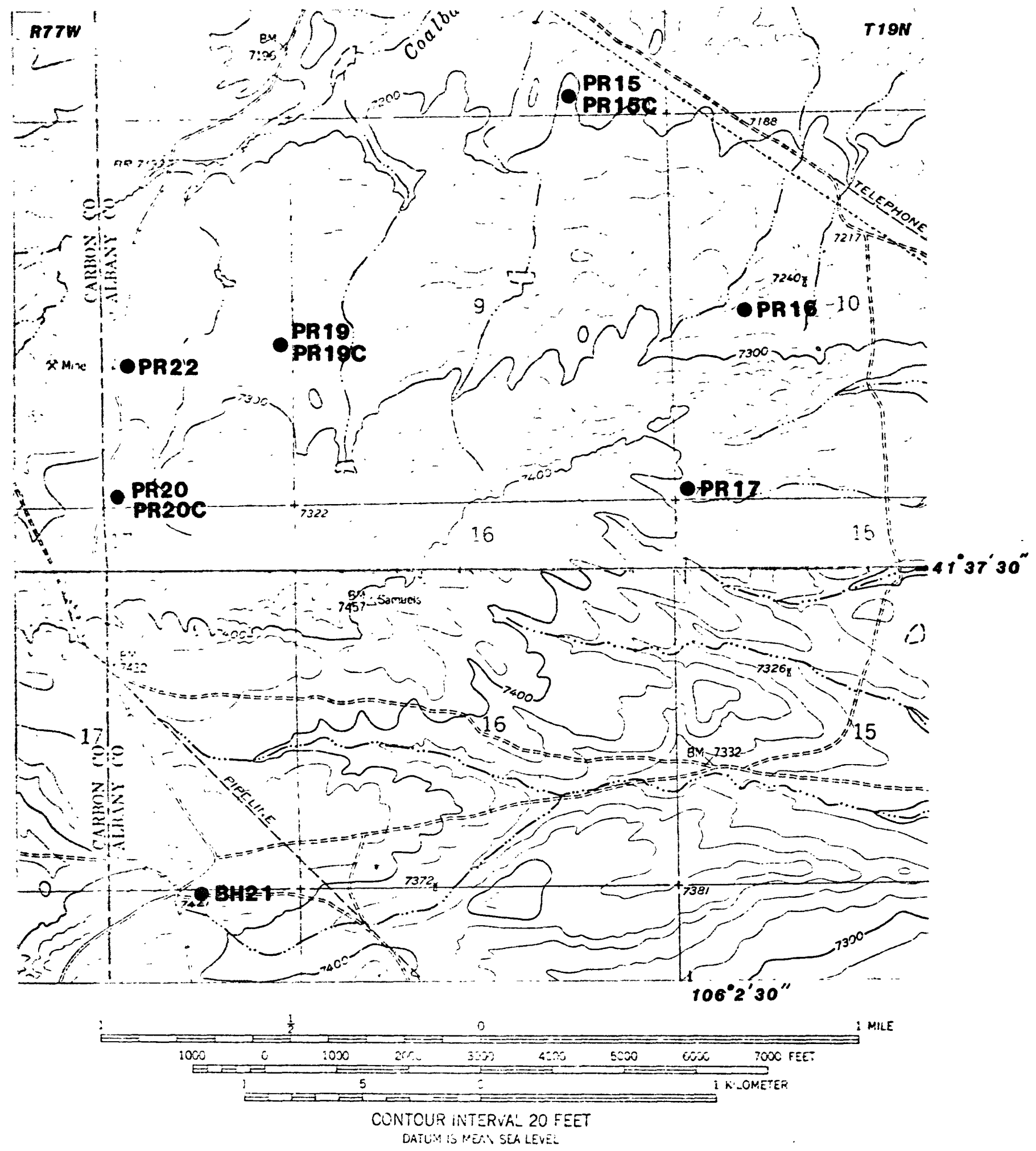

Fig.2 Drillhole location map, central part of Pierce ReservoirBengwugh Hill Quadrangle, Albany County, Wyoming 


\section{Pierce Reservoir Quad.}

\section{Albany Co. Wyoming}

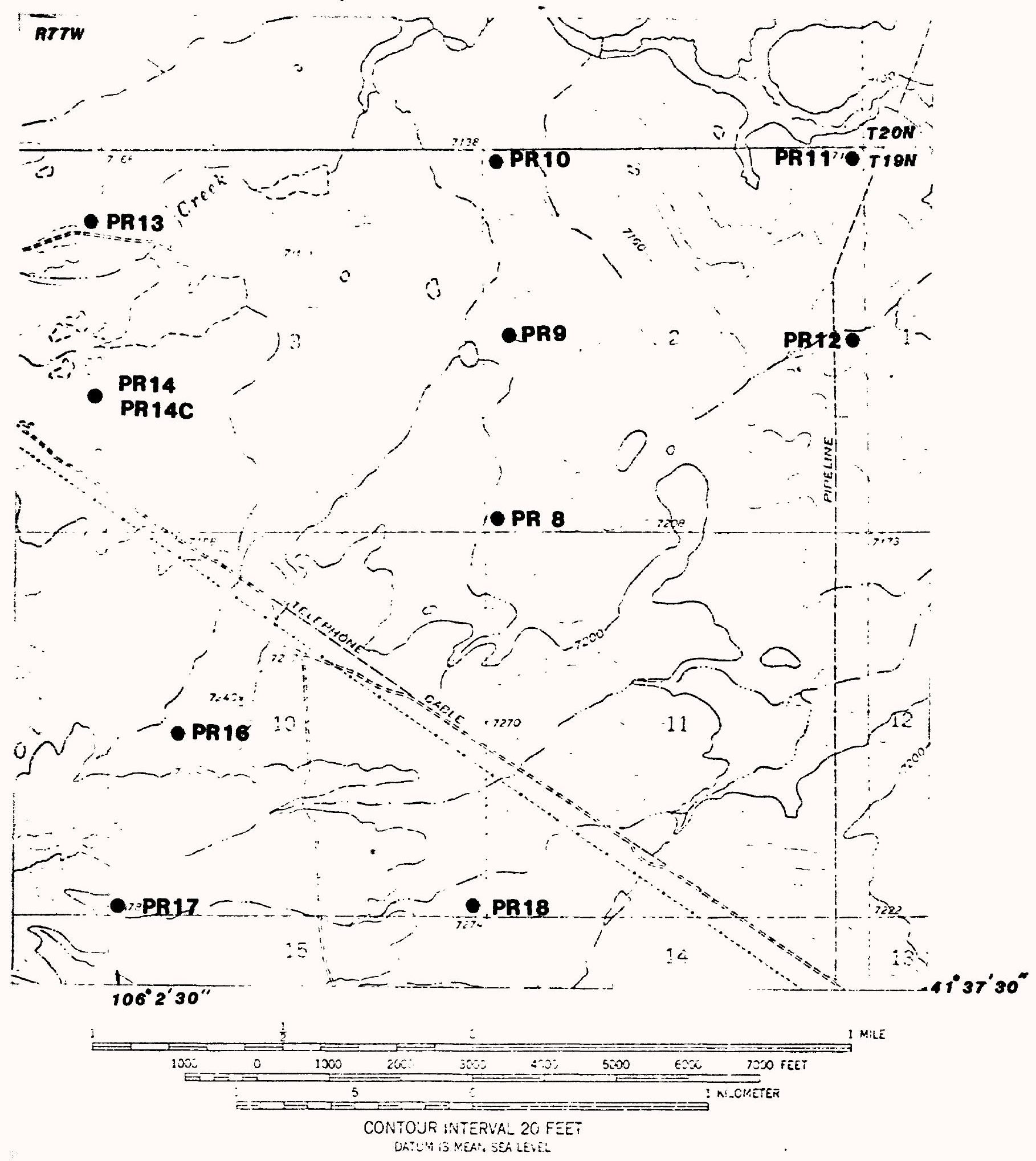

Fis.3 Dris ole location map, southeast part of Bierce Reservoir Quac *ngle, Aibany County, hyoming 


\section{Reference}

Hansen, D. E., 1980, Geophysical and Lithologic Logs of Seven Test Holes drilled during 1978 and 1979 in the Pierce Reservoir and Bengough Hill quadrangles, Albany and Carbon Counties, Wyoming: U.S. Geo1. Survey, Open-file Report 80-381. 


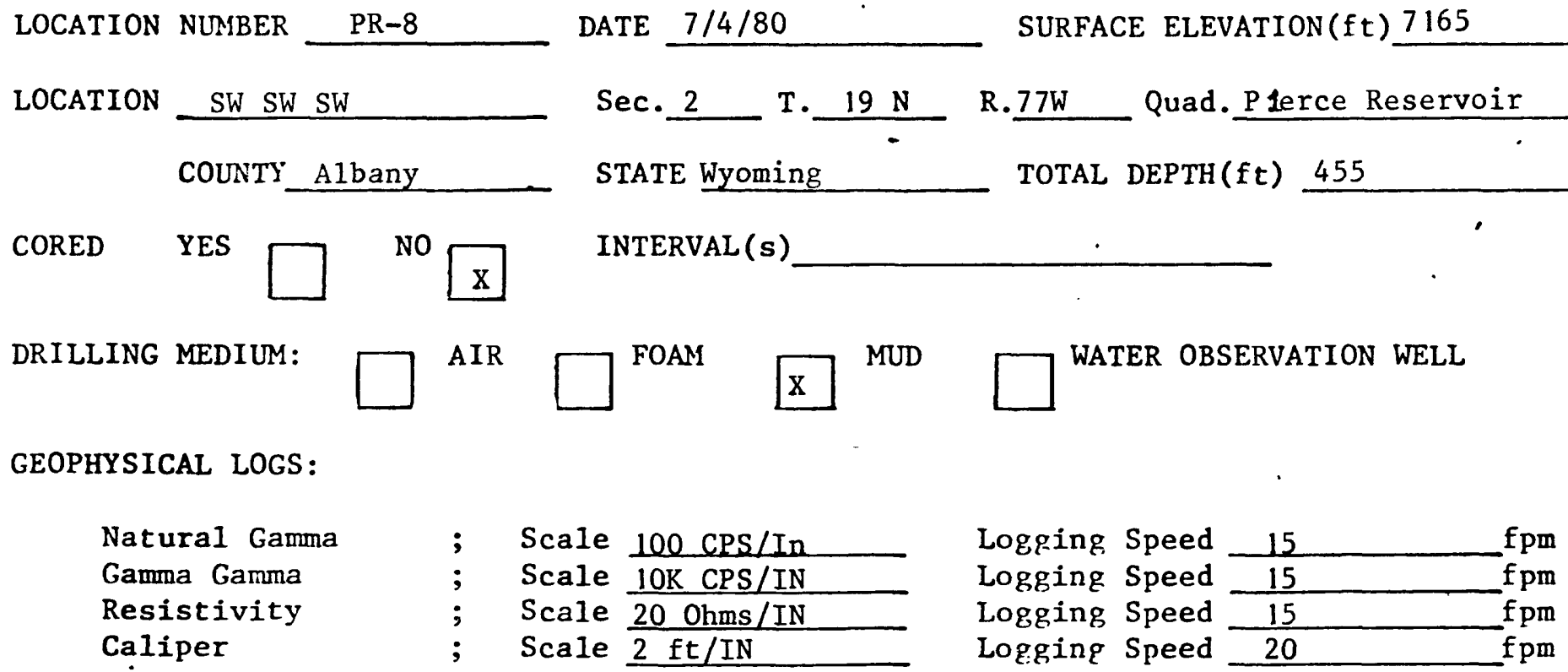

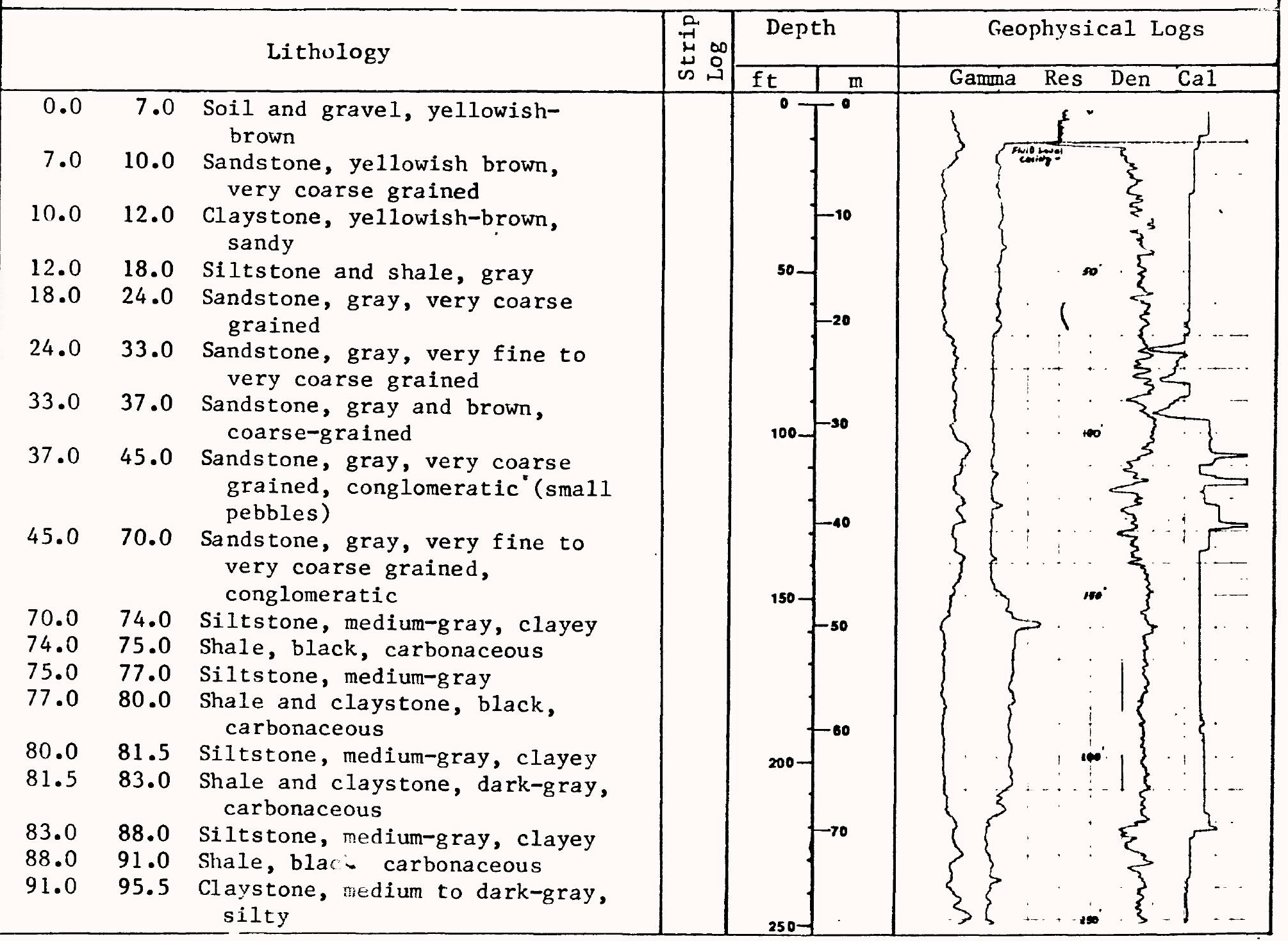




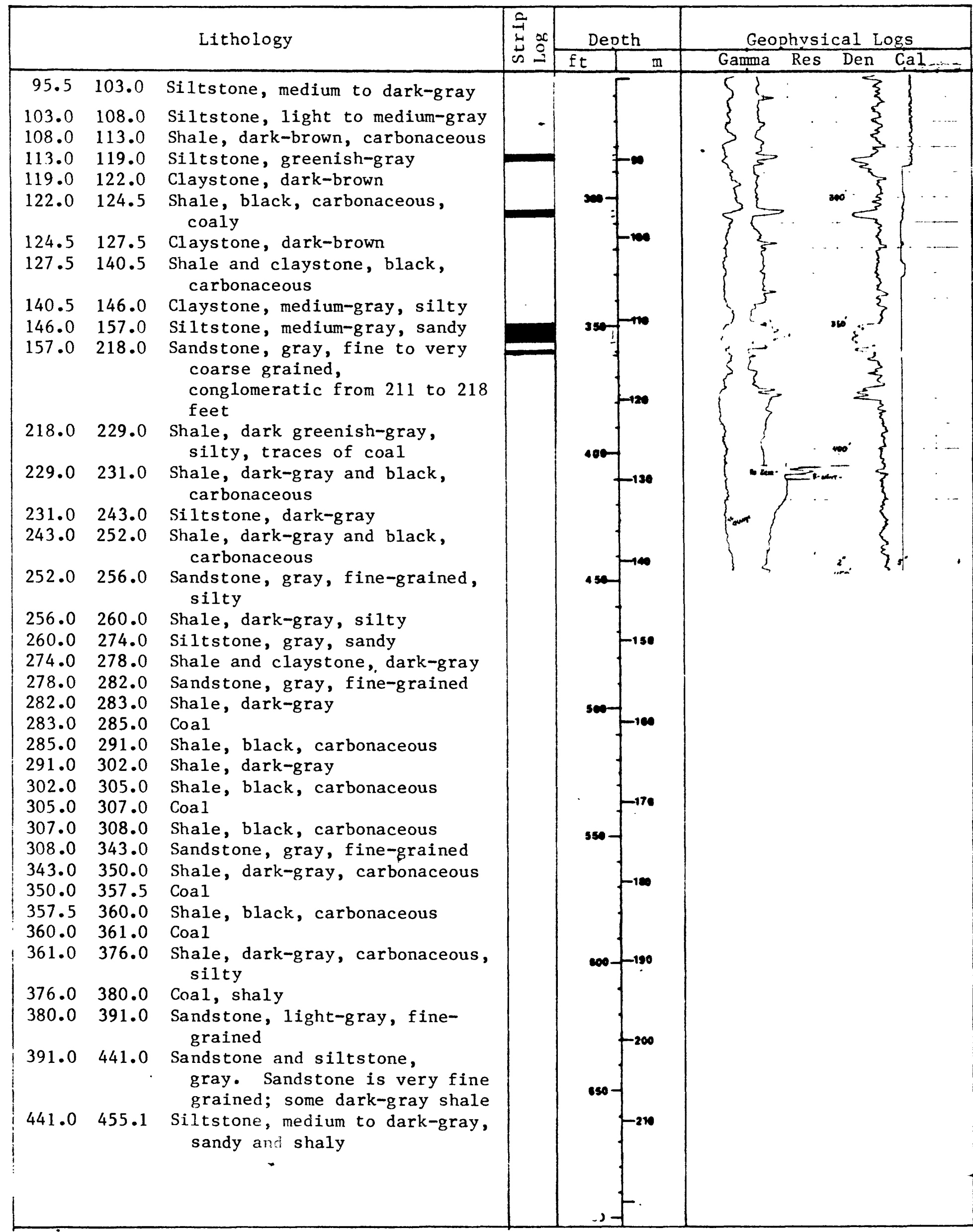


LOCATION NUNBER PR-9-B

LOCATION SW SW NW COUNTY Albany

CORED YES

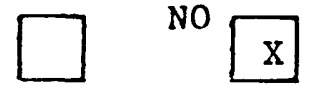

DATE $7 / 3 / 80$

Sec. 2

T.19N

STATE Wyoming

INTERVAL (s)
SURFACE ELEVATION(ft) 7160

R. 77W Quad. Pierce Reservoir TOTAL DEPTH(ft) 335

DRILLING MEDIUM:
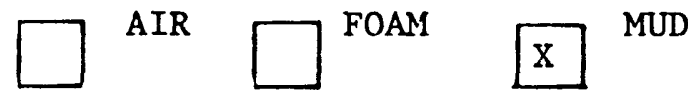

WATER OBSERVATION WELL

GEOPHYSICAL LOGS :

Natural Gamma

Gamma Gamma

Resistivity

Caliper
; Scale $100 \mathrm{CPS} / \mathrm{In}$

; Scale 4K CPS/In

; Scale 20 Ohms/In

; Scale $2 \mathrm{ft} / \mathrm{In}$
Logging. Speed

Logging Speed

Logging Speed

Logging Speed

\begin{tabular}{ll}
15 & $f \mathrm{pm}$ \\
\hline 1 & $\mathrm{fpm}$ \\
\hline 11 & $\mathrm{fpm}$ \\
\hline 1 & $\mathrm{fpm}$
\end{tabular}

fpm

$\mathrm{fpm}$

$\mathrm{fpm}$

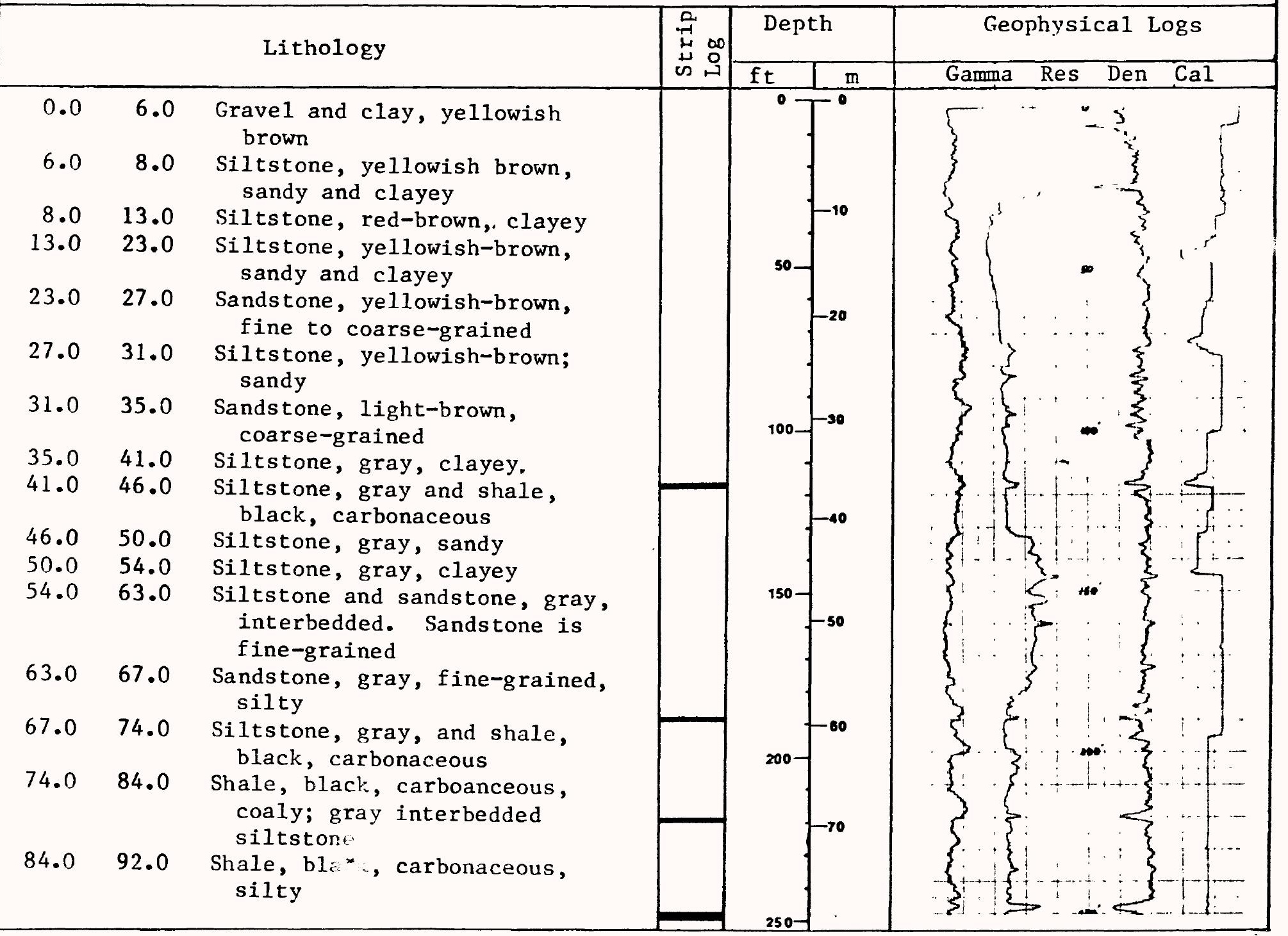




\begin{tabular}{|c|c|c|c|c|c|c|}
\hline & & Lithology & $\mid \begin{array}{ll}0 \\
5 \\
5 & a c \\
& 0\end{array}$ & De & th & Geophysical Logs \\
\hline & & & 皮品 & $\mathrm{ft}$ & $\mathrm{m}$ & Gamma Res Den Cal \\
\hline 92.0 & 103.0 & $\begin{array}{l}\text { Shale, black, carbonaceous; } \\
\text { some coal }\end{array}$ & & & $\Gamma^{-80}$ & \\
\hline 103.0 & 112.0 & $\begin{array}{l}\text { Sandstone, gray, fine-grained, } \\
\text { silty }\end{array}$ & & & & \\
\hline $\begin{array}{l}112.0 \\
114.0\end{array}$ & $\begin{array}{l}114.0 \\
116.0\end{array}$ & & & & 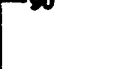 & \\
\hline 116.0 & 117.0 & $\begin{array}{l}\text { Shale, black, carbonaceous } \\
\text { Coal }\end{array}$ & & $300-$ & & \\
\hline 117.0 & 121.0 & Shale, black, carbonaceous & & & -100 & \\
\hline 121.0 & 133.0 & Siltstone, gray, sandy & & & & \\
\hline 133.0 & 156.0 & $\begin{array}{l}\text { Sandstone, gray, very coarse } \\
\text { grained }\end{array}$ & & & & \\
\hline $\begin{array}{l}156.0 \\
183.5\end{array}$ & $\begin{array}{l}183.5 \\
185.5\end{array}$ & $\begin{array}{l}\text { Sandstone, gray, fine-grained } \\
\text { Siltstone, gray }\end{array}$ & & 350- $-1-2-1-10$ & -110 & \\
\hline 185.5 & 189.0 & Shale, black, carbonaceous & & & & \\
\hline 189.0 & 190.0 & Coal, shaly & & & & \\
\hline 190.0 & 195.5 & $\begin{array}{l}\text { Shale, black, carbonaceous, } \\
\text { silty, coaly; some brownish- } \\
\text { gray claystone }\end{array}$ & & & -120 & \\
\hline 195.5 & 201.0 & Claystone, gray, partly silty & & & & \\
\hline 201.0 & 212.0 & $\begin{array}{l}\text { Sandstone, gray, coarse- } \\
\text { grained }\end{array}$ & & & $F^{-130}$ & \\
\hline 212.0 & 216.5 & Claystone, gray, silty & & & & \\
\hline 216.5 & 219.0 & $\begin{array}{l}\text { Shale, brown and black, } \\
\text { carbonaceous }\end{array}$ & & & -140 & \\
\hline 219.0 & 220.0 & Coal, shaly & & 450 & & \\
\hline 220.0 & 224.5 & $\begin{array}{l}\text { Sandstone, gray, fine-grained, } \\
\text { silty }\end{array}$ & & & F 150 & \\
\hline $\begin{array}{l}224.5 \\
229.0\end{array}$ & 229.0 & Siltstone, gray, clayey & & & $\Gamma$ & \\
\hline 229.0 & 241.0 & Sandstone, gray, fine-grained, & & 500 & & \\
\hline 241.0 & 242.0 & Shale, dark-gray & & & -160 & \\
\hline 242.0 & 243.0 & $\begin{array}{l}\text { Siltstone, gray } \\
\text { Shale, black, carbonaceous }\end{array}$ & & & & \\
\hline $\begin{array}{l}243.0 \\
245.5\end{array}$ & $\begin{array}{l}245.5 \\
247.0\end{array}$ & $\begin{array}{l}\text { Shale, black, carbonaceous } \\
\text { Sandstone, brownish-gray, very } \\
\text { fine grained }\end{array}$ & & & & \\
\hline $\begin{array}{l}247.0 \\
248.0\end{array}$ & $\begin{array}{l}248.0 \\
250.0\end{array}$ & $\begin{array}{l}\text { Ilne grained } \\
\text { Shale, black, carbonaceous } \\
\text { Coal }\end{array}$ & & 550 & & \\
\hline 250.0 & 266.0 & $\begin{array}{l}\text { Siltstone, gray and brownish- } \\
\text { gray }\end{array}$ & & & - 180 & \\
\hline 266.0 & 269.0 & Sands tone, gray, fine-grained, & & & & \\
\hline 269.0 & 273.0 & $\begin{array}{l}\text { Claystone, brownish-gray, } \\
\text { silty }\end{array}$ & & & & \\
\hline 273.0 & 281.0 & $\begin{array}{l}\text { Sandstone, gray, fine-grained, } \\
\text { silty }\end{array}$ & & $600-$ & -190 & \\
\hline $\begin{array}{l}281.0 \\
285.0\end{array}$ & $\begin{array}{l}285.0 \\
288.0\end{array}$ & $\begin{array}{l}\text { Shale, black, carbonaceous } \\
\text { Coal }\end{array}$ & & & & \\
\hline 288.0 & 291.0 & Shale, black, carbonaceous & & & $\dagger^{200}$ & \\
\hline 291.0 & 300.0 & Siltstone, gray, sandy & & & & \\
\hline 300.0 & 303.0 & Shale, black, carbonaceous & & $650-$ & & \\
\hline $\begin{array}{l}303.0 \\
310.0\end{array}$ & $\begin{array}{l}310.0 \\
312.0\end{array}$ & $\begin{array}{l}\text { Coal } \\
\text { Shale, black, carbonaceous }\end{array}$ & & & -210 & \\
\hline 312.0 & 313.0 & Coal, shat. & & & & \\
\hline 313.0 & 322.0 & Sandstone, gray, very fine & & & & \\
\hline 322.0 & 328.0 & $\begin{array}{l}\text { gralned, } \mathrm{s} \\
\text { Coal }\end{array}$ & & 700 & & \\
\hline
\end{tabular}



LOCATION NUNBER PR-10-B DATE $7 / 1 / 80$ SURFACE ELEVATION(ft) 7138

LOCATION NW NW NW

$\operatorname{Sec} \cdot \underline{2} T \cdot \underline{19 N}$ R. $77 \mathrm{~W}$ Quad. Pierce Reservoir COUNTY Albany STATE Wyoming TOTAL DEPTH(ft) 195

CORED YES

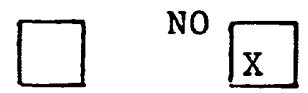

INTERVAL (s)

DRILLING MEDIUM:

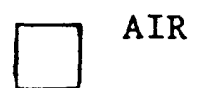

$\square^{\text {FOAM }}$

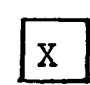

MUD $\square$ WATER OBSERVATION WELL

GEOPHYSICAL LOGS:

Natura1 Gamma

Gamma Gamma

Resistivity

Caliper

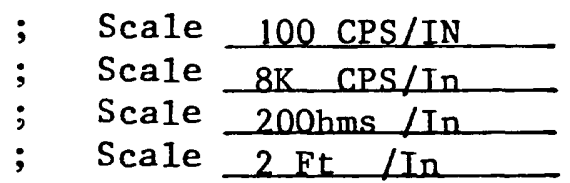

Logging Speed Logging Speed Logging Speed Logging Speed

\begin{tabular}{rr}
20 & $\mathrm{fpm}$ \\
\hline 20 & $\mathrm{fpm}$ \\
\hline 15 & $\mathrm{fpm}$ \\
\hline 15 & $\mathrm{fpm}$
\end{tabular}

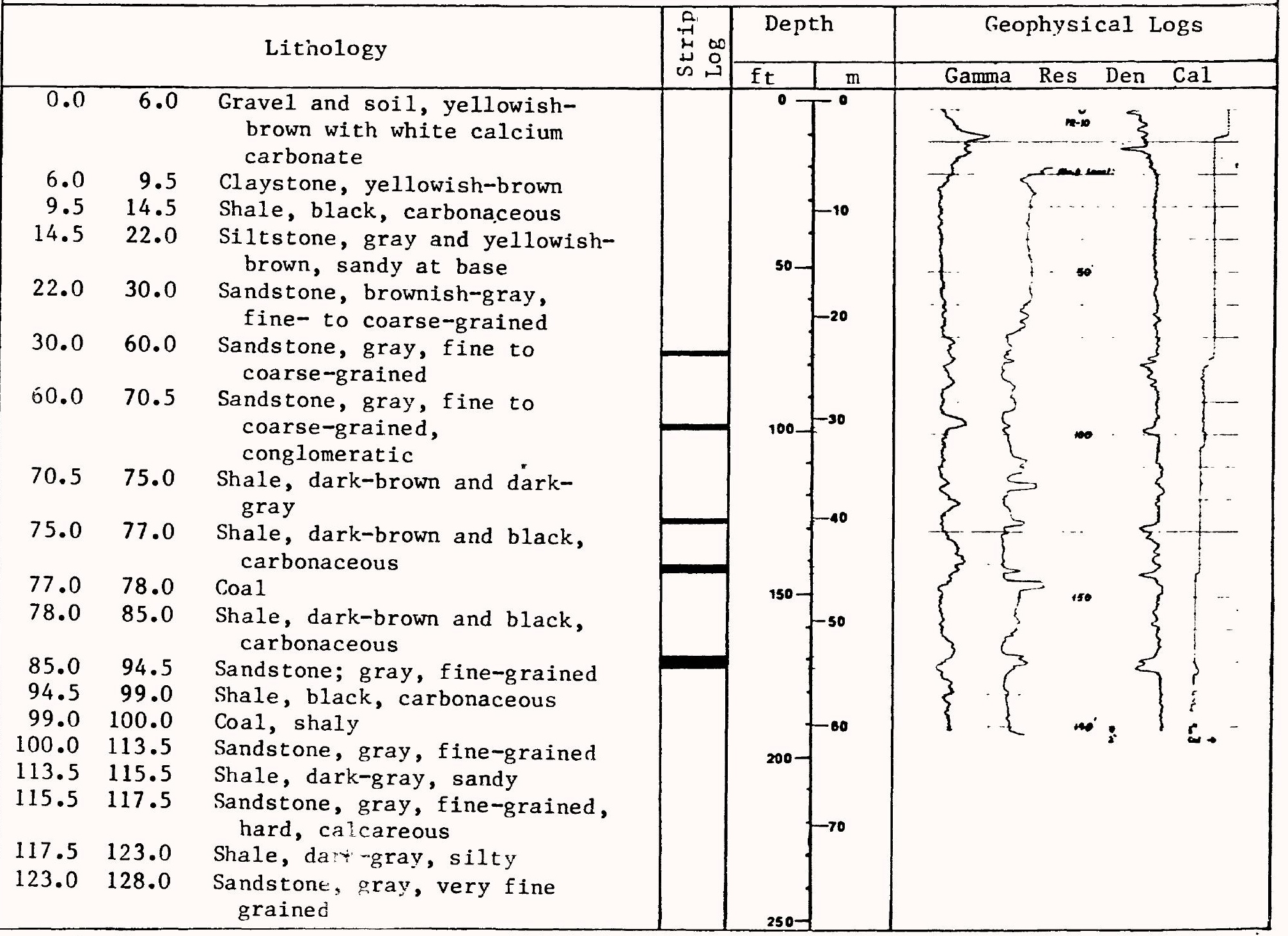




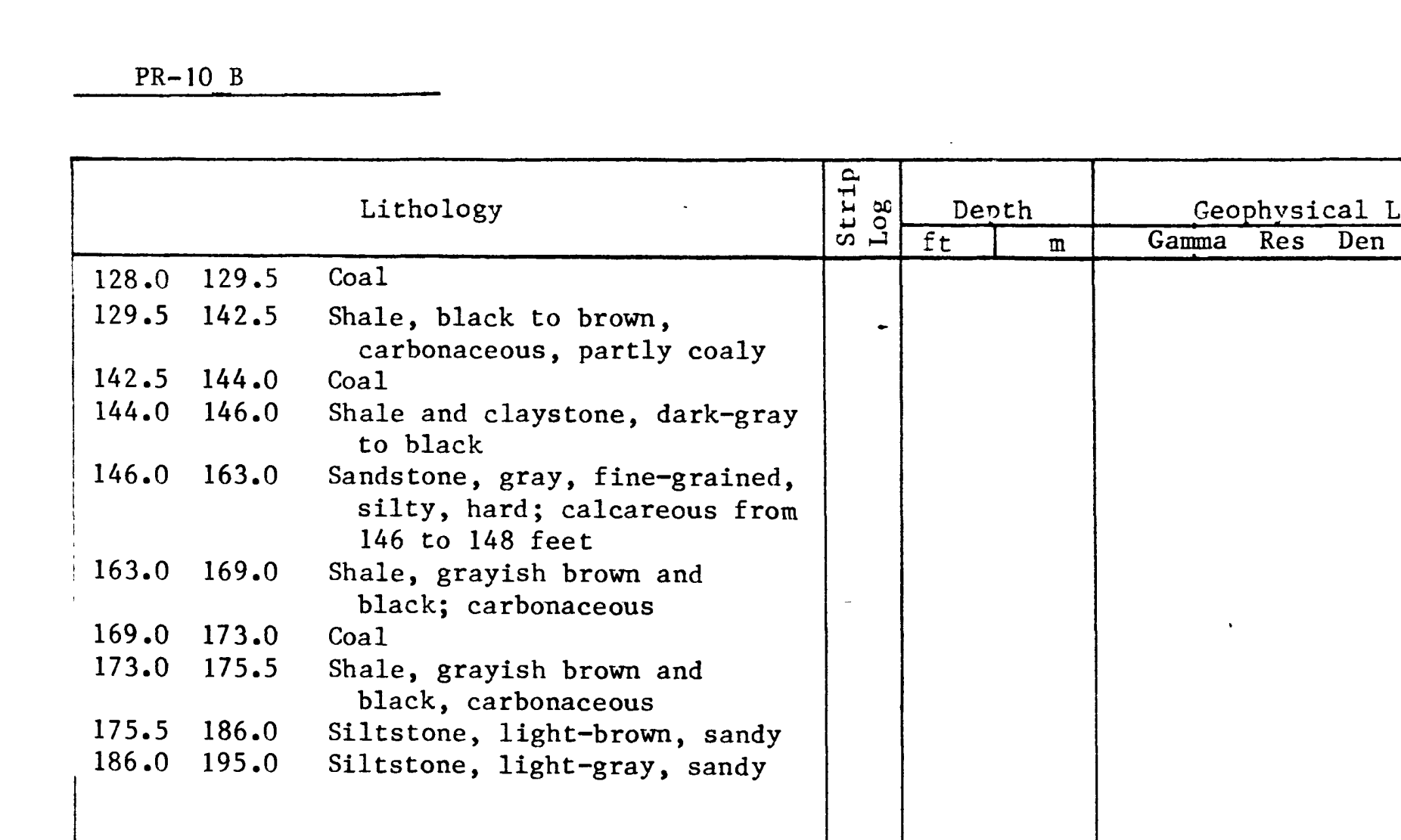




\section{LITHOLOGIC AND GEOPHYSICAL LOGS}

LOCATION NUMBER

$P R-11$

DATE $7 / 5 / 80$

SURFACE ELEVATION(ft) $\quad 7134$

LOCATION

NE NE NE

Sec. 2 T. 19N

R. $77 \mathrm{~W}$ Quad.Pierce Reservoir

COUNTY

Albany

STATE Wyoming TOTAL DEPTH(ft) 515

CORED

YES

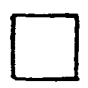

No $x$

INTERVAL (s)

DRILLING MEDIUM:
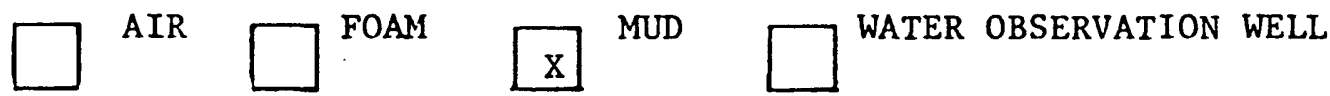

GEOPHYSICAL LOGS :

Natural Gamma

Gamma Gamma

Resistivity

Caliper
; Scale

; Scale

; Scale

; Scale

$\frac{\frac{100 \mathrm{CPS} / \mathrm{IN}}{20 \mathrm{~K} \mathrm{CPS} / \mathrm{IN}}}{\frac{20 \mathrm{Ohms} / \mathrm{IN}}{2 \mathrm{Ft} / \mathrm{IN}}}$

Logging Speed

Logging Speed

Logging Speed

Logging Speed

$\begin{array}{r}15 \\ \hline 15 \\ \hline 20\end{array}$

15
15
15
20

5

fpm

fpm

fpm

f pm

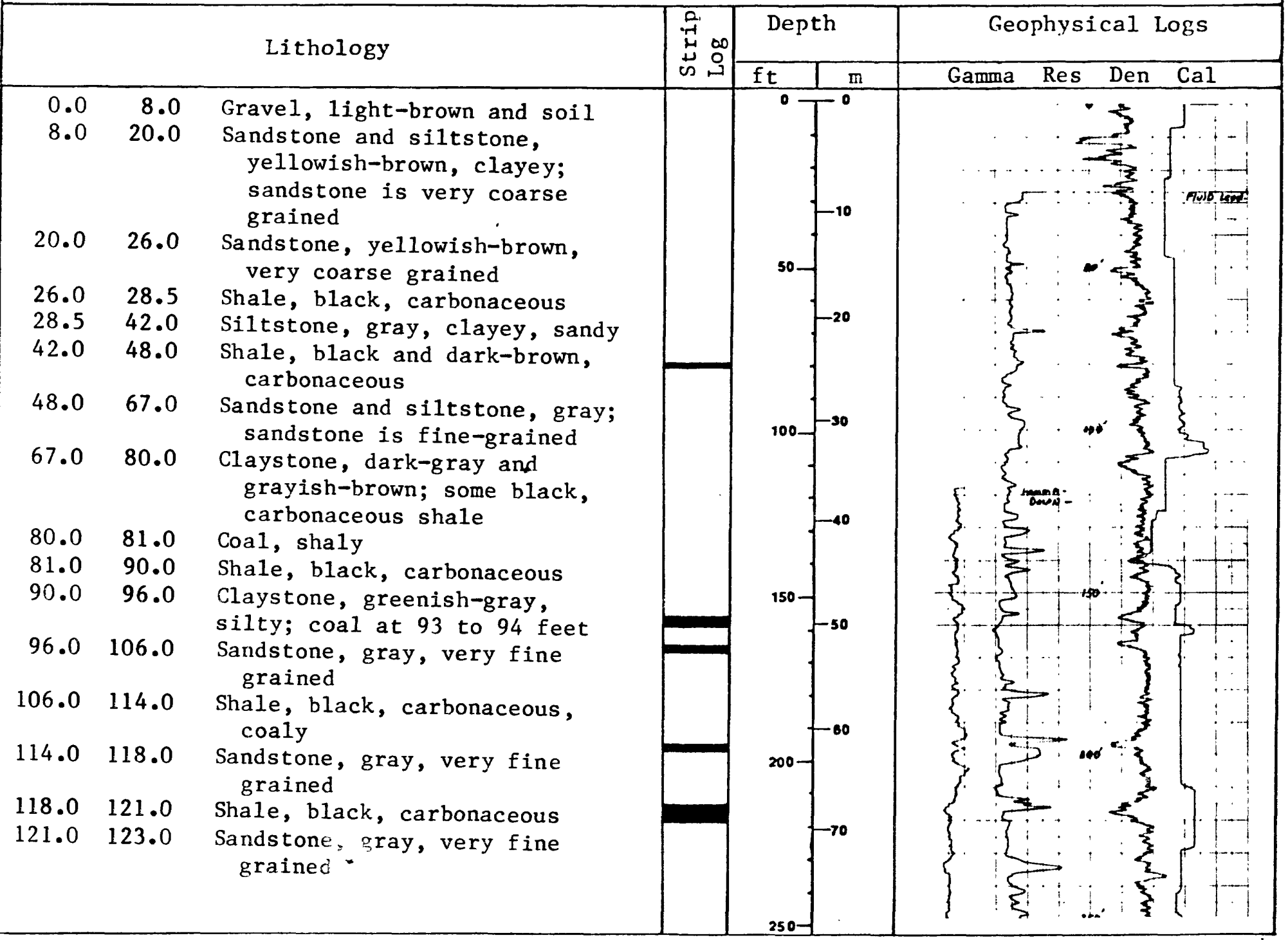




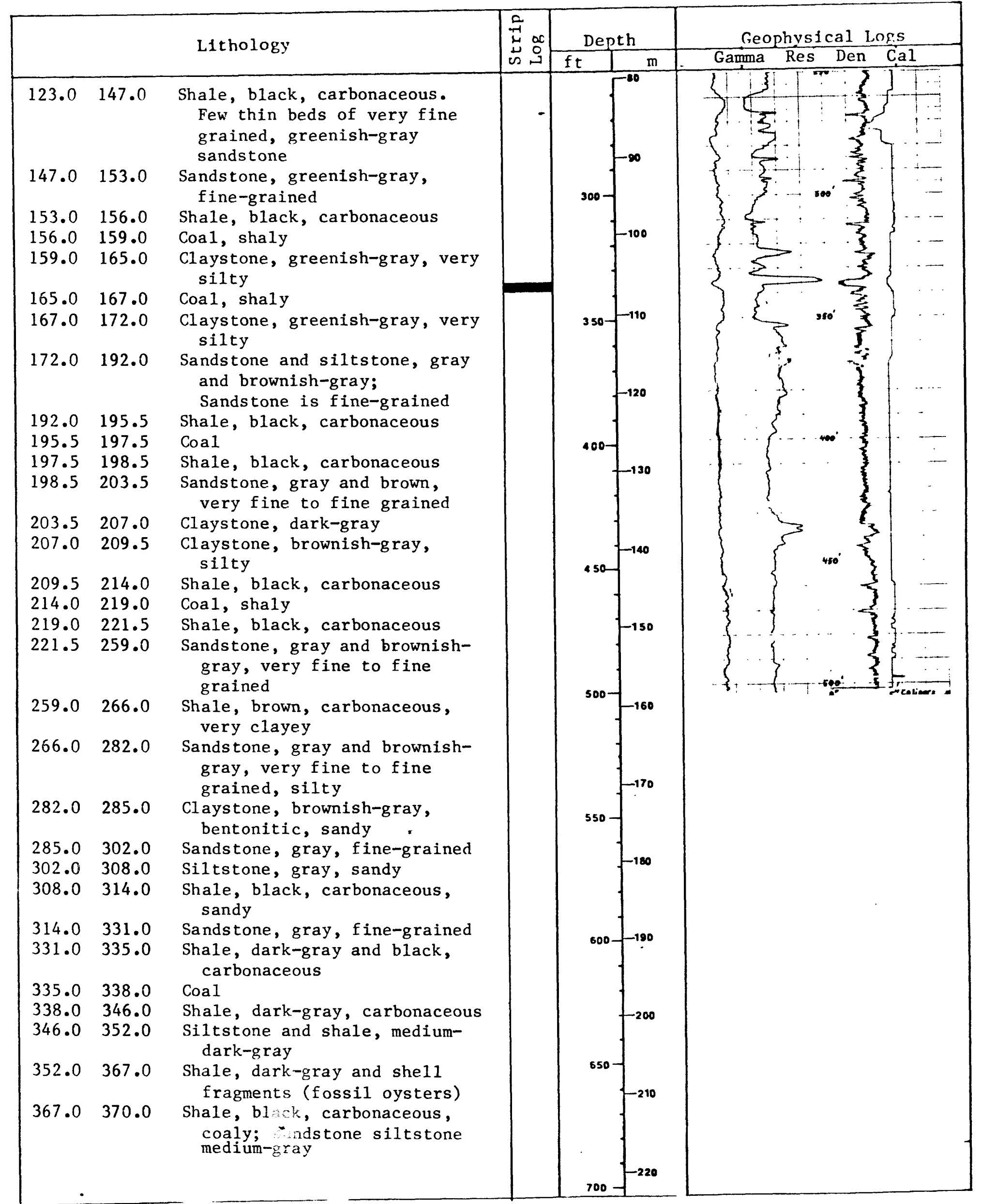


$P R=11$

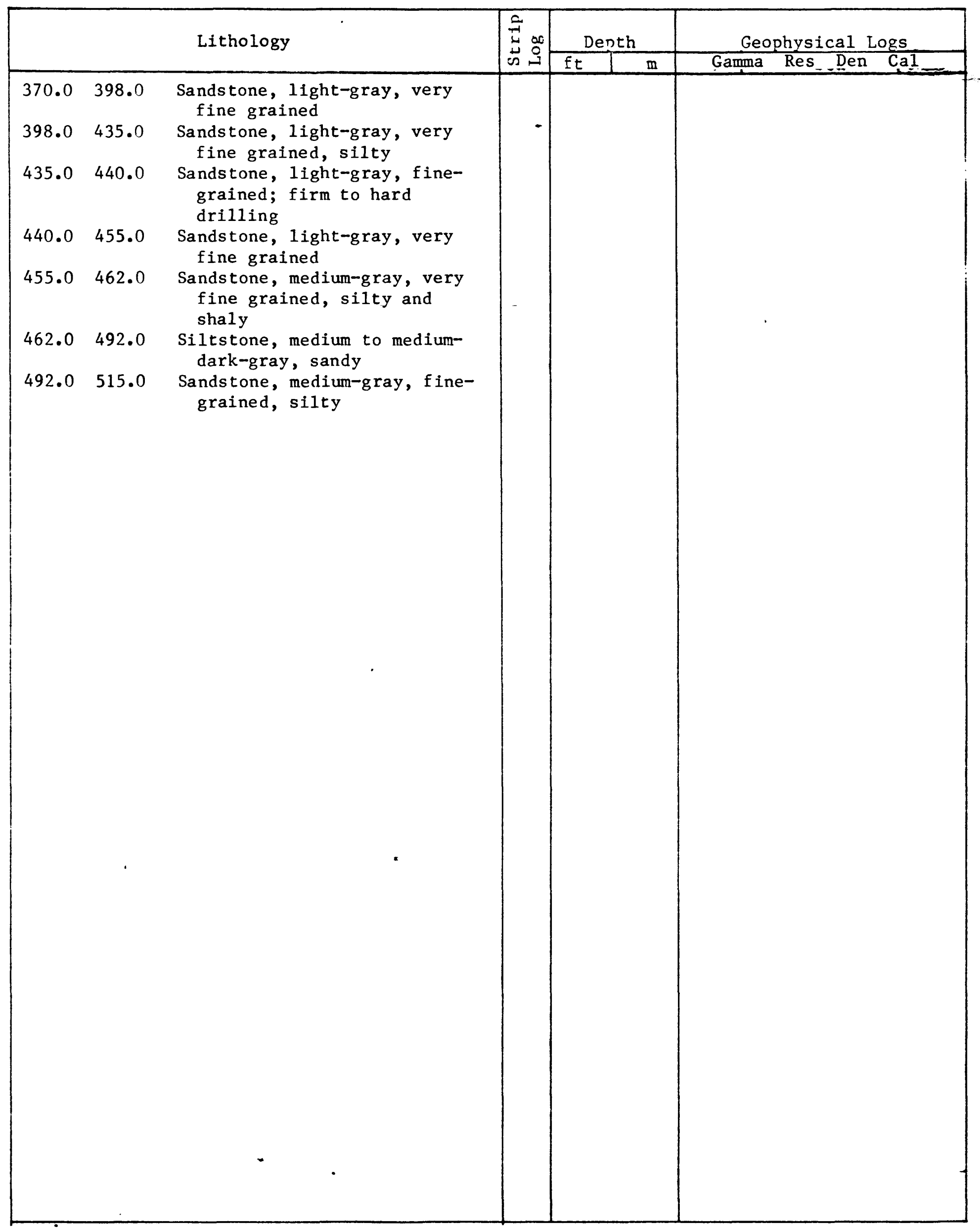

19 
LITHOLOGIC AND GEOPHYSICAL LOGS

LOCATION NUMBER

$P R-12$

DATE

$7 / 8 / 80$

SURFACE ELEVATION(ft)

7130

LOCATION

NE NE SE

$\operatorname{Sec} \cdot \underline{2} \mathrm{~T} \cdot \underline{19 \mathrm{~N}}$

R. $77 \mathrm{~W}$

Quad. Pierce Reservoir

COUNTY Albany

STATE Wyoming

TOTAL DEPTH(ft)455

CORED

YES

$\square$ No $x$

INTERVAL ( $s$ )

DRILLING MEDIUM:

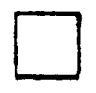

AIR
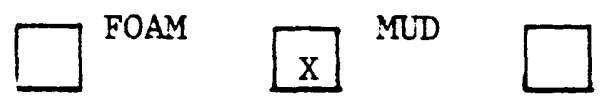

WATER OBSERVATION WELL

GEOPHYSICAL LOGS :

Natural Gamma

Gamma Gamma

Resistivity

Caliper

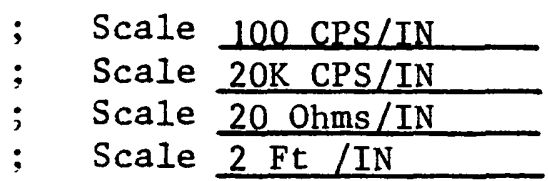

Logging Speed Logging Speed Logging Speed Logging Speed

\begin{tabular}{ll}
15 & $f \mathrm{pm}$ \\
15 & $\mathrm{fpm}$ \\
\hline 20 & $\mathrm{pmm}$ \\
\hline 20 & $\mathrm{pmm}$
\end{tabular}

\section{Lithology}

$0.0 \quad 6.0$ Silt and clay, brownish-gray

$6.0 \quad 17.0$ Sandstone, brown, very coarse grained, argillaceous conglomeratic; with granules and small pebbles

17.022 .0 Shale, light-olive-gray, clayey

22.026 .0 Siltstone, light to mediumgreenish-gray, sandy

26.029 .0 Sandstone, light to mediumgreenish-gray, fine-grained, silty

$29.0 \quad 35.0$ Siltstone, medium-greenish-

35.040 .0 Claystone, medium-dark-gray,

40.046 .0 Siltstone, medium-dark-gray, clayey

$46.0 \quad 48.0$ Siltstone, light-gray, coaly

$48.0 \quad 49.0$ Coal, clayey

$49.0 \quad 55.0$ Claystone and siltstone,

$55.0 \quad 62.0$ Shale and siltstone, brownish-

gray; interbedded

$62.0 \quad 63.0$ Shale, dark-brownish-gray, carbonaceous

63.0 65.0 Shale and siltstone, brownish-

65.0 gray, in

65.0 66.0 Shale, darn-brownish-gray, carbonaceous

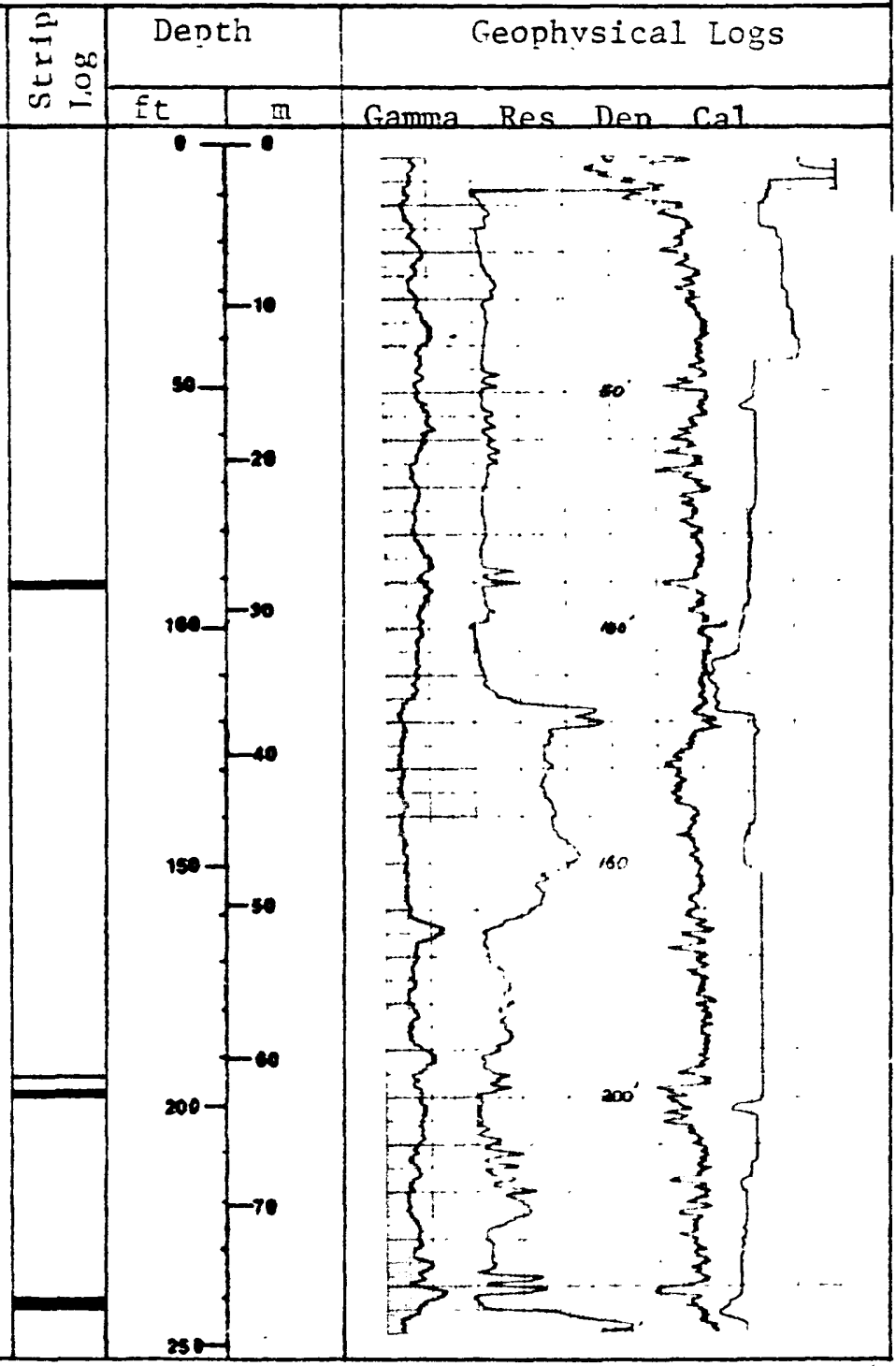




\begin{tabular}{|c|c|c|c|c|c|c|}
\hline & & \multirow[t]{2}{*}{ Lithology } & \multirow{2}{*}{ 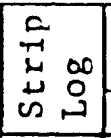 } & \multicolumn{2}{|c|}{ Depth } & Geophystcal Logs \\
\hline & & & & $\mathrm{ft}$ & $\mathrm{m}$ & Gamma \\
\hline 66.0 & 73.0 & $\begin{array}{l}\text { Shale and siltstone, brownish- } \\
\text { gray, interbedded }\end{array}$ & & & $\Gamma^{80}$ & \\
\hline 73.0 & 84.3 & $\begin{array}{l}\text { Siltstone and claystone, } \\
\text { medium to medium-dark-gray }\end{array}$ & & & & - \\
\hline 84.3 & 87.0 & Shale, medium-dark-gray & & & $-\infty$ & \\
\hline 87.0 & 88.0 & Siltstone, medium-gray & & $300-$ & & $-\ldots$ \\
\hline $\begin{array}{l}88.0 \\
90.0\end{array}$ & $\begin{array}{l}90.0 \\
91.0\end{array}$ & $\begin{array}{l}\text { Shale, medium-dark-gray } \\
\text { Coal, shaly }\end{array}$ & & & & \\
\hline 91.0 & 92.5 & Shale, medium-dark-gray & & & $1^{-100}$ & \\
\hline 92.5 & 99.0 & $\begin{array}{l}\text { Siltstone, medium-gray, } \\
\text { argillaceous }\end{array}$ & & & & $\because$ \\
\hline 99.0 & 105.0 & Claystone, medium-gray, silty & & $350-$ & $f^{-110}$ & 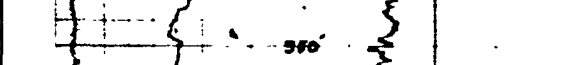 \\
\hline 105.0 & 115.0 & $\begin{array}{l}\text { Siltstone and shale, olive- } \\
\text { gray, interlaminated }\end{array}$ & & & & \\
\hline 115.0 & 121.0 & $\begin{array}{l}\text { Sandstone, 1ight-gray, medium- } \\
\text { grained }\end{array}$ & & & -120 & $(\cdots-$ \\
\hline 121.0 & 152.0 & $\begin{array}{l}\text { Sandstone, light-gray, coarse- } \\
\text { to very coarse grained }\end{array}$ & & & & $-\infty$ \\
\hline 152.0 & 162.0 & $\begin{array}{l}\text { Conglomerate, light-gray; } \\
\text { granule }\end{array}$ & & 40 & -130 & 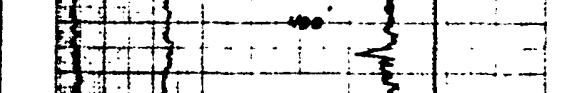 \\
\hline 162.0 & 167.0 & Shale, brownish-gray & & & & $\therefore-1$ \\
\hline 167.0 & 180.0 & $\begin{array}{l}\text { Sandstone, greenish-gray, } \\
\text { silty }\end{array}$ & & & & 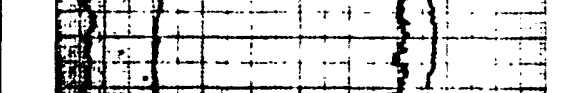 \\
\hline $180 \cdot 0$ & 190.0 & $\begin{array}{l}\text { Sandstone, light to medium- } \\
\text { gray, fine-grained, silty }\end{array}$ & & $450-$ & -140 & 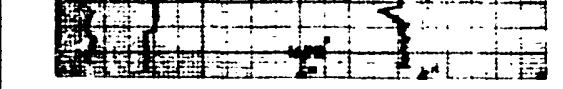 \\
\hline 190.0 & 195.0 & $\begin{array}{l}\text { Shale, black, carbonaceous } \\
\text { Coal }\end{array}$ & & & & \\
\hline $\begin{array}{l}195.0 \\
195.5\end{array}$ & 195.5 & $\begin{array}{l}\text { Coal } \\
\text { Shale, black, carbonaceous }\end{array}$ & & & -150 & \\
\hline $\begin{array}{l}195.5 \\
197.5\end{array}$ & $\begin{array}{l}197.5 \\
198.5\end{array}$ & $\begin{array}{l}\text { Shale, black, carbonaceous } \\
\text { Coal }\end{array}$ & & & $\Gamma+30$ & \\
\hline 198.5 & 206.0 & Shale, black, carbonaceous & & & & \\
\hline 206.0 & 209.0 & Siltstone, medium-gray & & $500-$ & & \\
\hline 209.0 & 214.0 & $\begin{array}{l}\text { Sandstone, light-gray, fine- } \\
\text { grained, silty }\end{array}$ & & & & \\
\hline 214.0 & 217.0 & Siltstone, medium-gray, sandy & & & & \\
\hline 217.0 & 226.0 & $\begin{array}{l}\text { Sandstone, light-gray, fine- } \\
\text { grained }\end{array}$ & & & Fi & \\
\hline $\begin{array}{l}226.0 \\
234.0\end{array}$ & $\begin{array}{l}234.0 \\
237.0\end{array}$ & $\begin{array}{l}\text { Siltstone, medium-gray, sandy } \\
\text { Shale, medium-gray, sandy, } \\
\text { silty }\end{array}$ & & s50- & -180 & \\
\hline 237.0 & 238.0 & $\begin{array}{l}\text { Sandstone, light-gray, fine- } \\
\text { grained, hard, silty }\end{array}$ & & & & \\
\hline 238.0 & 240.0 & Shale, medium-gray & & & & \\
\hline 240.0 & 242.0 & Coal, shaly & & $600-1$ & -190 & \\
\hline 242.0 & 243.0 & Shale, medium-gray & & & & \\
\hline 243.0 & 246.0 & Siltstone, medium-gray, shaly & & & & \\
\hline 246.0 & 253.0 & $\begin{array}{l}\text { Sandstone, light-gray, medium } \\
\text { to coarse-grained }\end{array}$ & & & -200 & \\
\hline 253.0 & 256.8 & Shale, medium-gray & & & & \\
\hline 256.8 & 259.0 & Shale, black, carbonaceous & & $650-$ & & \\
\hline 259.0 & 265.0 & Coal, shaly & & & -210 & \\
\hline 265.0 & 271.0 & Shale, black, carbonaceous & & & $5^{-210}$ & \\
\hline 271.0 & 283.0 & $\begin{array}{l}\text { Siltstone and shale, dark- } \\
\text { brownis -gray }\end{array}$ & & & & \\
\hline 283.0 & 291.5 & $\begin{array}{l}\text { Sandstone, light-gray, fine- } \\
\text { grained, silty }\end{array}$ & & $700-$ & & \\
\hline
\end{tabular}




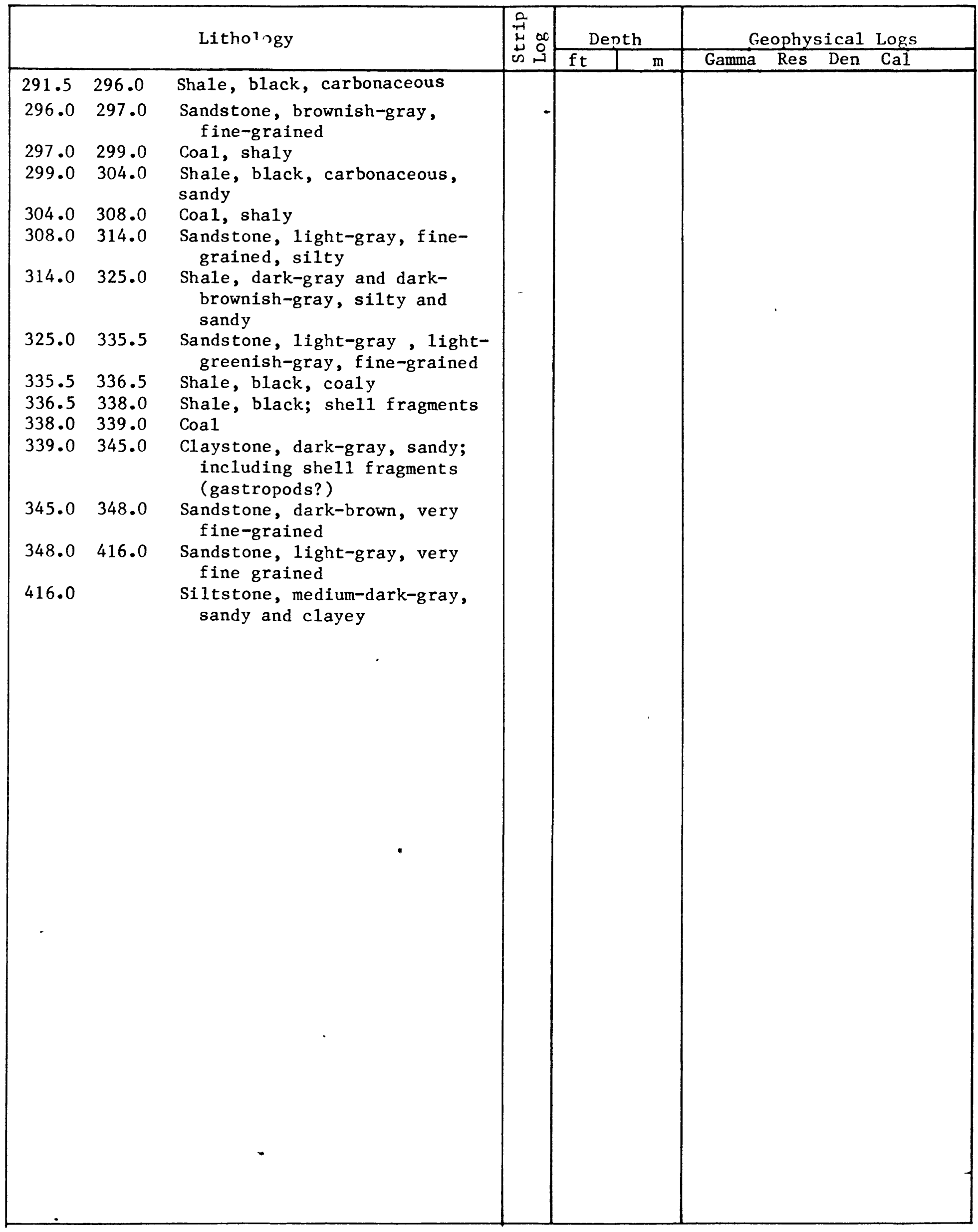


LOCATION NUMBER

$P R-13$

LOCATION SE NE NE COUNTY Albany

CORED YES

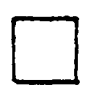

\section{No}<smiles>C1C2CC12</smiles>

DRILIING MEDIUM:

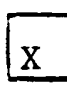

AIR
DATE $6 / 17 / 80$

Sec. $4 \quad T \cdot 19 \mathrm{~N}$

STATE Wyoming
SURFACE ELEVATION(ft) 7178

R. $77 \mathrm{~W}$ Quad. Pierce Reservoir TOTAL DEPTH(ft)

INTERVAL (s)

OAM

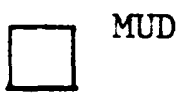

WATER OBSERVATION WELL

GEOPHYSICAL LOGS:

Natural Gamma Gamma Gamma

Resistivity

Caliper
; Scale

; Scale

; Scale

: Scale
100 CPS/TN $8 \mathrm{~K}$ CPS/IN

20 Ohms /IN
Logging Speed Logging Speed Logging Speed Logging Speed

$\begin{array}{ll}\frac{f p m}{15} & f \mathrm{pm} \\ 15 & \mathrm{fpm} \\ \mathrm{fpm}\end{array}$

\section{Iithology}

$0.0 \quad 2.0$ Grave1, brown

$2.0 \quad 5.0$ Gravel, light-brown, caliche

5.09 .2 Siltstone, gray, shaly, weathers olive-gray

9.2 14.0 Shale, dark-brown, weathered 14.019 .0 Sandstone, gray, fine-grained 19.028 .0 Sandstone, light-gray, finegrained, weathers brownishgray, silty

28.034 .0 Siltstone, yellowish-brown,

$34.0 \quad 39.5$ Siltstone, 1ight-gray, sandy

$39.5 \quad 46.0 \quad$ Siltstone, gray

$46.0 \quad 53.0$ Sandstone, gray, fine-grained

$53.0 \quad 61.5$ Siltstone, gray

61.578 .0 Sandstone, gray, fine-grained; calcareous near top of interval

$78.0 \quad 82.8 \quad$ Siltstone, gray

82.8 135.0 Sandstone and siltstone, gray; with interbedded thick laminations of shale

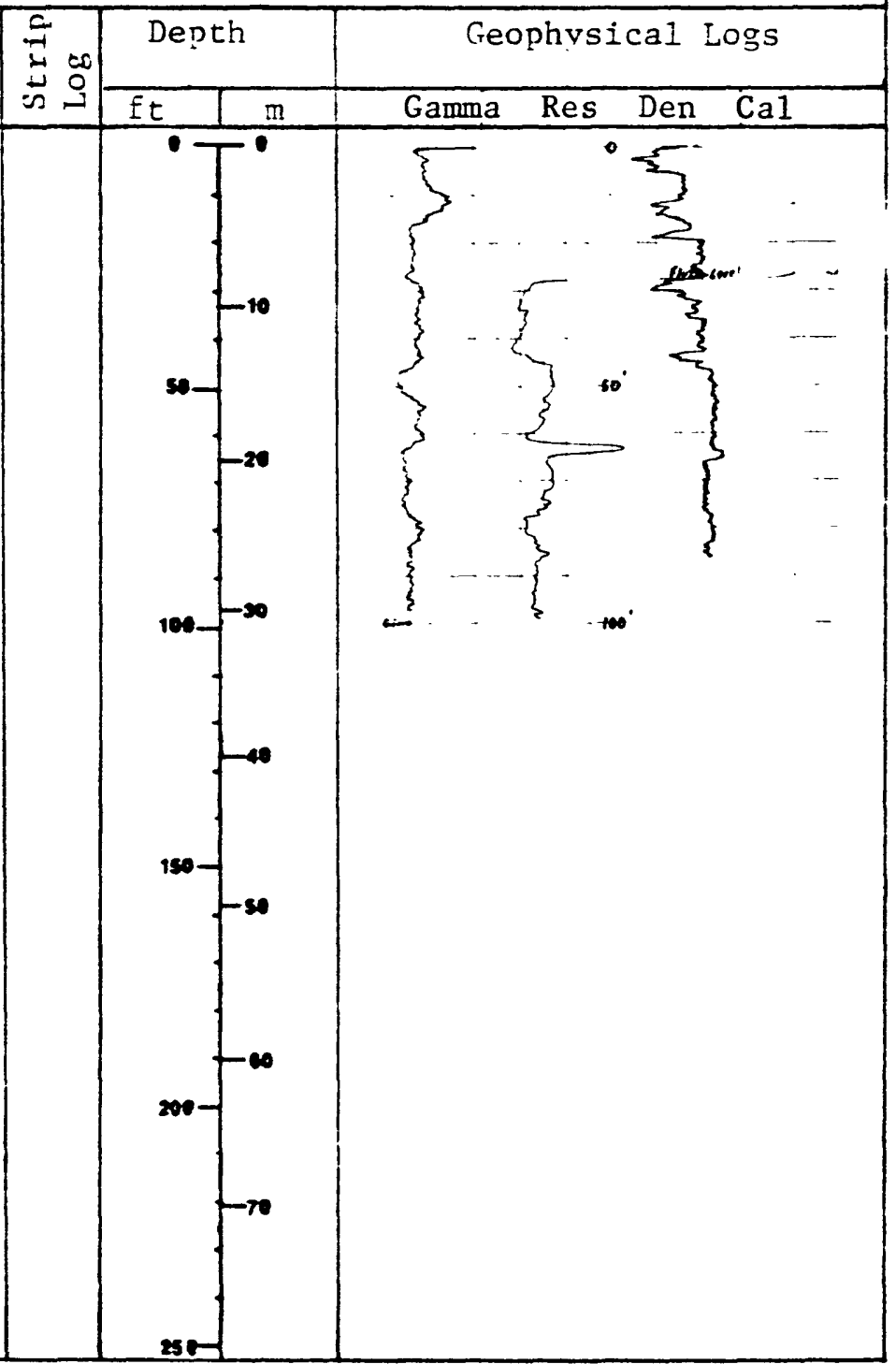


LOCATION NUMBER PR-14

LOCATION NE NE SE COUNTY Albany
DATE

$7 / 20 / 80$

Sec. 4 T. $19 \mathrm{~N}$

STATE Wyoming

No $\mathrm{x}$

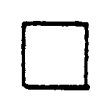

INTERVAL (s)

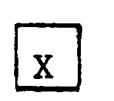

AIR

DRILLING MEDIUM:

$\mathrm{x}$

GEOPHYSICAL LOGS:

Natural Gamma

Gamma Gamma

Resistivity

Caliper

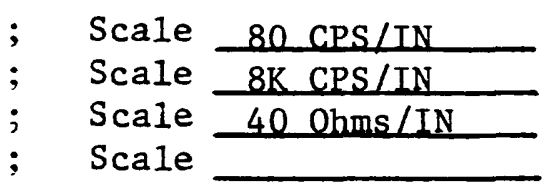

SURFACE ELEVATION(ft) 7175

R. $77 \mathrm{~W}$ Quad. Pierce Reservoir TOTAL DEPTH(ft) 55

MUD WATER OBSERVATION WELL

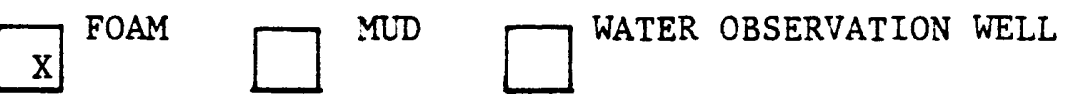

Lithology

Logging Speed

Logging Speed

Logging Speed

Logging Speed

\begin{tabular}{ll}
20 & $f \mathrm{pm}$ \\
\hline 1 & $\mathrm{fpm}$ \\
\hline 1 & $\mathrm{fpm}$ \\
& $\mathrm{fpm}$
\end{tabular}

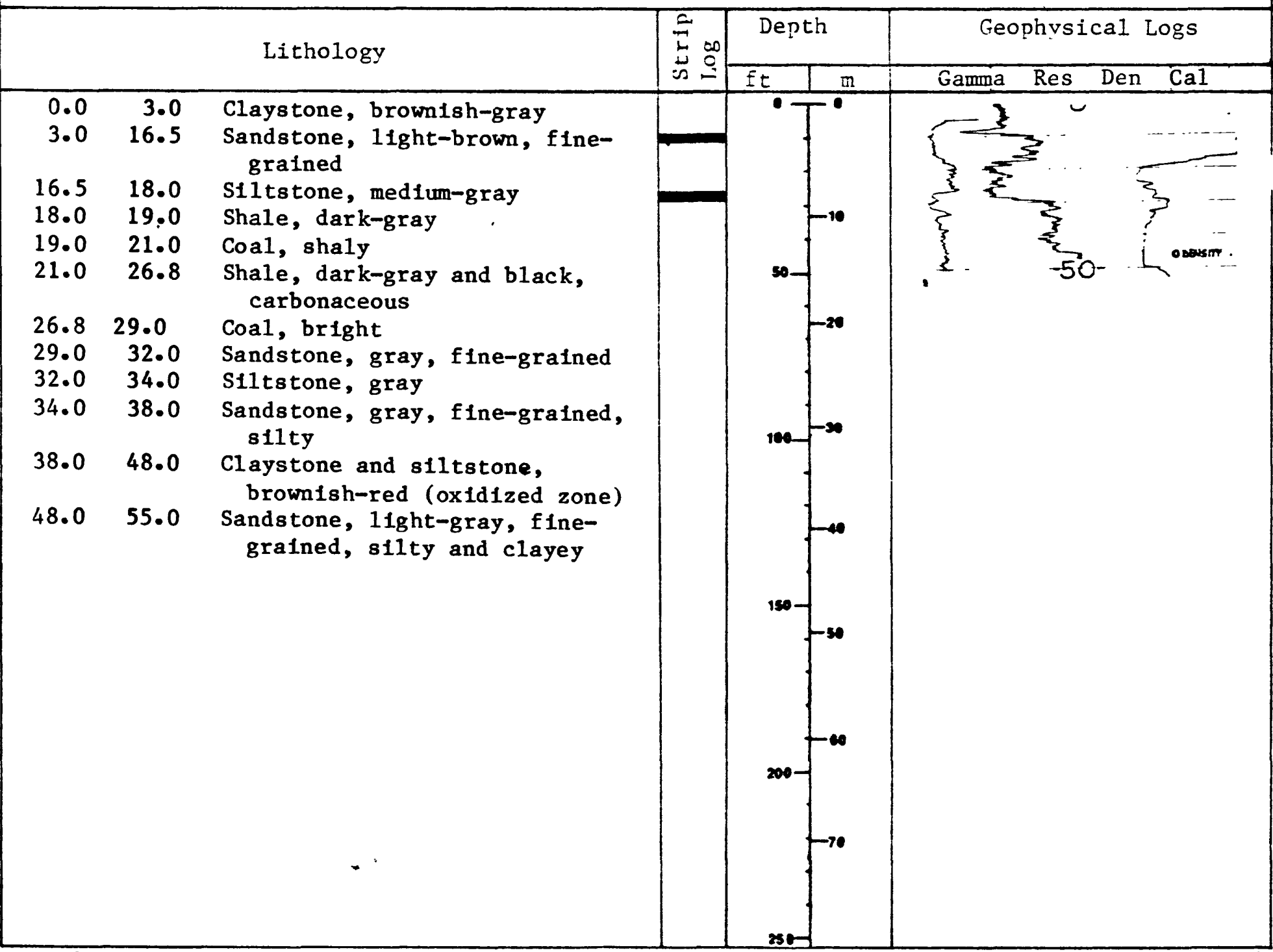


LOCATION NUMBER PR-14-C

LOCATION NE NE SE COUNTY Albany

CORED YES

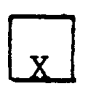

DATE $7 / 21 / 80$

$\operatorname{Sec} \cdot \underline{4}$

STATE Wyoming

INTERVAL (s) $20.0-42.8^{\prime}$

DRILLING MEDIUM:

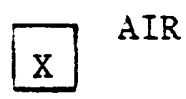

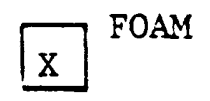

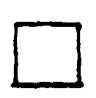

SURFACE ELEVATION(ft) 7175

R. $77 \mathrm{~W}$ Quad.Pierce Reservoir TOTAL DEPTH(ft) 55

MUD

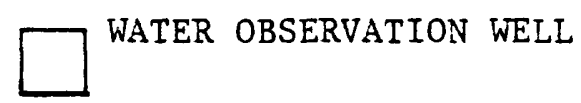

GEOPHYSICAL LOGS :

Natural Gamma

Gamma Gamma

Resistivity

Caliper
; Scale $80 \mathrm{CPS} / \mathrm{IN}$

: Scale 8K CPS/IN

; Scale 40 Ohms/IN

; Scale
Logging Speed Logging Speed Logging Speed Logging Speed

\begin{tabular}{ll}
20 & $f p m$ \\
20 & $f p m$ \\
\hline 20 & $f p m$ \\
& $f p m$
\end{tabular}

Lithelogy

0.020 .0 No samples. Pilot hole.

$20.0 \quad 21.3$ Missing

21.3 22.4 Shale, medium dark-gray with a medium-gray silt streak from 21.2 to 21.3 feet.

22.422 .8 Shale, dark-gray, clayey

$22.8 \quad 23.0$ Shale, black, carbonaceous

23.023 .4 Claystone, black, carbonaceous

23.423 .6 Claystone, brownish-gray

23.624 .9 Coal, bright

24.926 .1 Claystone, light brownish-gray

26.126 .9 Coal, bright and dull, banded

26.933 .7 Coal, bright, pyritic, fractured

33.7 34.0 Shale, black, carbonaceous, sandy

$34.0 \quad 42.4$ Sandstone, brownish-gray, fine-grained; irregular bedding; disturbed

$42.4 \quad 42.8 \quad$ Missing (core loss)

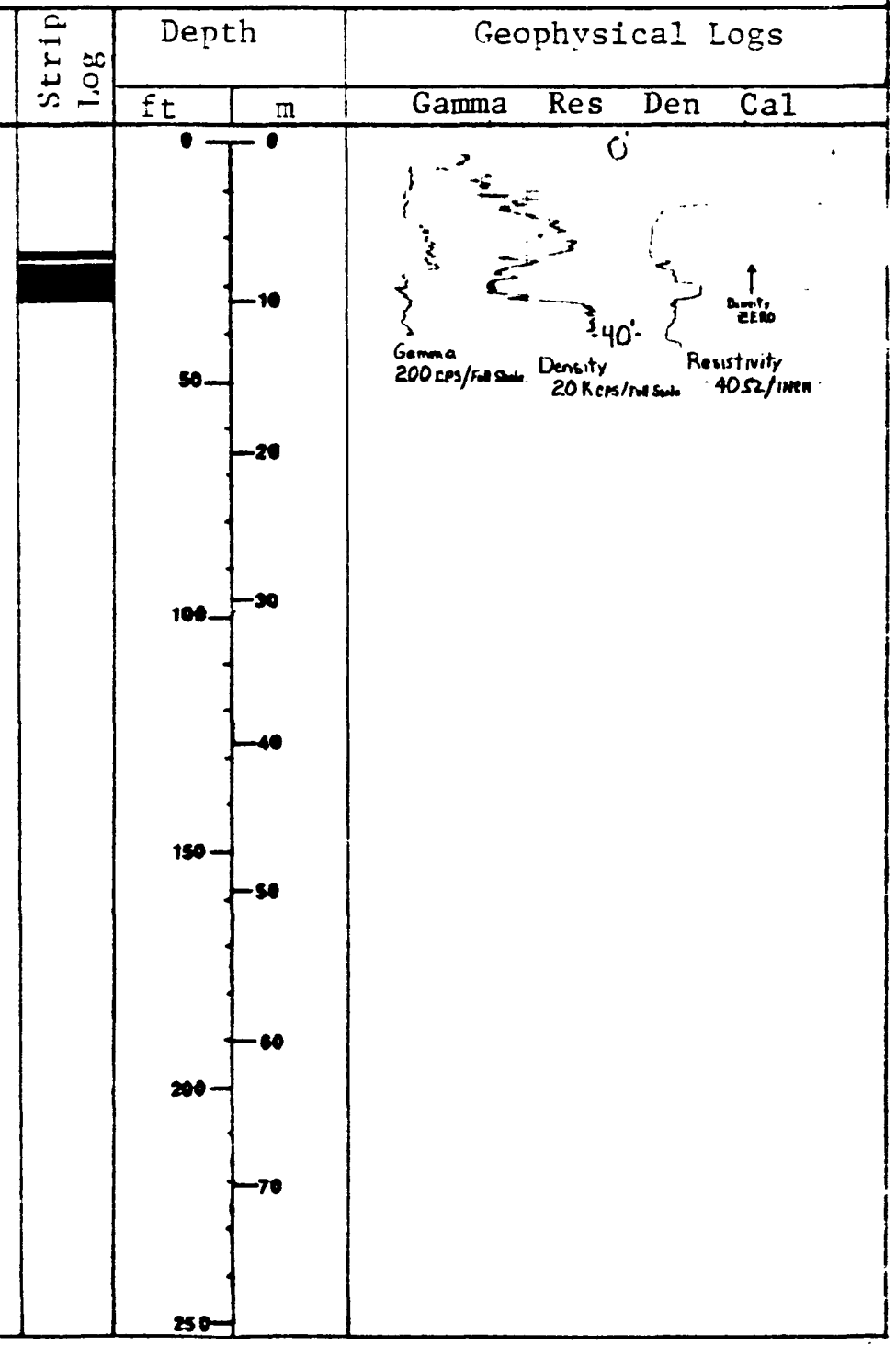


LOCATION NUMBER PR-15

LOCATION SW SE SE COUNTY Albany

No

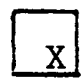

DRILLING MEDIUM:

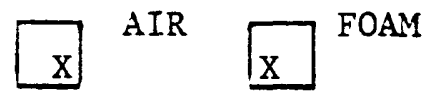

CORED

YES

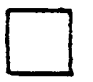

DATE Z/17/80

Sec. 4 - T. $19 \mathrm{~N}$ STATE Wyoming

INTERVAL (s)
SURFACE ELEVATION(ft) 7205

R. $77 W$ Quad. Pierce Reservoir TOTAL DEPTH(ft) $\quad 115$

INTERAL(s)

GEOPHYSICAL LOGS :

Natural Gamma

Gamma Gamma

Resistivity

Caliper
; Scale 80 CPS/IN

: Scale 20K CPS/IN

; Scale 40 Ohms/IN

: Scale
MUD

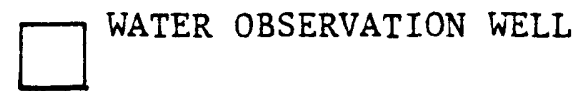

Lithology

$0.0 \quad 3.0 \quad$ Sandstone, brownish-gray, fine-grained

3.0 9.5 Shale, dark gray and brownishgray, carbonaceous

9.5 27.0 Sandstone, yellowish-gray, fine-grained

$27.0 \quad 31.0 \quad$ Siltstone and shale, medium to dark-gray, interlaminated

$31.0 \quad 32.0$ Sandstone, gray, fine-grained, silty

$32.0 \quad 34.5$ Shale, black, carbonaceous

$34.5 \quad 36.0 \quad$ Coa 1

$36.0 \quad 37.0$ Shale, black, carbonaceous

$37.0 \quad 44.0$

Coal

$44.0 \quad 50.0$

Sands tone, 1ight-gray, finegrained

$50.0 \quad 57.0$ Sandstone and siltstone, light to medium-gray, interbedded; sandstone is very finegrained

$57.0 \quad 59.0$ Sandstone, light-gray, very fine grained

$59.0 \quad 64.0$ Sandstone and siltstone, 1ight to medium-gray, interbedded; sandstone is very finegrained

64.070 .0 Siltstone, medium-dark-gray

$70.0 \quad 88.5$ Sandstone. 1ight-brownishgray, - ne-grained

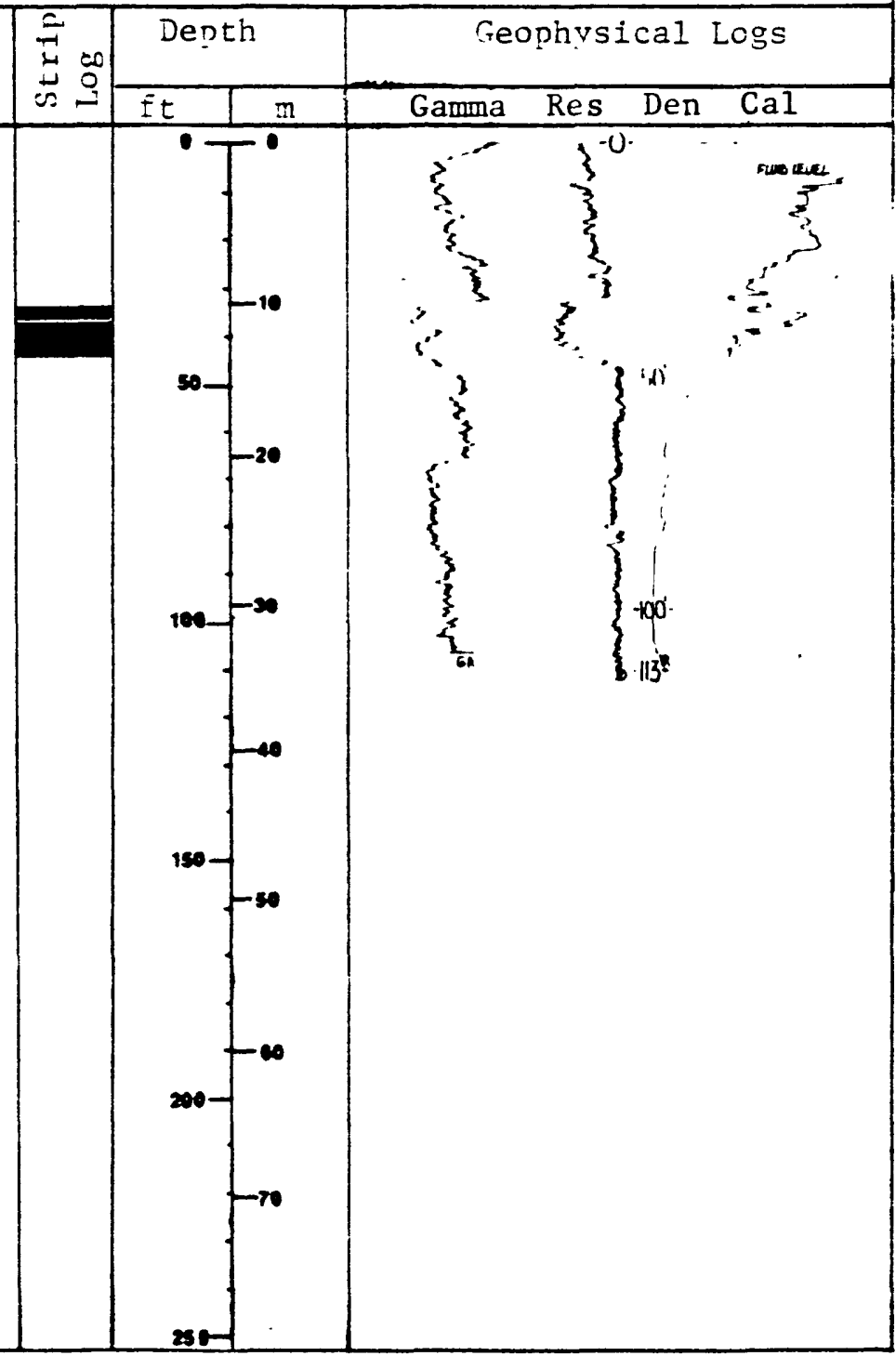

Logging Speed 20

Logging Speed 15

Logging Speed 20

Logging Speed fpm

fpm

fom fpm 
$P R-15$

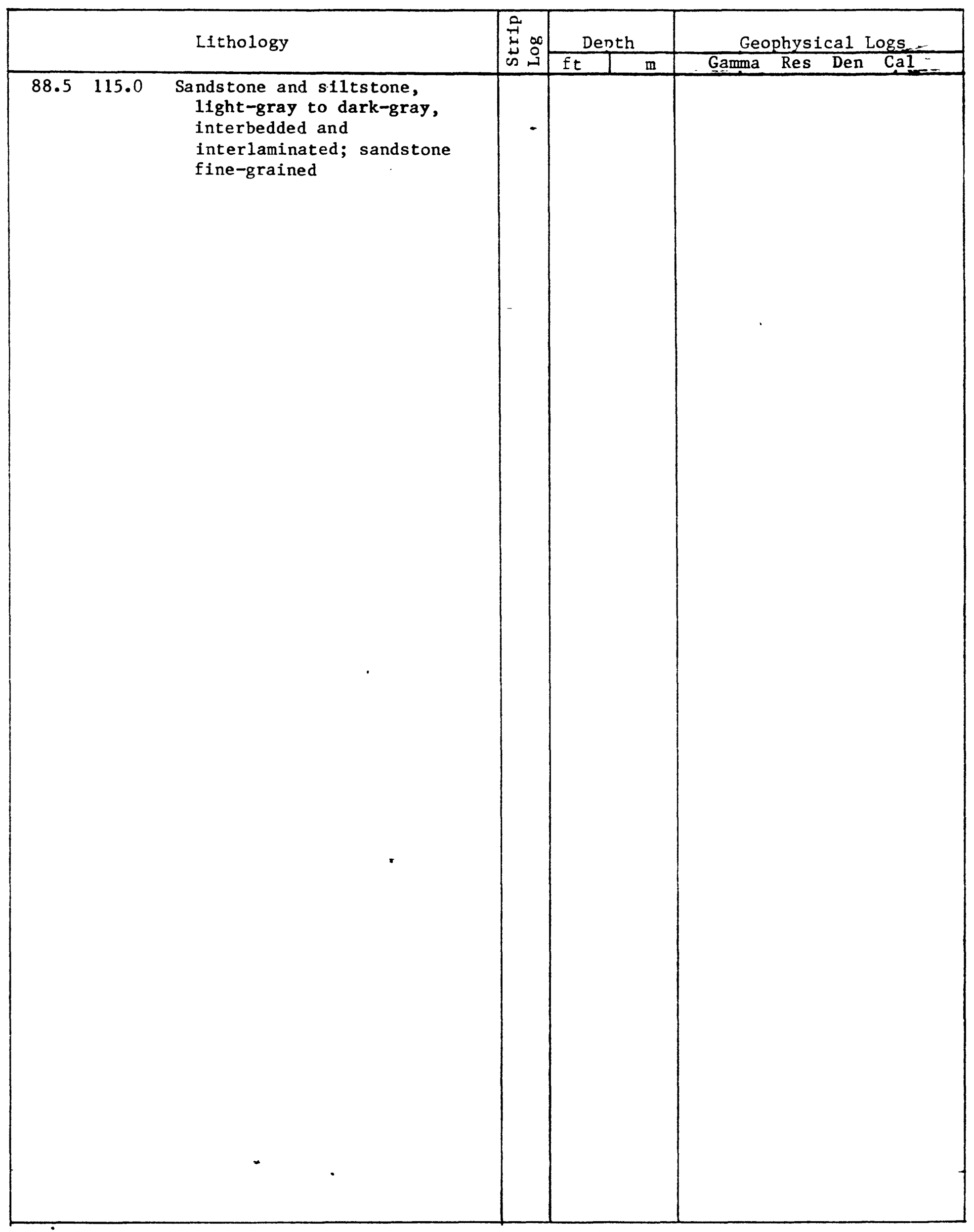

27 


\section{LITHOLOGIC AND GEOPHYSICAL LOGS}

LOCATION NLMBER

$P R-15-C$

LOCATION SW SE SE

COLNTY Albany

CORED

YES

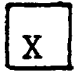

DAT

Sec. 4

STATE Wyoming

INTERVAL (s) $30.0-51.0^{\prime}$
SURFACE ELEVATION(ft) 7205

R. $77 \mathrm{~W}$ Quad. Pierce Reservoir TOTAL DEPTH (Et) 51.0

DRILLING MEDIUM:
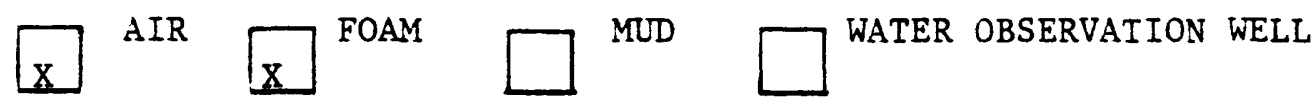

GEOPHYSICAL LOGS :

Natural Gamma

Gamma Gamma

Resistivity

Caliper

\begin{tabular}{ll}
$;$ & Scale $80 \mathrm{CPS} / \mathrm{IN}$ \\
$;$ & Scale $8 \mathrm{~K} \mathrm{CPS} / \mathrm{IN}$ \\
$;$ & Scale $40 \mathrm{Ohms} / \mathrm{IN}$ \\
\hline
\end{tabular}

Logging Speed

Logging Speed

Logging Speed

Logging Speed

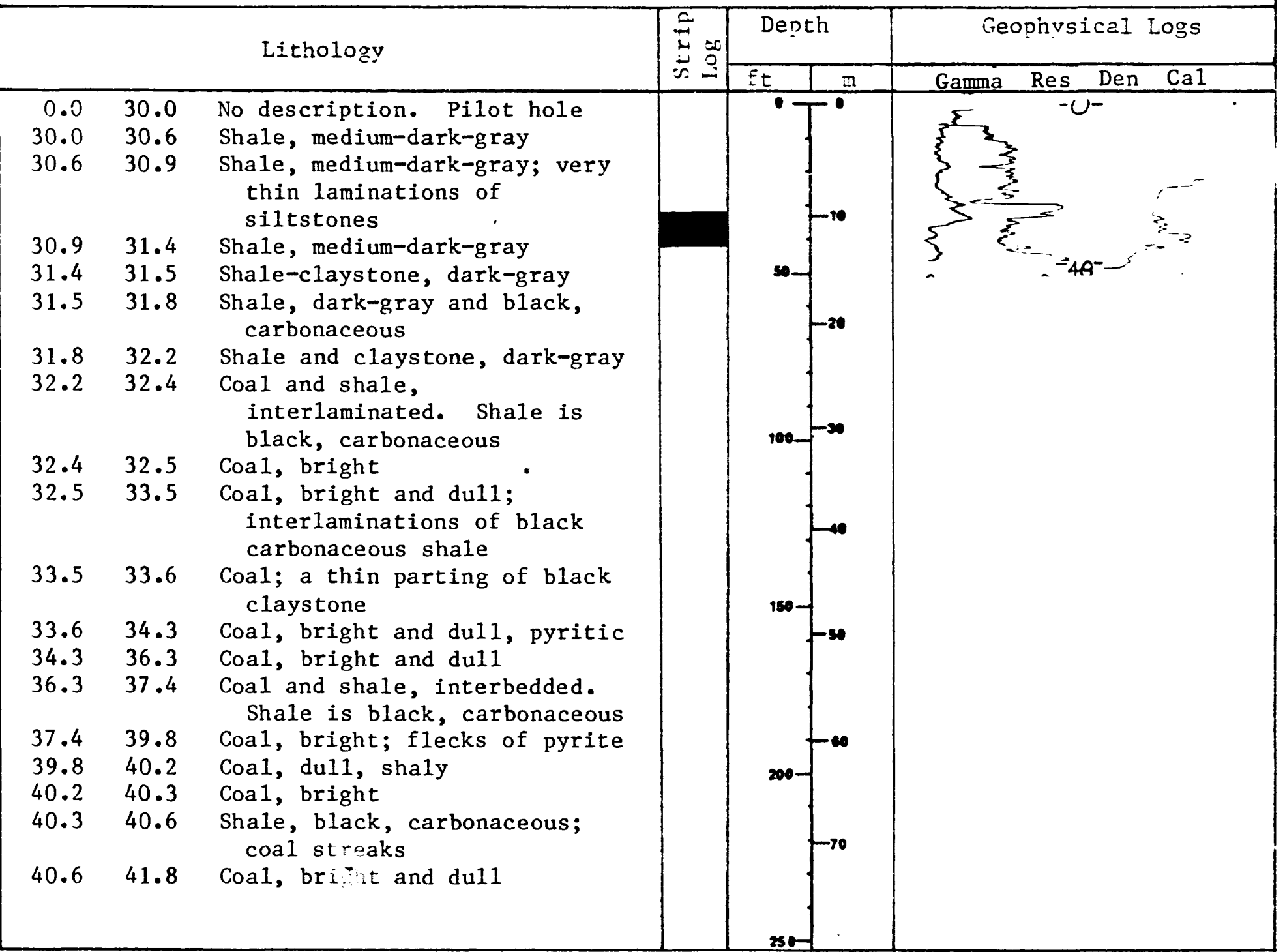


PR-15-C

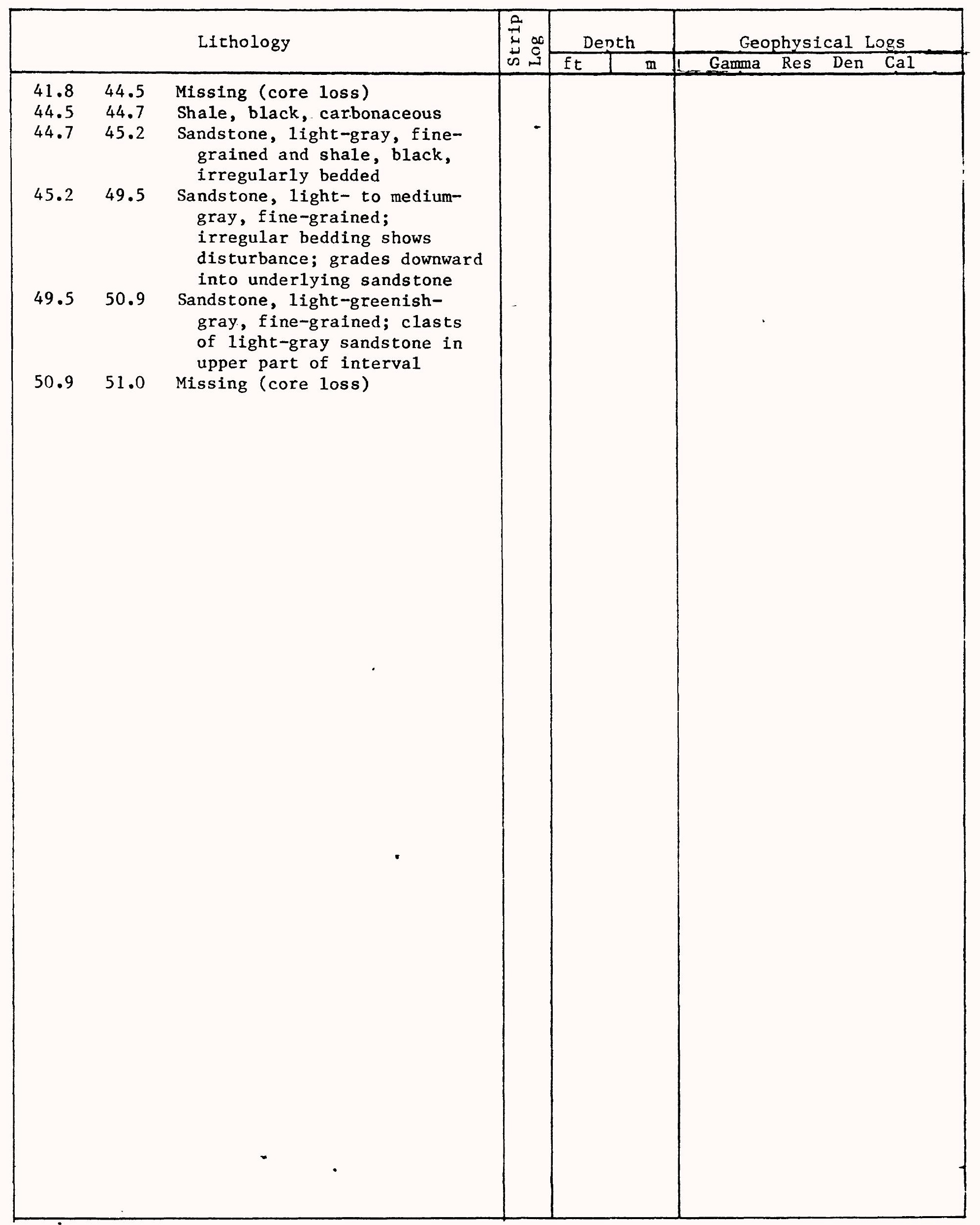


LOCATION NLMBER PR-16-B

LOCATION NW NW SW

COUNTY Albany
DATE $7 / 17 / 80$

Sec. 10 T. $19 \mathrm{~N}$

STATE Wyoming

$\operatorname{INTERVAL~(s)~}$

CORED YES

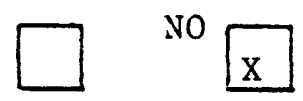

DRILLING MEDIUM:
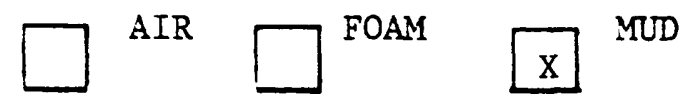

GEOPHYSICAL LOGS :

Natural Gamma

Gamma Gamma

Resistivity

Caliper

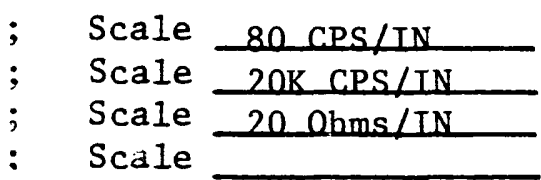

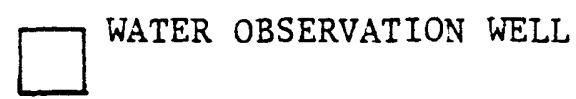

SURFACE ELEVATION(ft) 7265

R. 77W Quad.Pierce Reservoir TOTAL DEPTH(ft) 475

Logging Speed Logging Speed Logging Speed Logging Speed
Lithology

$0.0 \quad 4.0$

$4.0 \quad 5.0$

$5.0 \quad 10.0$

$10.0 \quad 12.0$

$12.0 \quad 15.0$ siltstone, brown, sandy

$15.0 \quad 18.0$ Sandstone, light-brown and

1ight-olive-gray, silty

18.0 22.0 Shale, 1ight-brown and 1ight-

olive-gray, silty

22.025 .0 Siltstone, light-olive-gray

$25.0 \quad 31.0$ Shale and siltstone, 1ight-

31.0 brown and light-olive-gray

$31.0 \quad 34.5$ Siltstone, 1ight-olive-gray

$34.5 \quad 40.5$

$40.5 \quad 47.0$

$47.0 \quad 55.0$

$55.0 \quad 58.0$

$58.0 \quad 60.0$

$60.0 \quad 62.0$

$62.0 \quad 73.0$

$73.0 \quad 78.0$

Shale, light-brown

Siltstone, gray, clayey

Claystone, gray, silty

Silts tone, gray, sandy

Sandstone, gray, fine-grained, silty

Siltstone, gray, sandy

Sands tone, 1ight-gray, finegrained

Sands tone, 1ight-gray, very coarse grained, conglomeratic (chiefly granule size)

$78.0 \quad 83.0$ Siltstone: gray, sandy

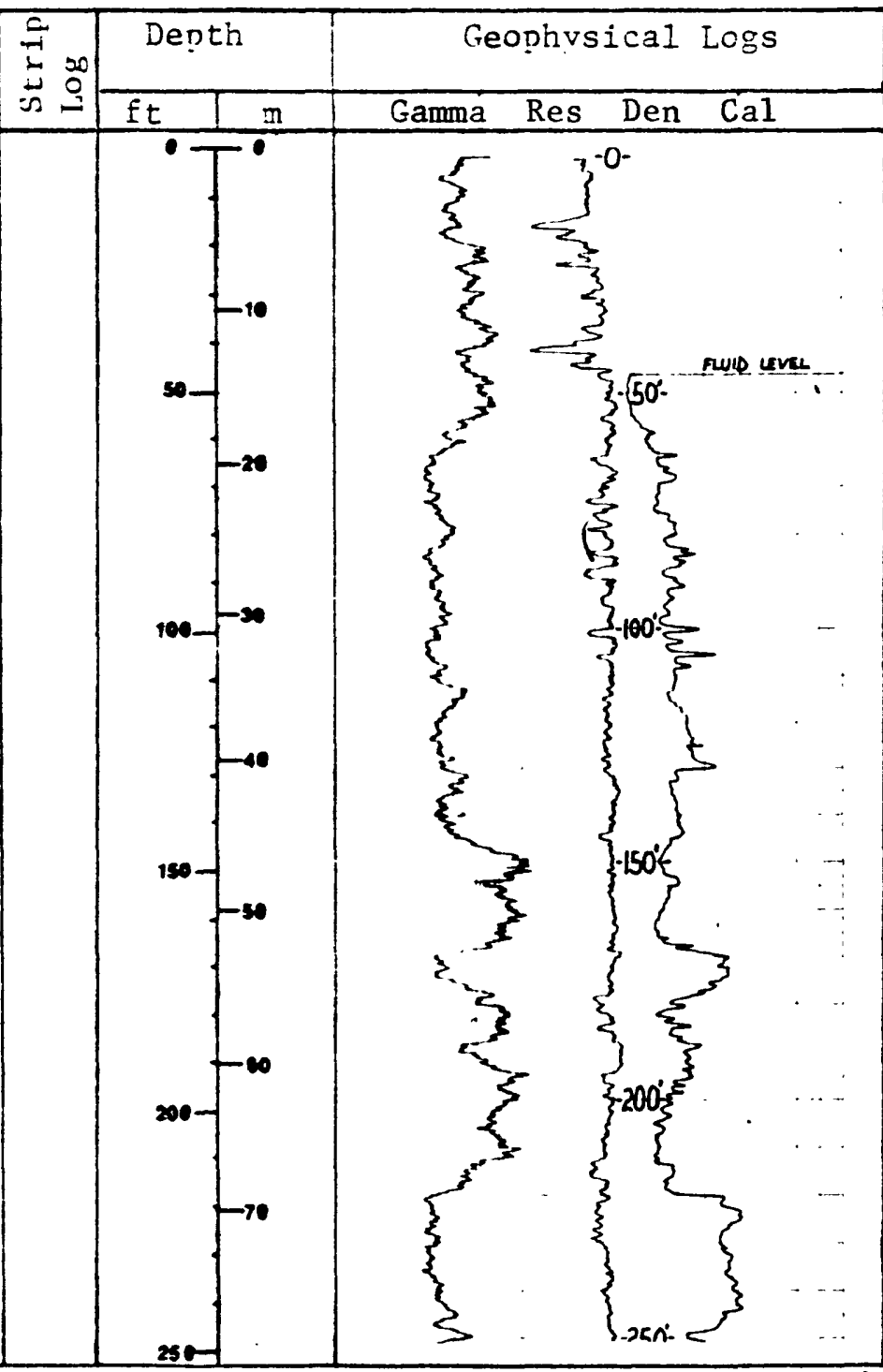




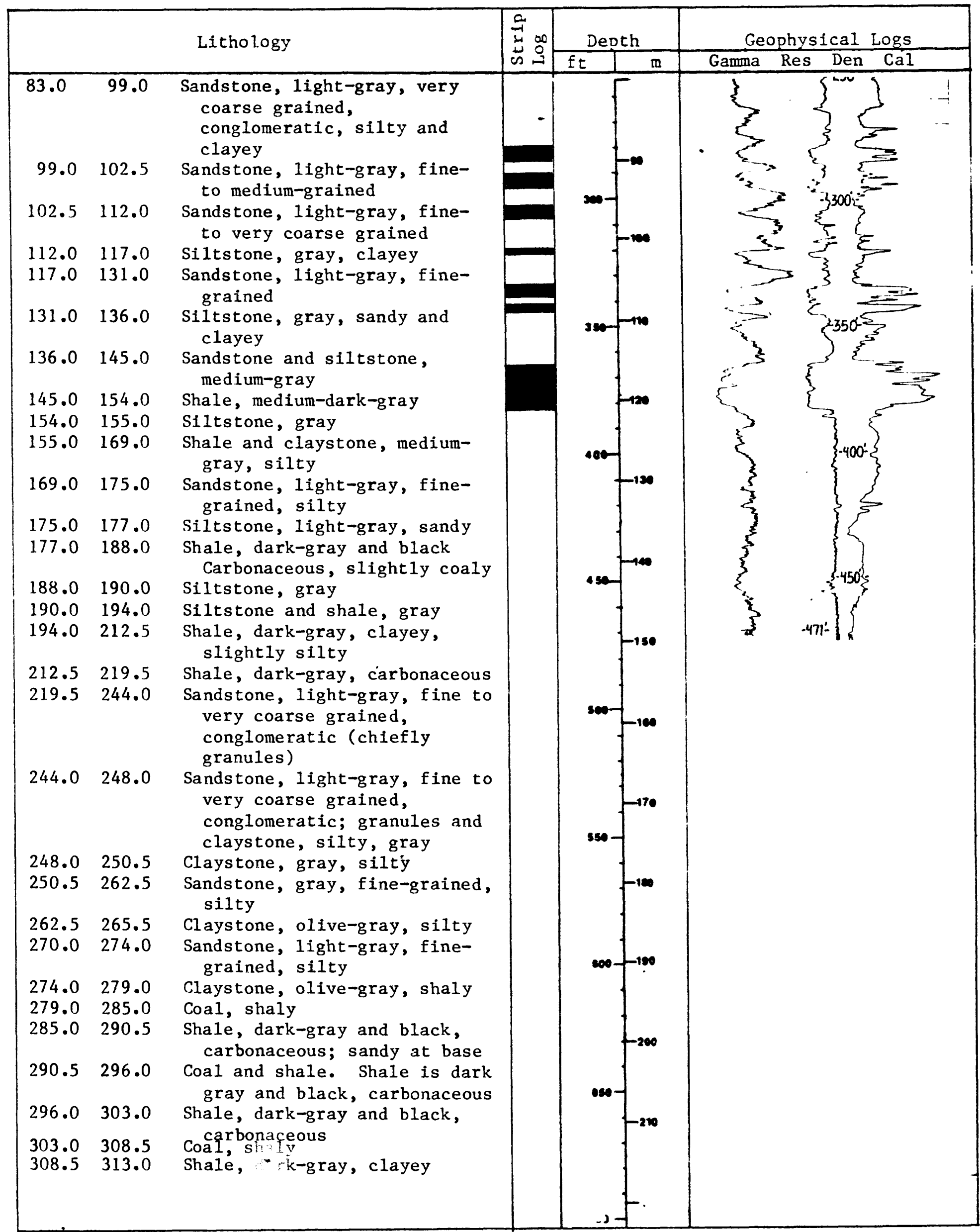




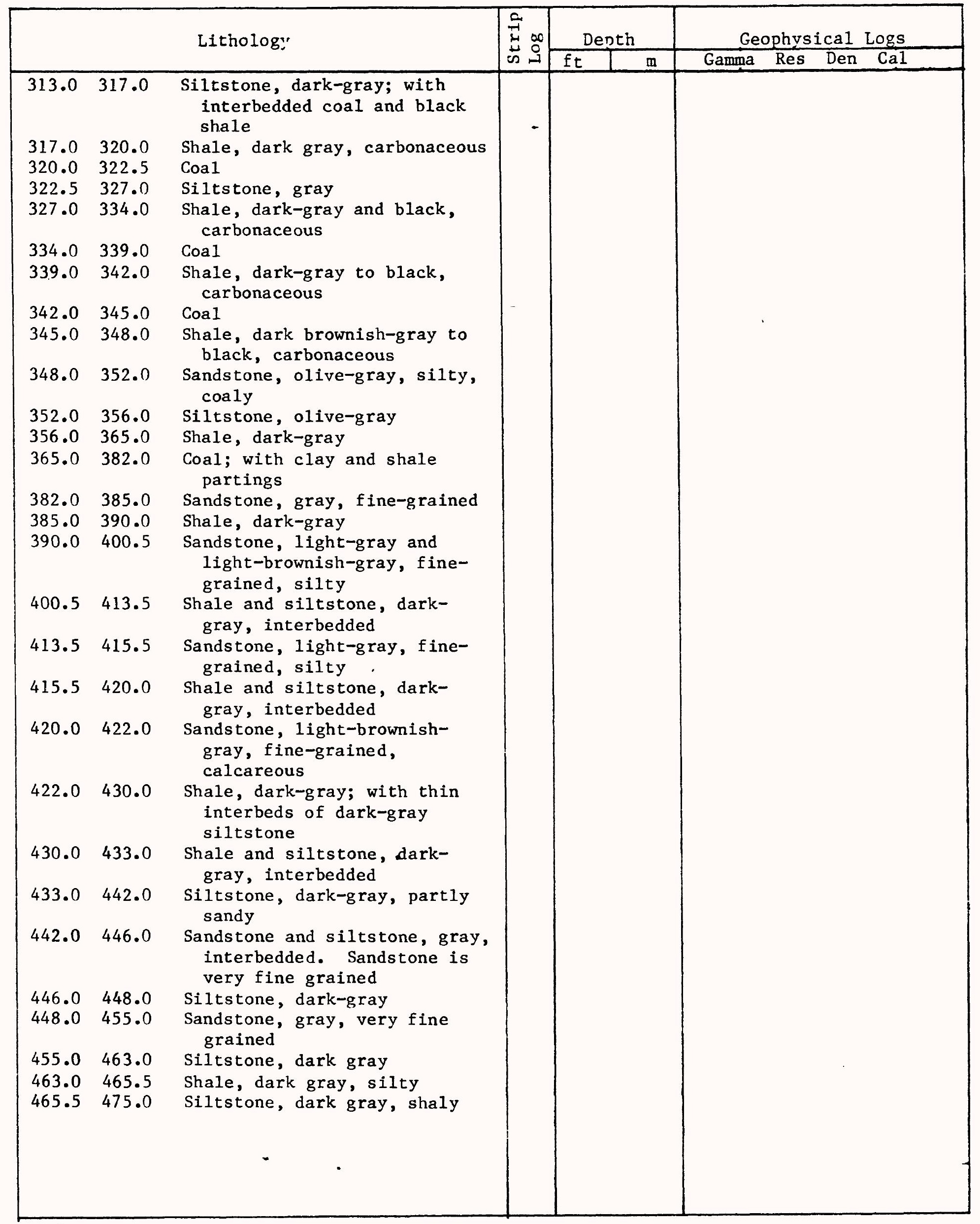


LITHOLOGIC AND GEOPHYSICAL LOGS

LOCATION NLMBER PR-17 DATE $6 / 22 / 80$ SURFACE ELEVATION(ft) 7478

LOCATION SW SW SW Sec. 10 T. $19 \mathrm{~N}$ R. $77 \mathrm{~W}$ Quad. Pierce Reservoir COUNTY Albany STATE Wyoming_ TOTAL DEPTH(ft) 555

CORED YES

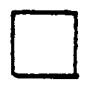

No

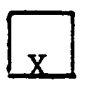

INTERVAL (s)

DRILLING MEDILM:
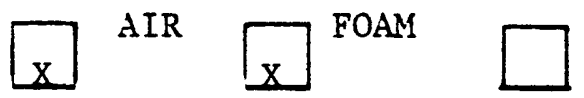

MUD WATER OBSERVATION WELL

GEOPHYSICAL LOGS :

Natural Gamma Gamma Gamma Resistivity Caliper
; Scale 200 CPS/IN : Scale $8 \mathrm{~K}$ CPS/IN

; Scale 20 ohms/IN

; Scale 3 IN/IN
Logging Speed

Logging Speed

Logging Speed

Logging Speed

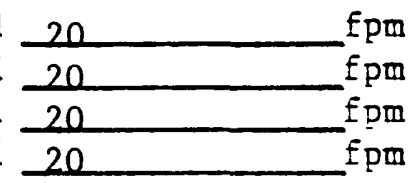

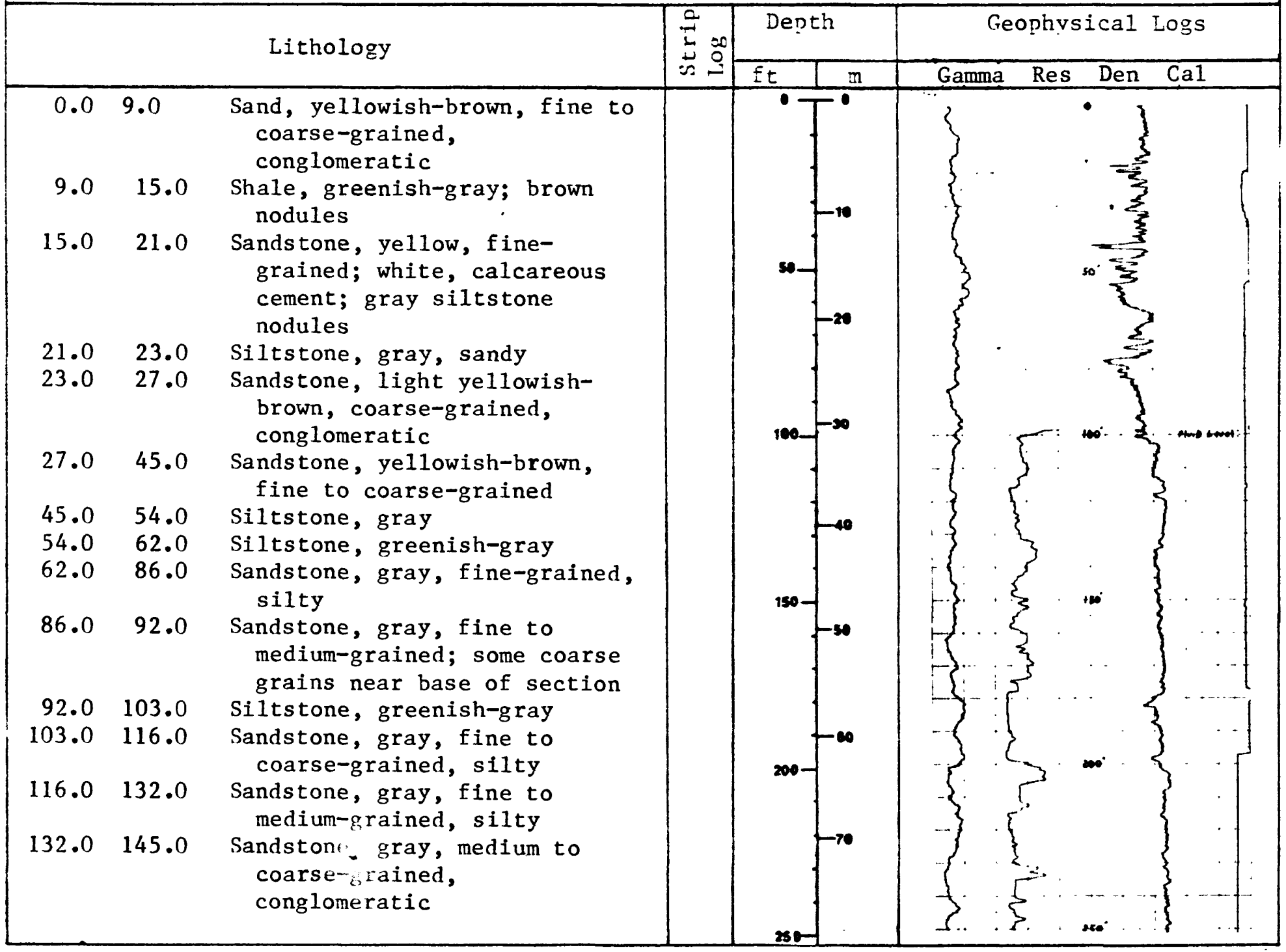




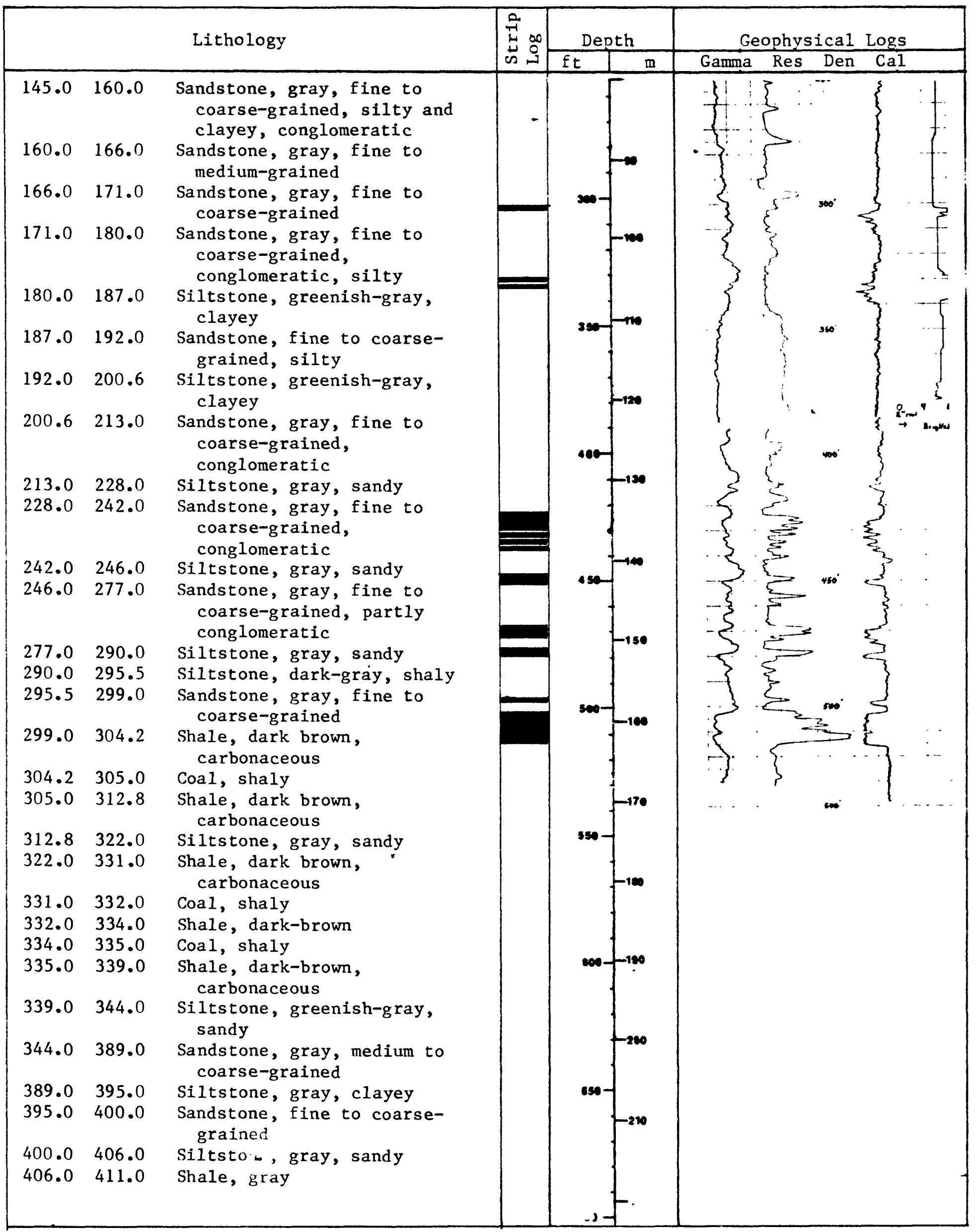




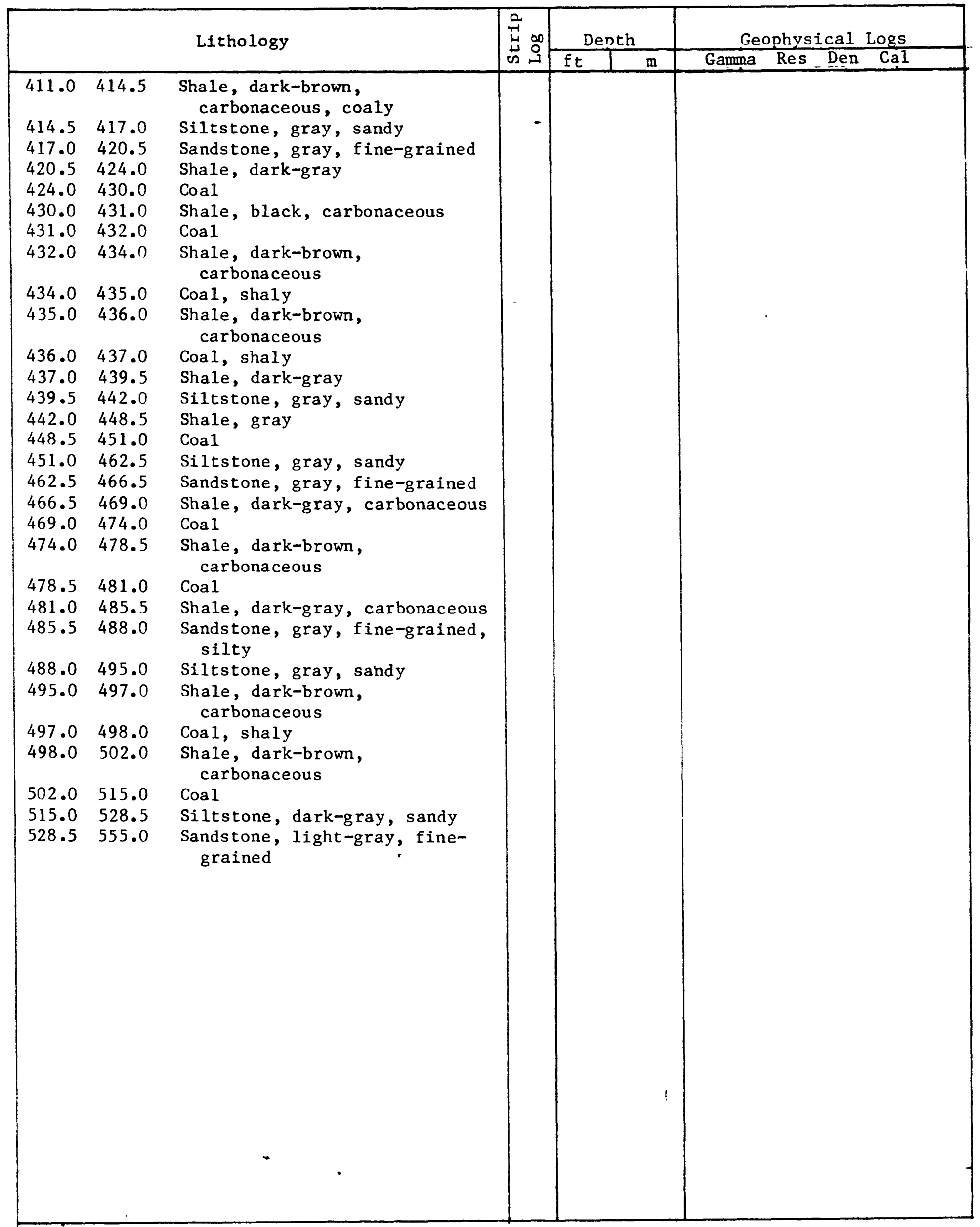


LOCATION NLMBER PR-18

LOCATION SE SE SE COUNTY

Albany
DATE $7 / 14 / 80$

Sec. 10 T. $19 \mathrm{~N}$

STATE Wyoming

INTERVAL (s)
CORED
YES

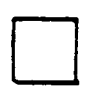

No $\mathrm{x}$

DRILLING MEDIUM:

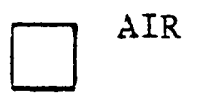

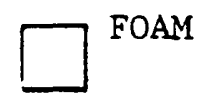

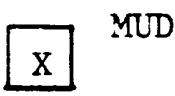

SURFACE ELEVATION(ft)

R. 77W Quad.Pierce Reservoir TOTAL DEPTH(ft) 605

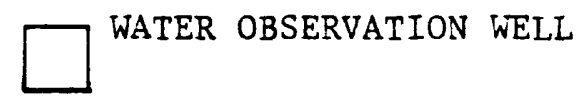

GEOPHYSICAL LOGS :

Natural Gamma

Gamma Gamma

Resistivity

Caliper
; Scale

; Scale

; Scale

: Scale
Logging Speed

Logging Speed

Logging Speed

Logging Speed

\begin{tabular}{l}
$\mathrm{fpm}$ \\
$\mathrm{fpm}$ \\
$\mathrm{fpm}$ \\
\hline 20
\end{tabular}

Lithology

$0.0 \quad 7.0 \quad$ Grave1, brown

$7.0 \quad 11.0$ Claystone, dark-gray, silty

$11.0 \quad 17.0$ Sandstone, brown, coarsegrained, clayey

17.021 .0 Sandstone, brown, very coarsegrained and granules of feldspar and quartzite

21.025 .5 Siltstone, brown, sandy. Sandstone is coarse-grained

25.533 .0 Siltstone, olive-gray, clayey

$33.0 \quad 39.0$ Sandstone, light-gray and greenish-gray, fine- to coarse-grained

$39.0 \quad 60.0$ Sandstone, light-gray, very conglomeratic; including small pebbles and granules of chiefly angular feldspar and quartzite

$60.0 \quad 68.0$ Shale, dark-gray, clayey

68.076 .2 Siltstone, medium-dark-gray, sandy

76.2 82.0 Sandstone, medium-gray, finegrained, silty

82.0 85.2 Siltstone, greenish-gray, sandy

85.2 96.5 Claystone, gray and brown, silty

96.5 109.5 Siltstone and sandstone, interbecled, greenishgray. Sandstone is finegrained.

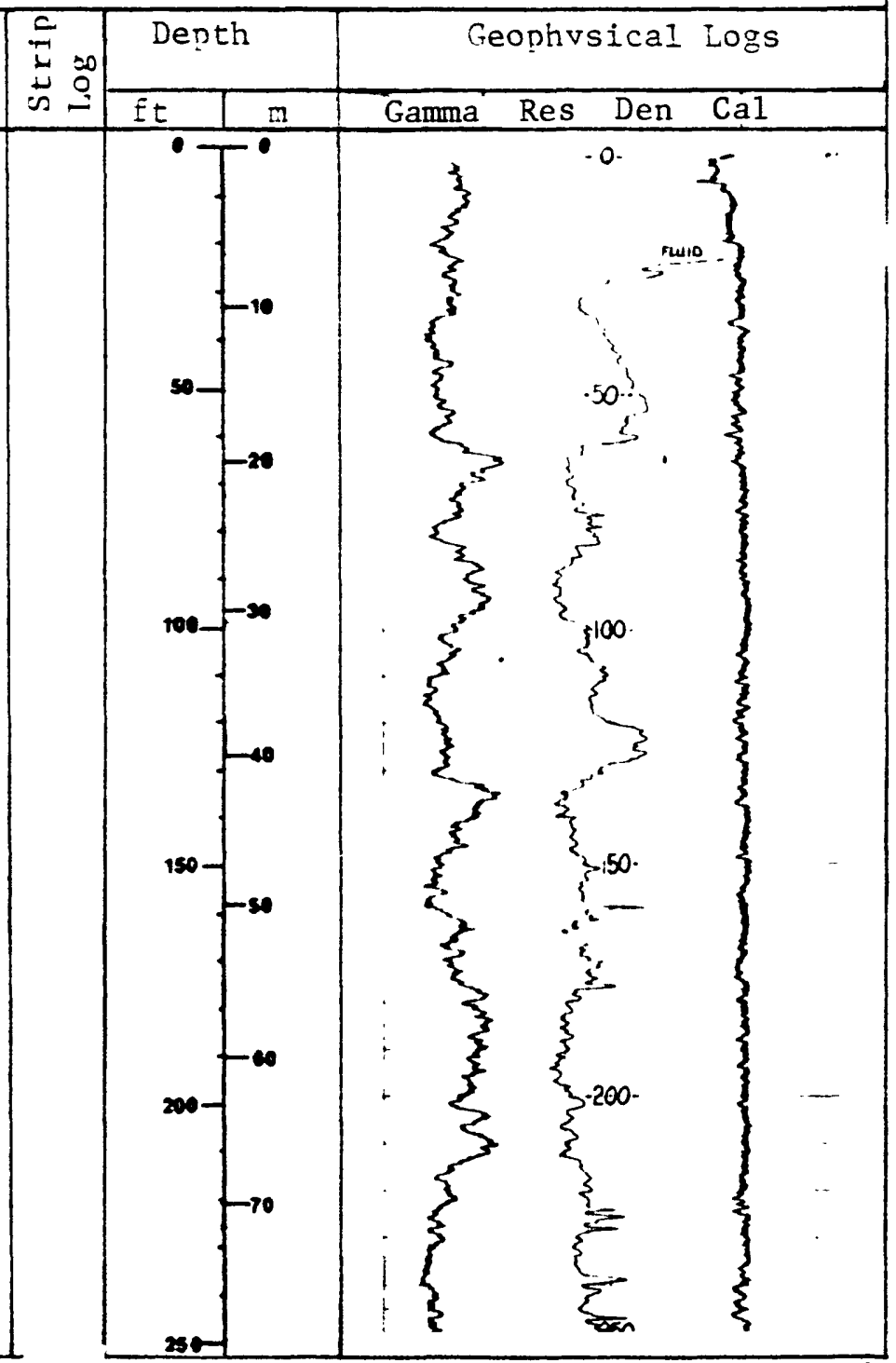




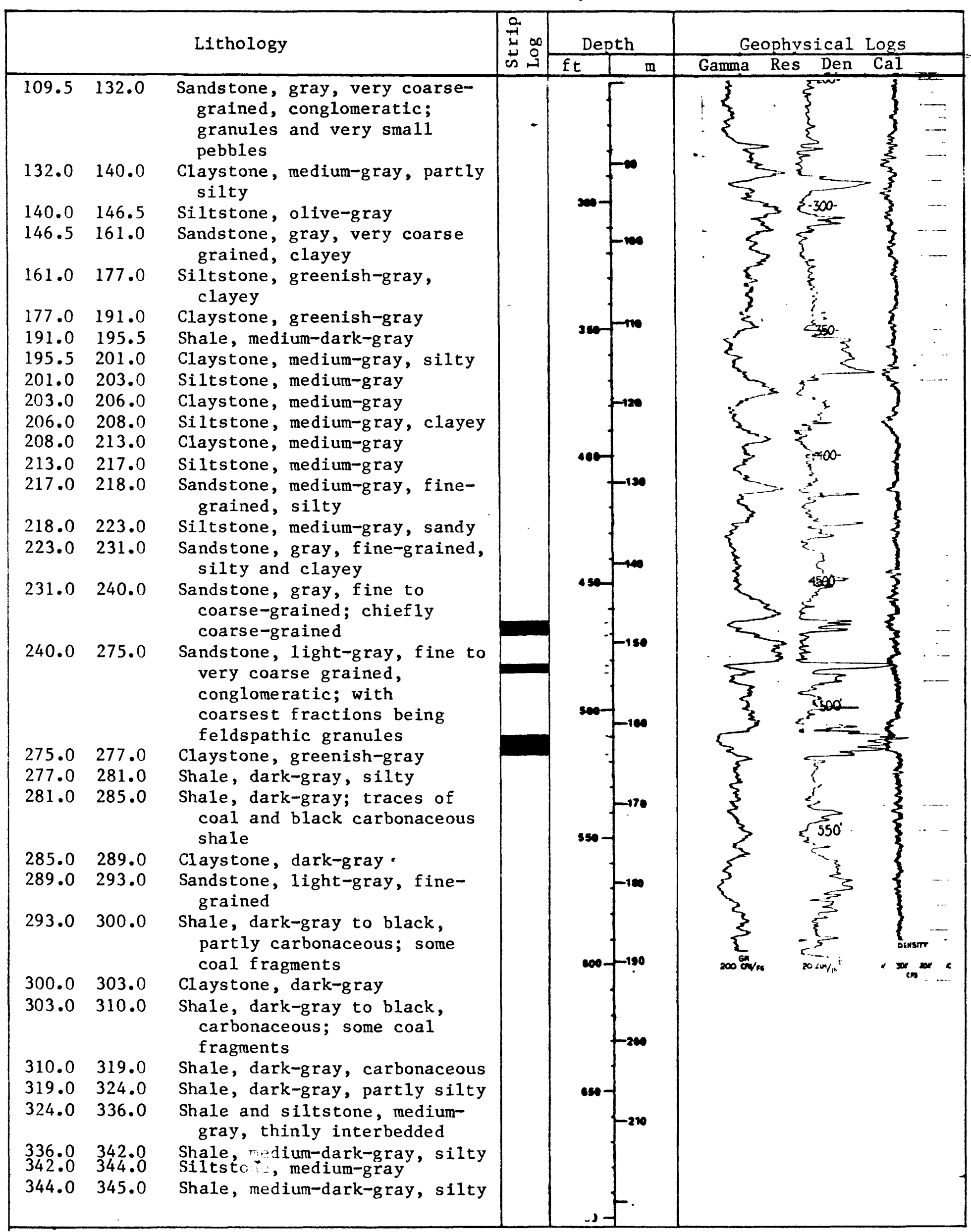




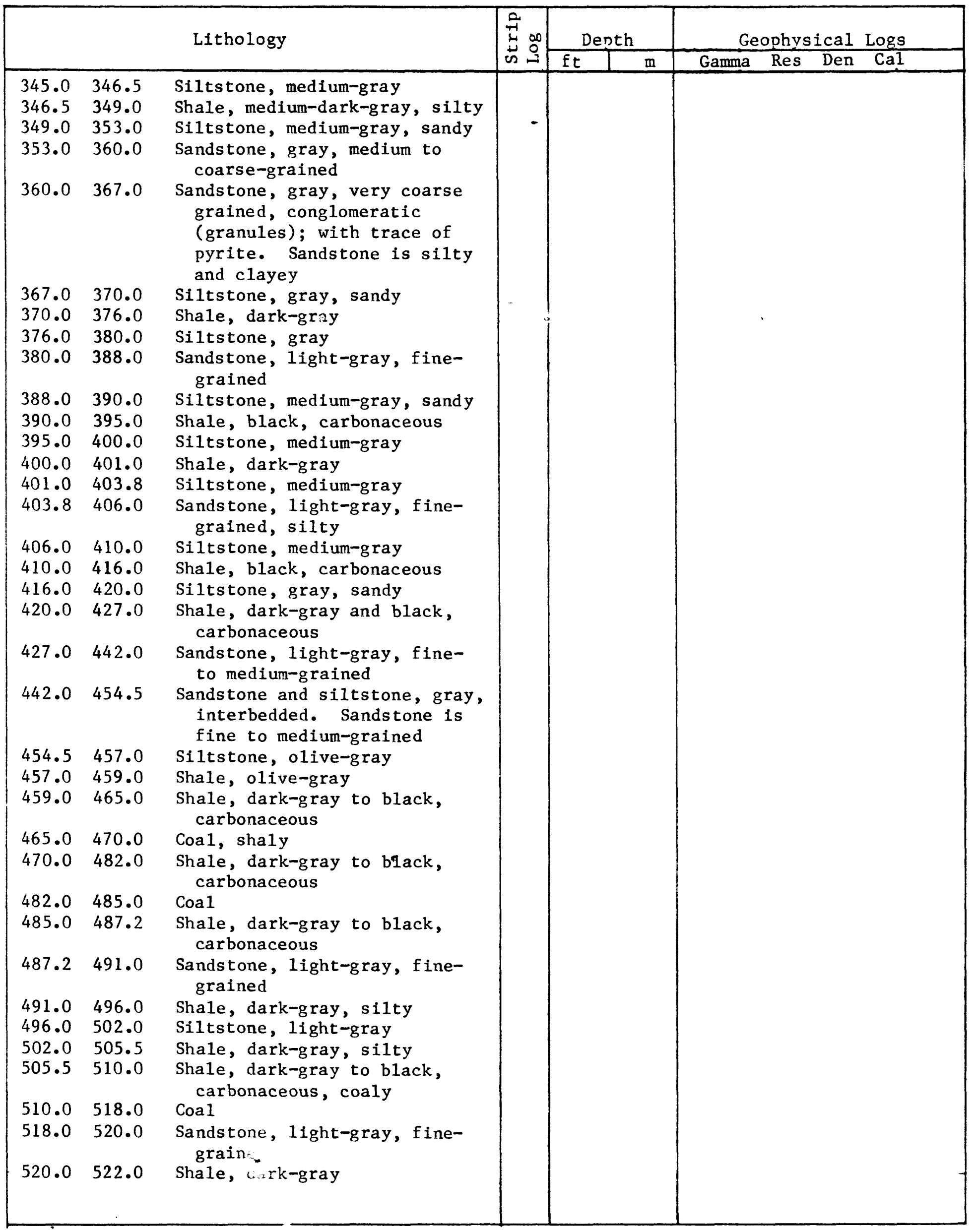




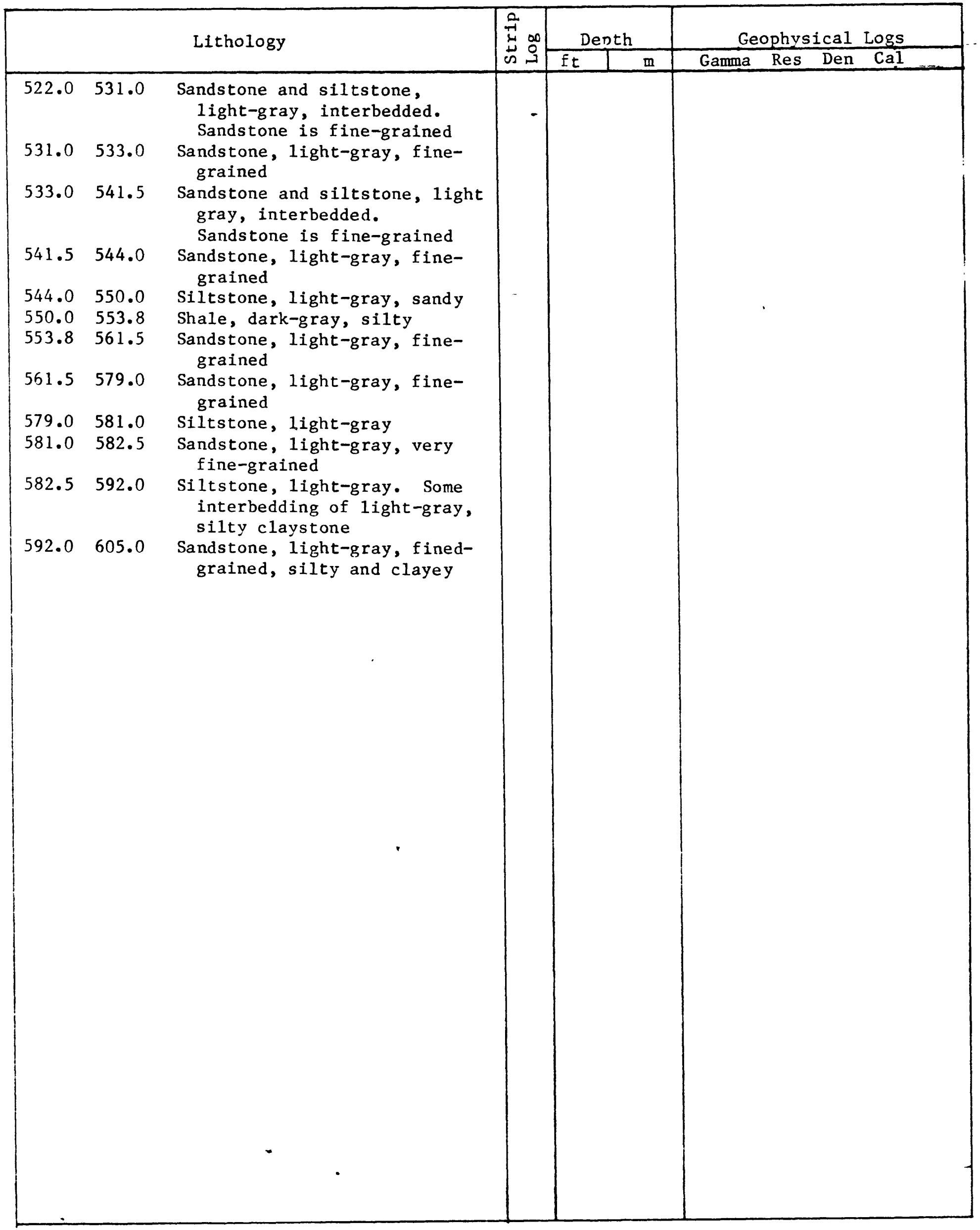


LOCATION NLMBER PR-19

LOCATION

NE NE SE

COUNTY Albany
DATE

$6 / 19 / 80$

Sec. 8 T. 19N

STATE Wyoming

INTERVAL (s)

CORED

YES

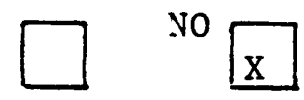

DRILLING MEDIUM:

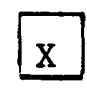

AIR

$\mathrm{X}$ FOAM

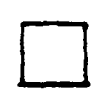

MUD

SURFACE ELEVATION (ft) 7265

GEOPHYSICAL LOGS :

Natural Gamma

Gamma Gamma

Resistivity

Caliper

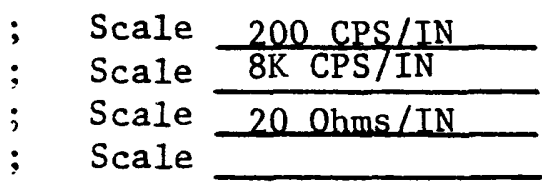

Logging Speed 15

Logging Speed 15

Logging Speed 15

Logging Speed
R. 77W Quad. Pierce Reservoir TOTAL DEPTH(ft) 130

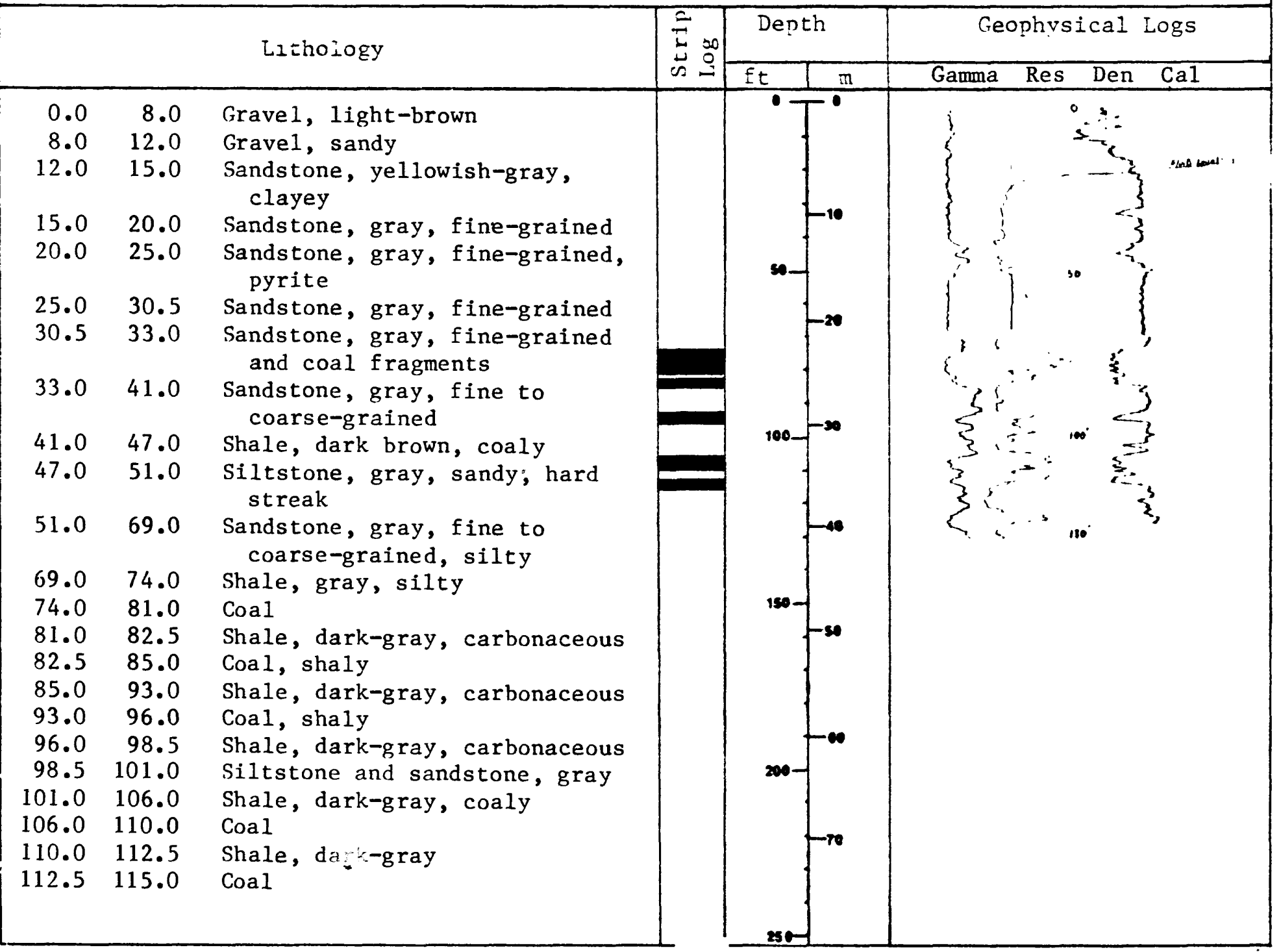


PR-19

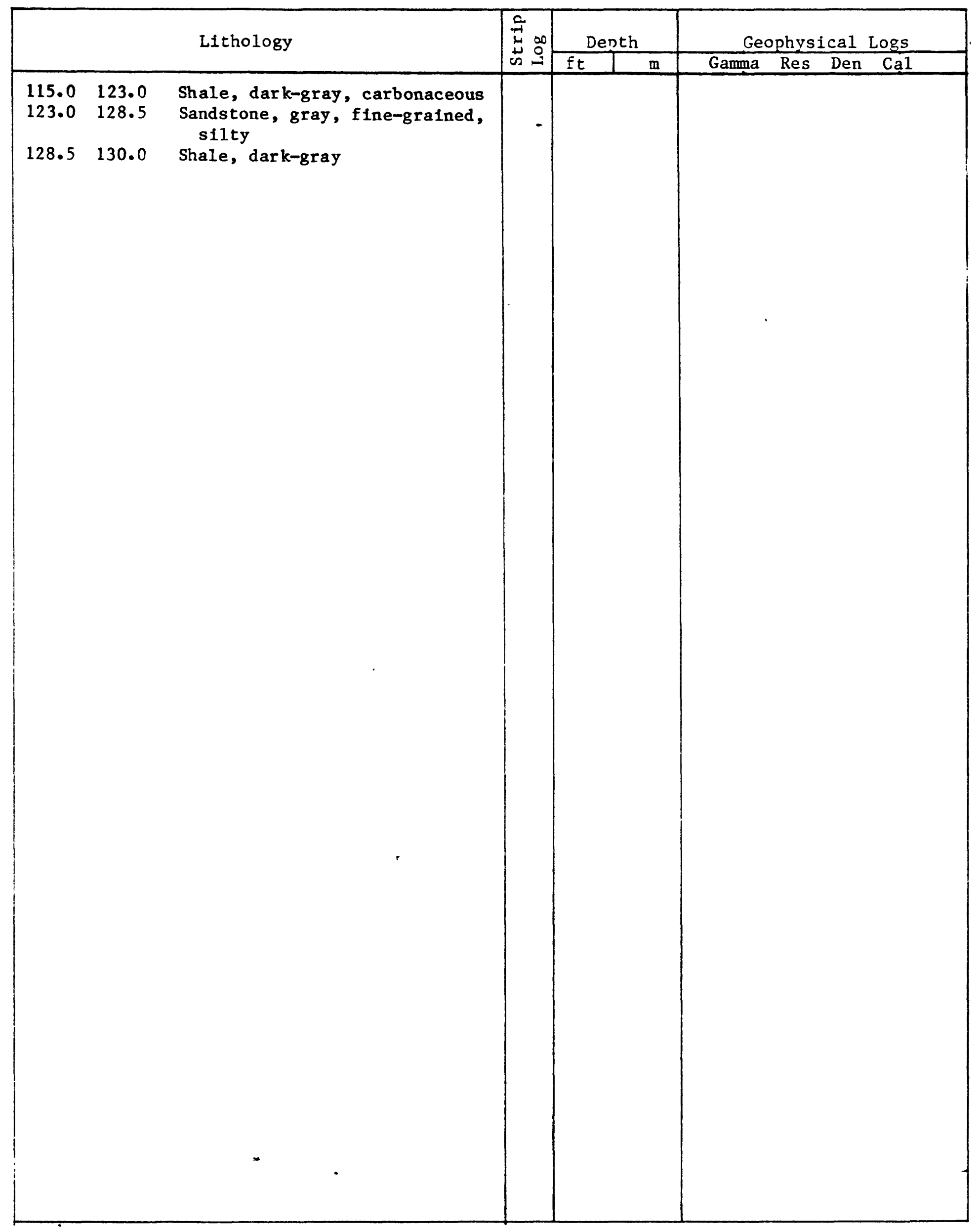




\section{LITHOLOGIC AND GEOPHYSICAL LOGS}

LOCATION NUMBER PR-19-C DATE $6 / 20 / 80$ SURFACE ELEVATION(ft) 7265

LOCATION NE NE SE

$\operatorname{Sec} \cdot \underline{8} T \cdot \underline{19 N}$

$\mathrm{R} \cdot \underline{77 \mathrm{~W}}$ Quad. Pierce Reservoir COUNTY Albany STATE Wyoming_ TOTAL DEPTH(ft) 165

CORED YES

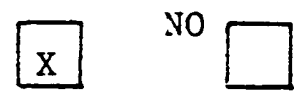

INTERVAL ( $s$ ) $70-161+1 t$

DRILLING MEDILM:

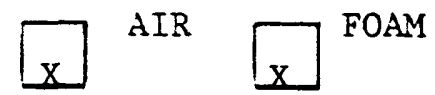<smiles>C1CCC1</smiles>
MUD $\square$ WATER OBSERVATION WELL

GEOPHYSICAL LOGS :

Natural Gamma

Gamma Ganma

Resistivity

Caliper
; Scale $200 \mathrm{CPS} / \mathrm{IN}$

: Scale 8K CPS/IN

; Scale 20 Ohms/IN

: Scale
Logging Speed 20

Logging Speed 20

Logging Speed 15

Logging Speed fpm

fpm

fpm fpm

\section{Lithology}

0.070 .2 No samples.

70.271 .6 Sandstone, gray, fine-grained, fine laminations. Contains some coal and clay clasts

$71.6 \quad 72.0 \quad$ Siltstone and sandstone, gray or medium dark-gray interbedded

72.076 .6 Shale, dark-gray; thin siltstone bands

76.6 79.9 Coal, bright and dull banding, pyritic

79.980 .0 Shale, dark brownish-gray

$80.0 \quad 81.1$ Coal, pyritic

81.181 .8 Coal; thin dark brown shale banding

$81.8 \quad 83.6$ Coal, pyritic

83.6 84.6 Shale, dark-brown, coaly

84.686 .0 Coal, bright and dull, pyritic; shaly at bottom

$86.0 \quad 87.5$ Shale, medium dark-gray, silty, coal stringers

$87.5 \quad 89.8$ Shale, dark gray, siltstone banding

89.8 92.8 Shale, dark gray, coal streaks

$92.8 \quad 93.5 \quad$ Claystone, dark-gray

93.595 .1 Shale, dark-gray and black, coal streaks

$95.1 \quad 97.6 \quad$ Coal, black shale bands

97.698 .8 Shale, do k-brown, silty

$98.8 \quad 99.6$ Siltstone, dark-gray

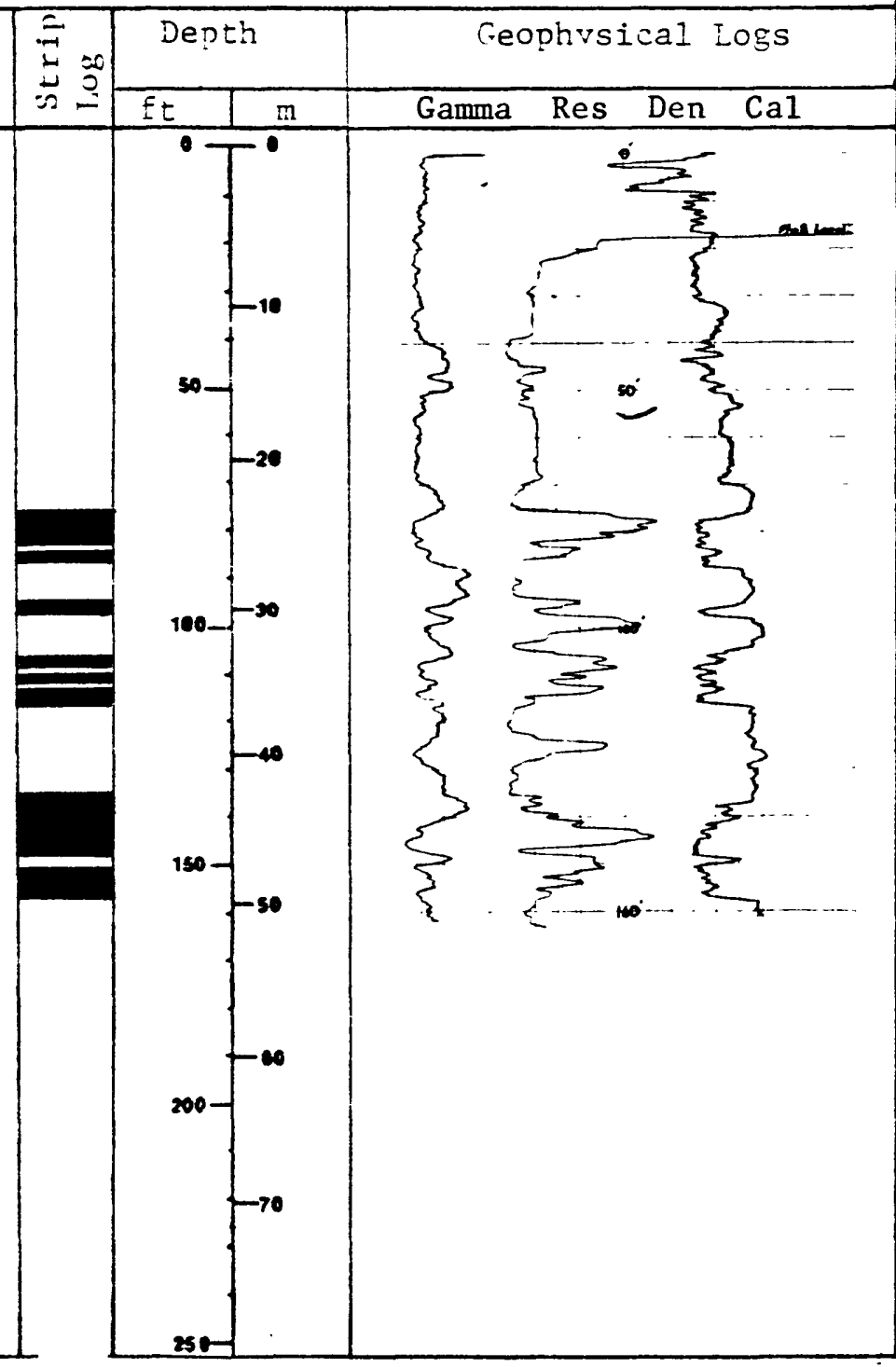




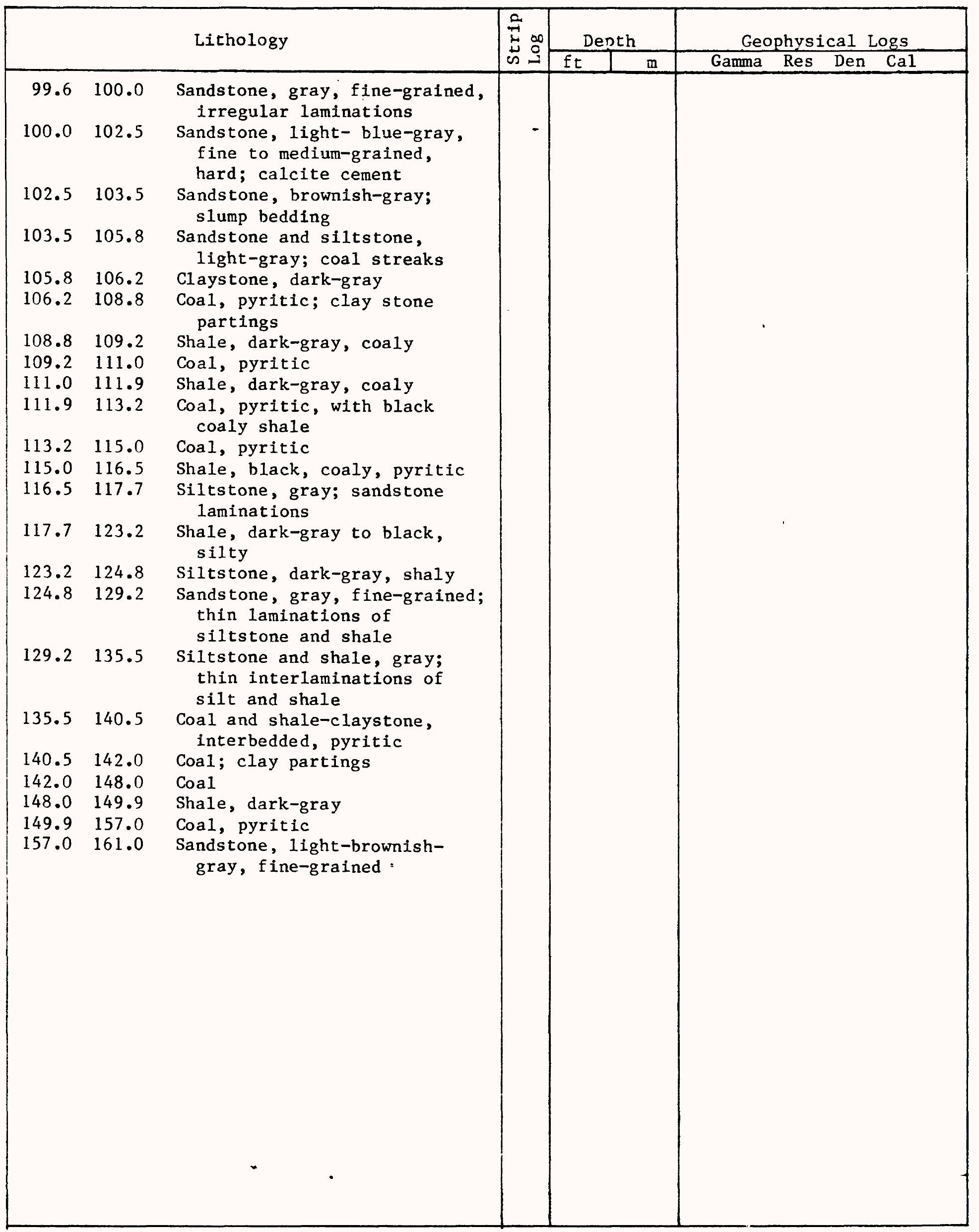


LOCATION NUMBER PR-20

LOCATION SW SW SE County \& ibany

CORED YES $\square$ No $\mathrm{x}$
DATE $6 / 18 / 80$

$\operatorname{Sec} \cdot \underline{8}$

STATE T. Wyoz:-:-

INTERVAL (s)

DRILLING MEDILM:

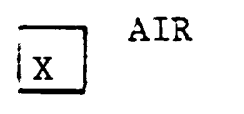

SURFACE ELEVATION(Et) 7325

․ $77 \mathrm{~W}$ Quad.Pierce Reservoir IOTAL DEPTH(Et) 240

GEOPHYSICAL LOGS :

Natural Gana

Gamma Gamma

Resistivity

Caliper $\begin{array}{ll}; & \text { Scale } 200 \mathrm{CPS} / \mathrm{II} \\ ; \quad \text { Scale } \frac{8 \mathrm{KCPS} / \mathrm{IR}}{20 \mathrm{hms} / \mathrm{TH}}\end{array}$

Logging Speed

zogging Speed

-ogging Speed

-ogging Speed

\section{Z-h.nlogy}

$0.0 \quad 4.0$ Grave1, light-brownish-gray

4.0 28.0 Sandstone, light-brown

gray, fine-grained

28.041 .0 Sandstone, 1ight-brownish-

$41.0 \quad 51.0 \quad$ Shale, olive-gray, partly

carbonaceous

$51.0 \quad 55.0$ Sandstone, light-gray to

$55.081 .0 \quad \begin{gathered}\text { white, fine-grained } \\ \text { Sandstone, dark-brown and }\end{gathered}$ yeilowish-brown, fine to coarse-grained

81.089 .0 Sandstone, gray, fine to coarse-grained; small pebbles, conglomeratic

89.096 .0 Silestone, gray, hard streaks, sandy; thin claystone at middle of unit

96.0 103.3 Sandstone, gray, fine-grained, partly calcareous, hard

103.3 109.5 Siltstone, gray, sandy; some

$109.5 \quad 116.3$ interbedding of brownishgray clay

116.3116 .8 Sha?e, gray

$116.8 \quad 118.8 \quad$ Coal, shaly

118.8127 .0 Clayston, gray, silty

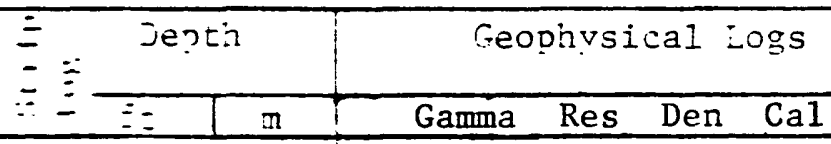

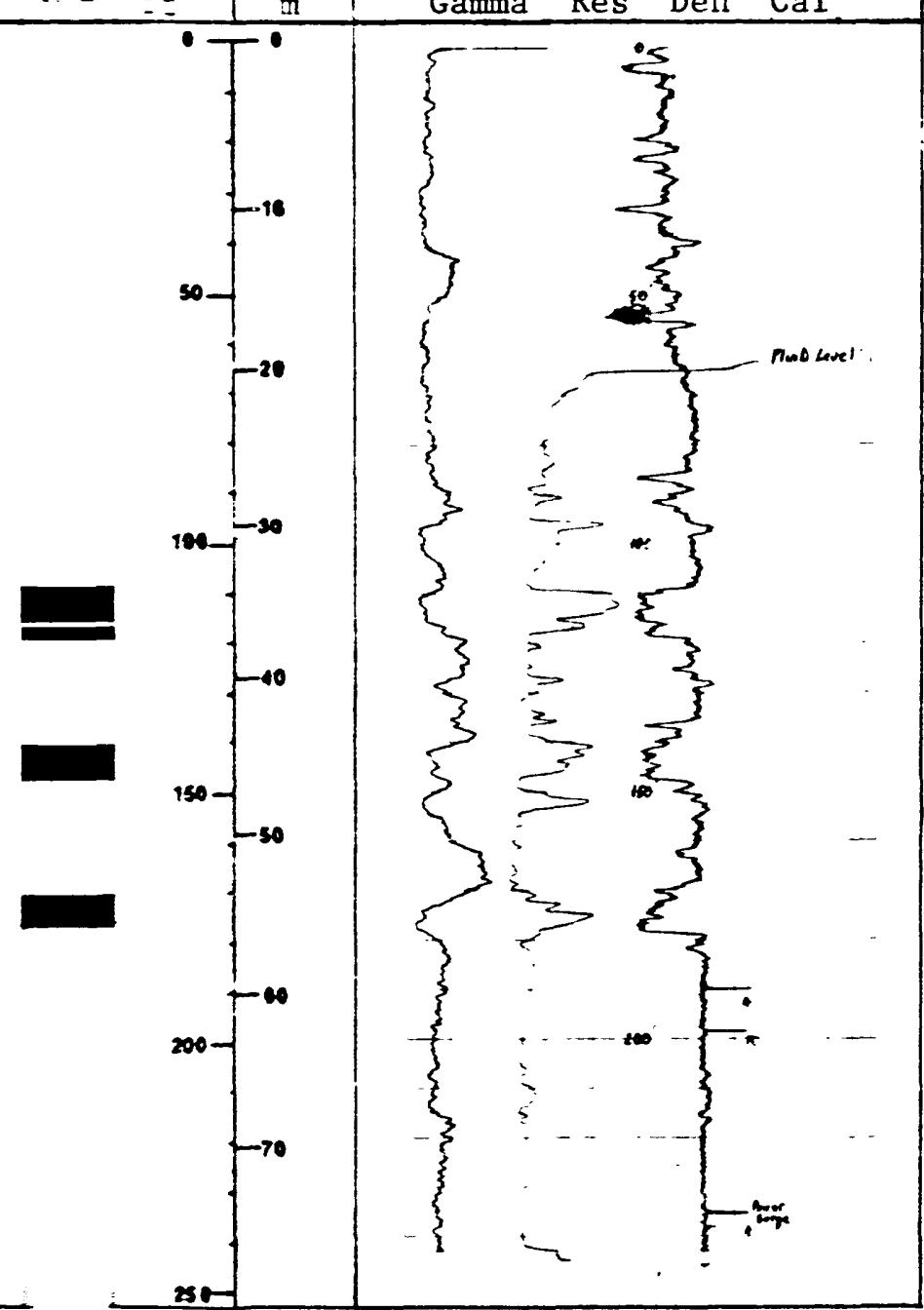




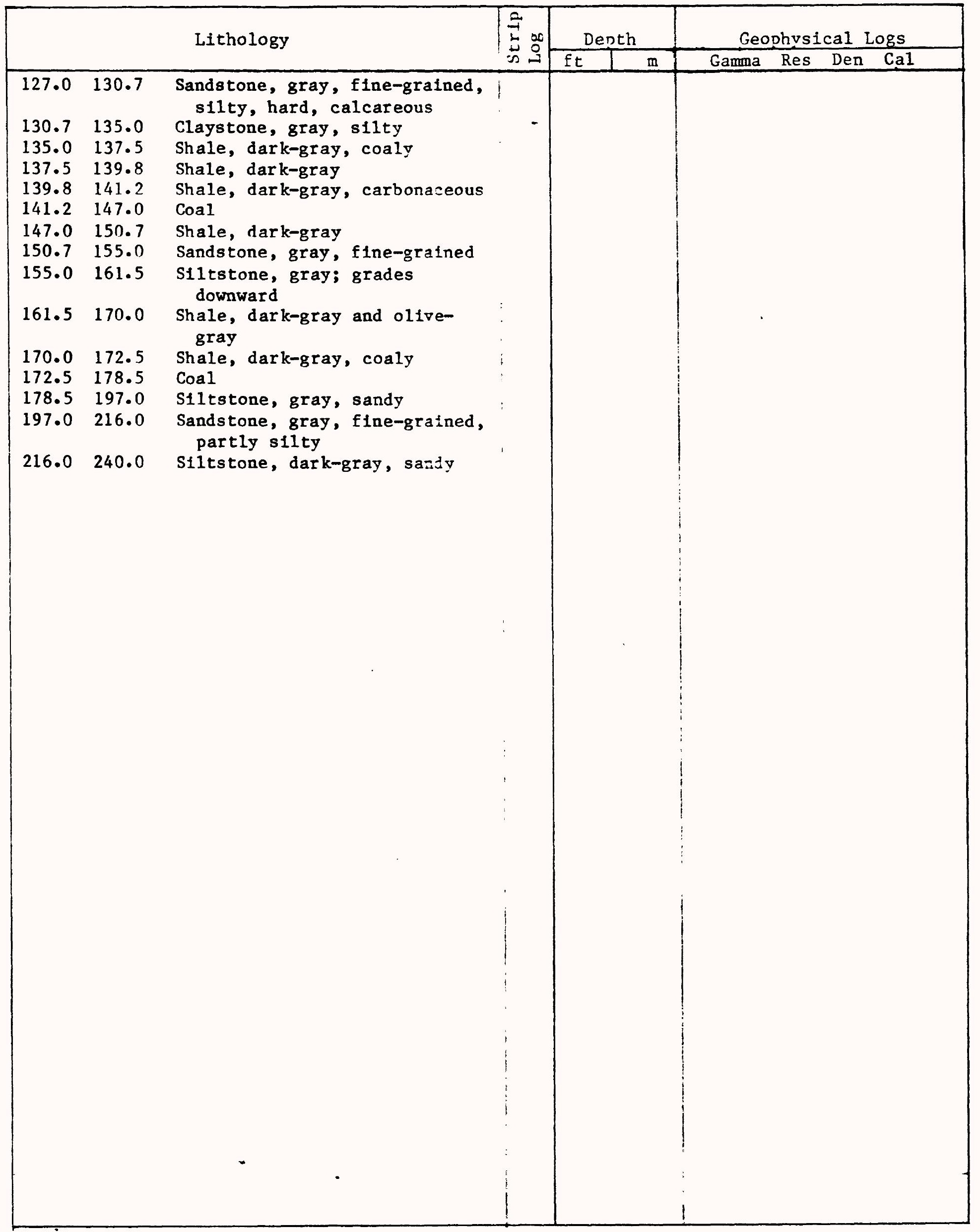


LOCATION NUMBER PR-20-C DATE $6 / 19 / 80$ SURFACE ELEVATION(ft) 7310

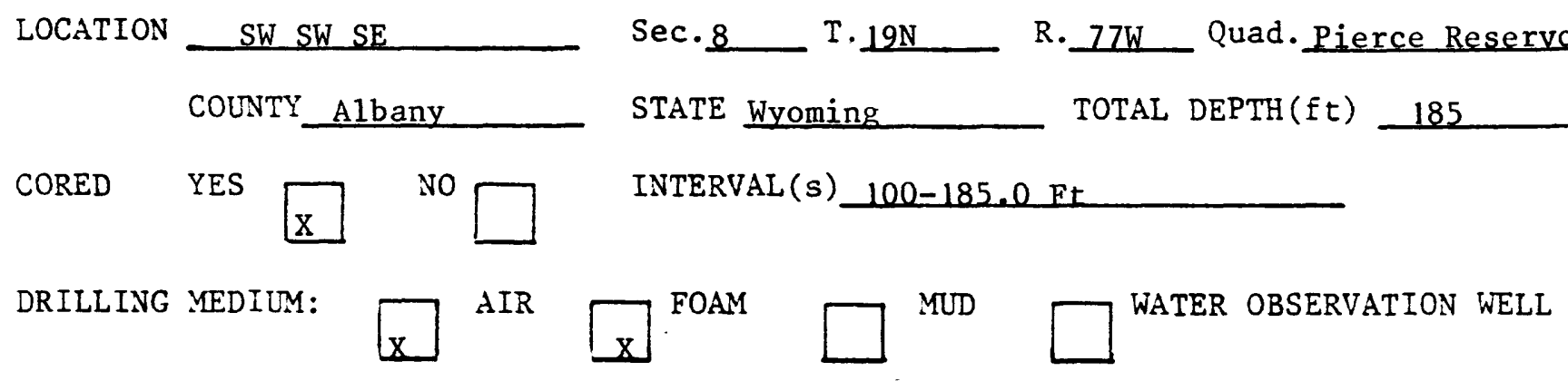

GEOPHYSICAL LOGS :

Natural Gamma

Gamma Gamma

Resistivity

Caliper $\begin{array}{ll}; & \text { Scale } 200 \mathrm{CPS} / \mathrm{IN} \\ ; & \text { Scale } \\ ; & \text { Scale } \mathrm{KPS} / \mathrm{IN} \\ 20 \text { Ohmes/IN }\end{array}$
Logging Speed 15

Logging Speed 15

Logging Speed 15

Logging Speed
Epm

fpm

fom Epm

\section{Lithology}

0.0100 .0 No sample

100.0101 .6 Siltstone, gray; irregular

laminations

101.6102 .0 Shale, medium-dark-gray, silty

$102.0 \quad 105.0$ Shale and claystone, dark-gray

105.0 106.2 Shale, black, coaly

106.2 111.2 Coal, bright and dul1; minute crystals of pyrite

$111.2113 .5 \quad$ Coal; lenses of pyrite

113.5121 .1 Shale, medium to dark-gray;

thin coal lenses

121.1 121.2 Sandstone and shale, gray,

irregular bedded

121.2123 .0 Sandstone and shale,

$123.0 \quad 124.2$ interbedded, gray

123.0124 .2 Sandstone, gray, very fine

$124.1 \quad 127.0$ Sandstone and shale, interbedded. Sandstone is gray, fine to coarse-

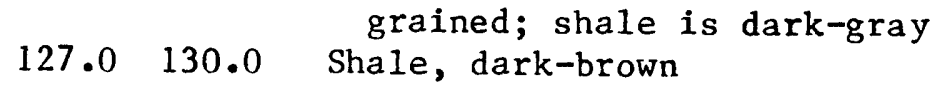

130.0131 .0 Sandstone, gray, fine to medium-grained;

interlaminations of gray shale

$131.0 \quad 131.8$ Shale, dark-gray

$131.8 \quad 132.5 \quad$ Coal, shaly

132.5135 .8 Shale, ne-gray to darkgray; thin lenses of coal, plant impressions

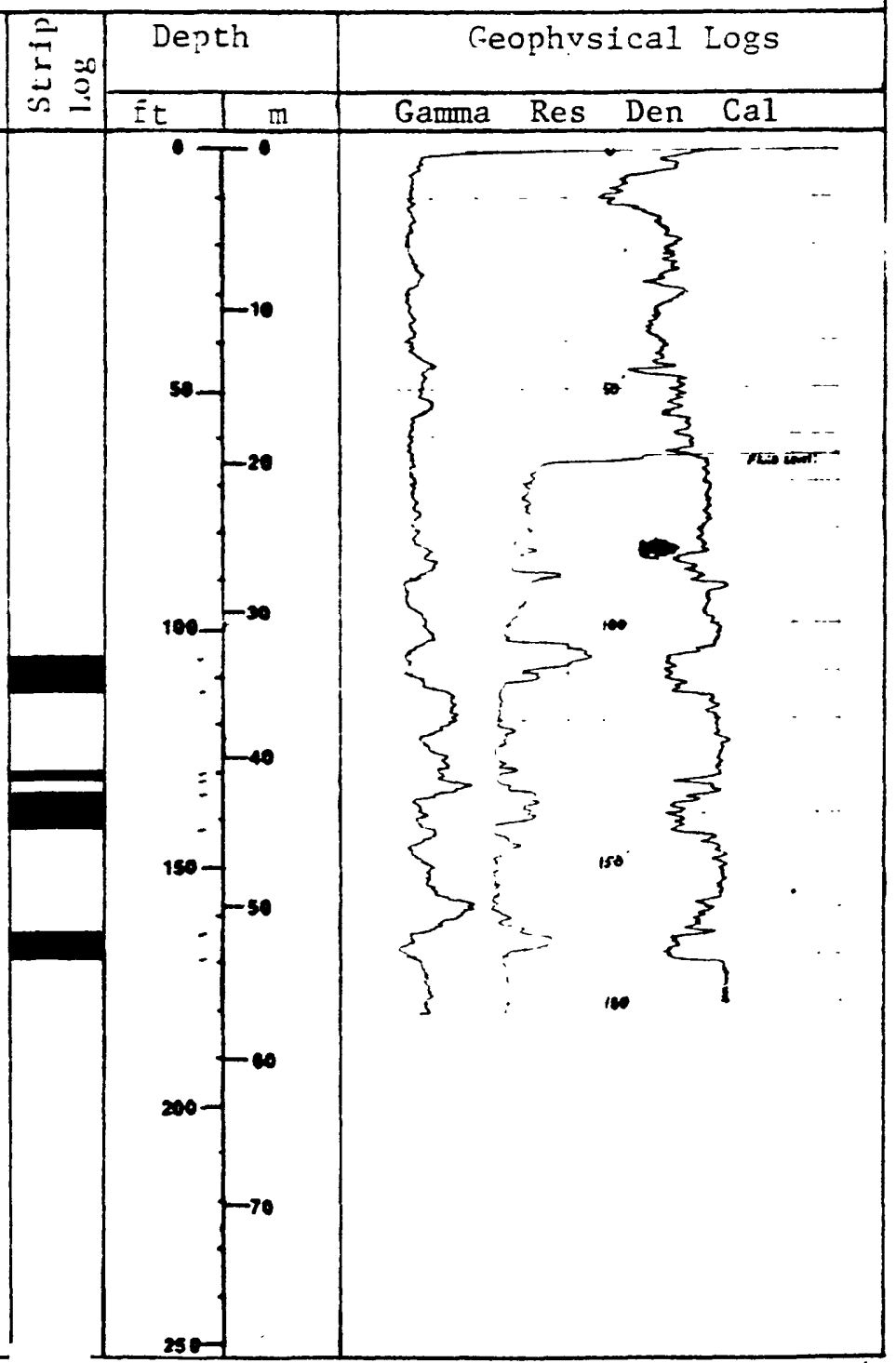




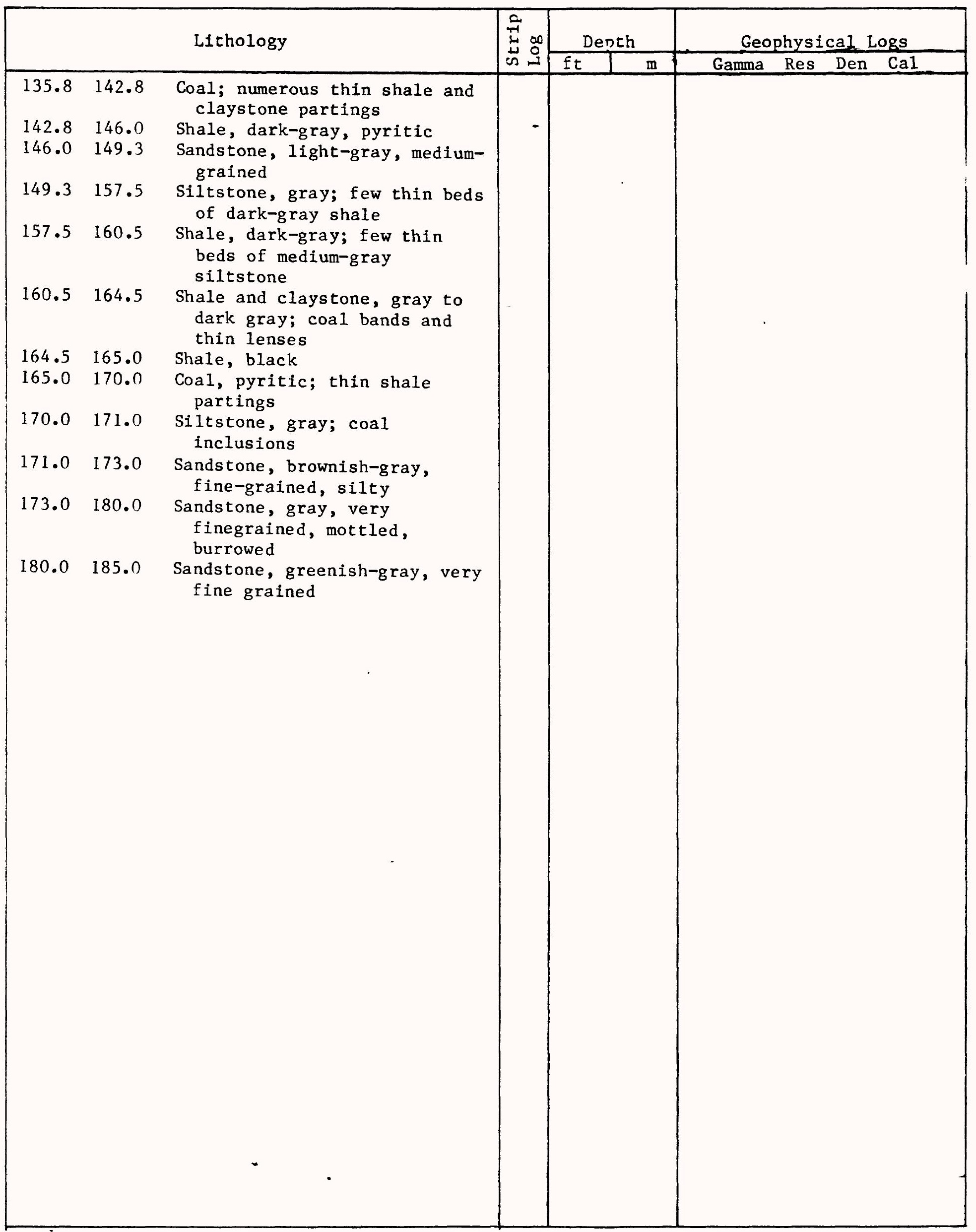




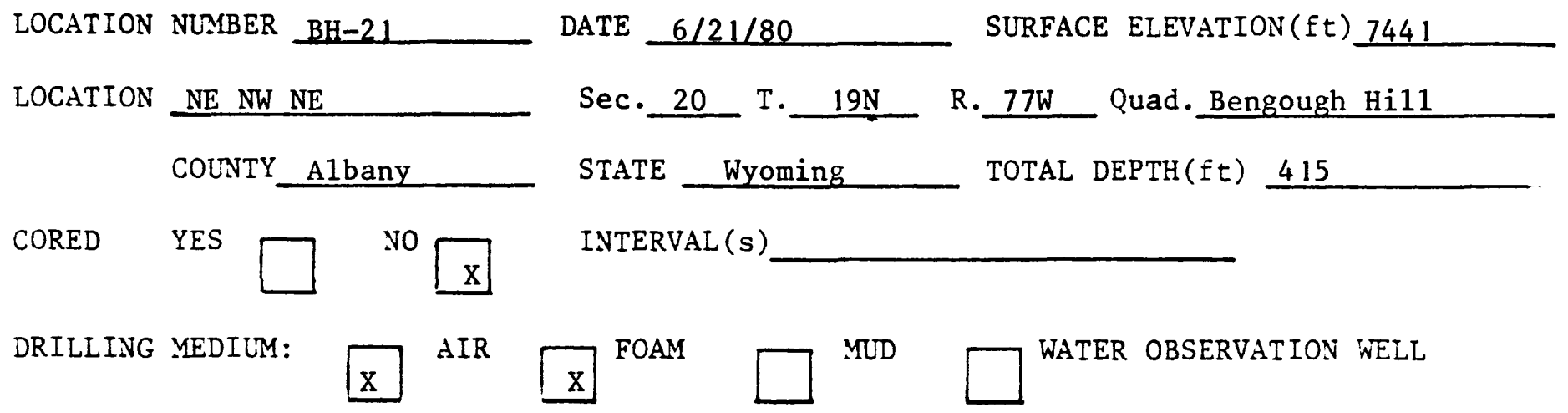

GEOPHYSICAL LOGS:

Natural Gamma

Gamma Gamma

Resistivity

Caliper

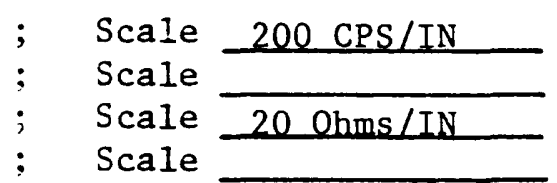

Logging Speed

Logging Speed

Logging Speed

Logging Speed

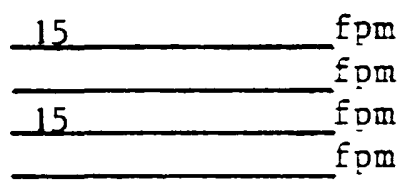

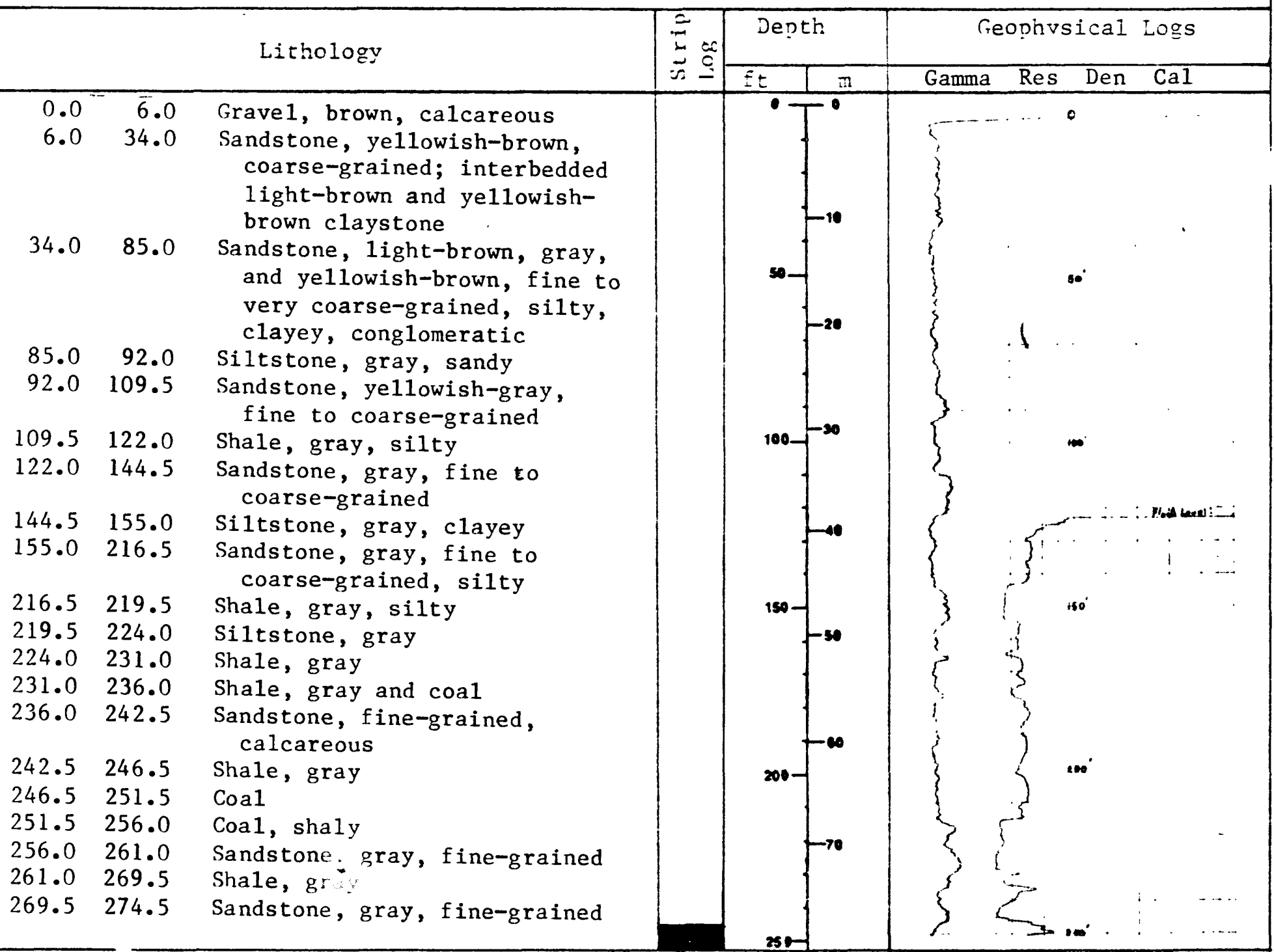




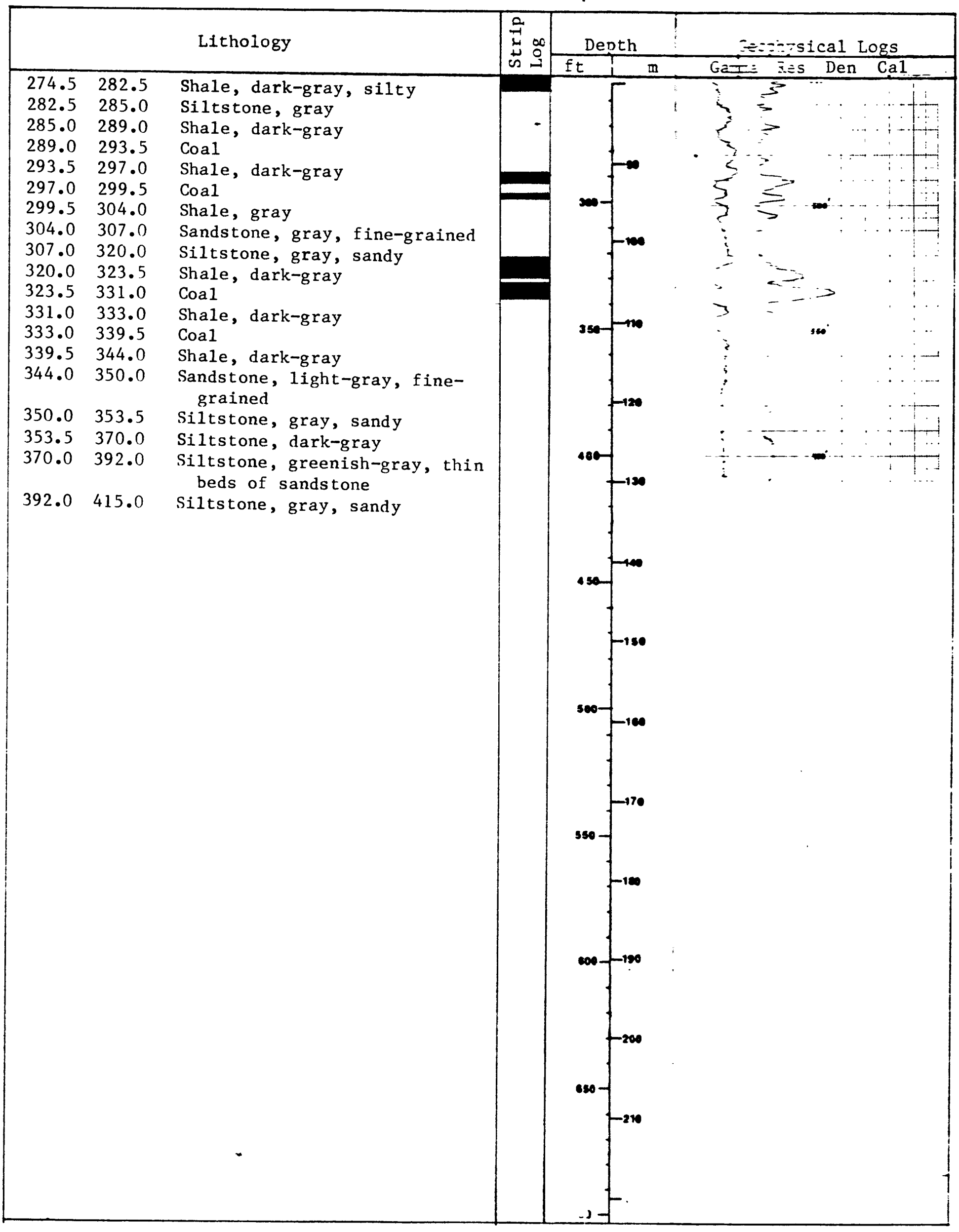




\section{LITHOLOGIC AND GEOPHYSICAL LOGS}

LOCATION NLMBER

$P R-22$

DATE $6 / 21 / 80$

SURFACE ELEVATION(ft) 7270

LOCATION

NW NW SE

Sec. 8 T. $19 \mathrm{~N}$.

R. $77 \mathrm{~W}$

Quad.Pierce Reservoir

COLNTY Albany

STATE Wyoming

TOTAL DEPTH(ft) 155

CORED

YES
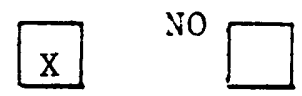

INTERVAL (s)

DRILLING MEDILM:
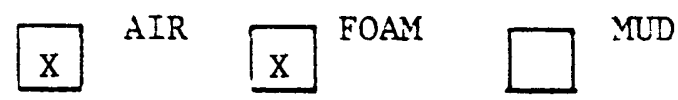

$\square$ WATER OBSERVATION WELL

GEOPHYSICAL LOGS:

Natural Gamma

Gamma Ganna

Resistivity

Caliper

\begin{tabular}{ll}
$;$ & Scale $200 \mathrm{CPS} / \mathrm{IN}$ \\
$;$ & Scale \\
$;$ & Scale $\mathrm{KCPS/IN}$ \\
\hline
\end{tabular}

Logging Speed Logging Speed Logging Speed Logging Speed
Lithology

$0.0 \quad 2.0$ Soil, rock, grave 1 , brown

2.010 .0 Shale-claystone, brown, sandy

10.020 .0 Sandstone, light-yellowishbrown, very fine grained, silty

20.026 .0 Siltstone, brownish-gray to dark-olive-gray

26.0 30.0 Shale, dark-brown to black

30.032 .0 Shale-claystone, medium-gray

32.036 .0 Shale, black, carbonaceous;

$36.0 \quad 40.5$ Coal

$40.5 \quad 42.8$ Shale, black, carbonaceous

42.8 45.0 Sandstone, light-gray, finegrained

45.0 63.5 Siltstone and sandstone, 1ight to medium-gray, interbedded. Sandstone is very fine-grained

63.5 66.3 Sandstone, gray, very fine grained

66.3 79.0 Sandstone and siltstone, medium to medium-dark-gray, interbedded. Sandstone is very fine-grained

79.0 89.0 Siltstone and sandstone, medium-dark-gray, interb - led. Sandstone is very $f$. $-g$ rained

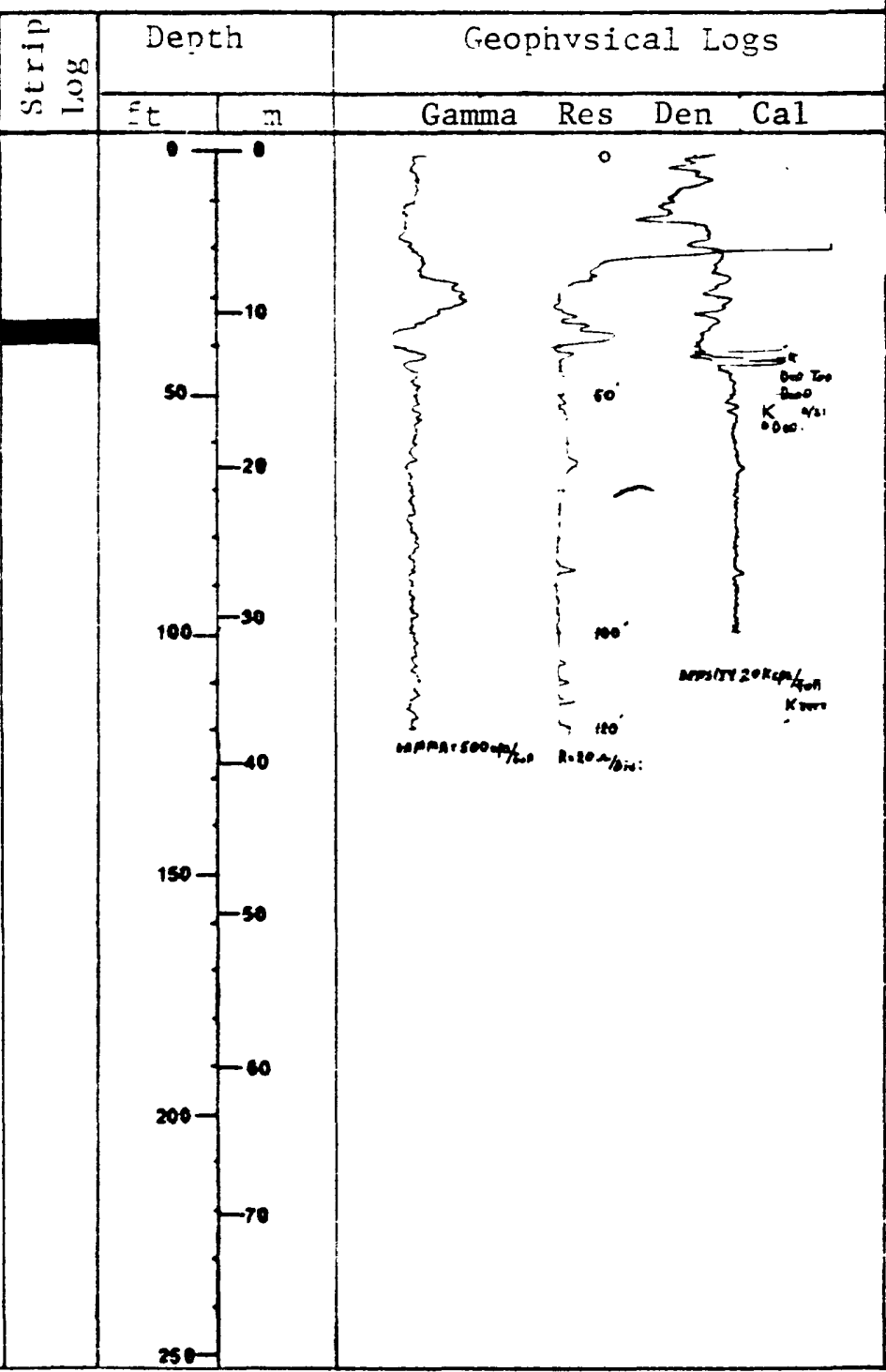


$P R-22$

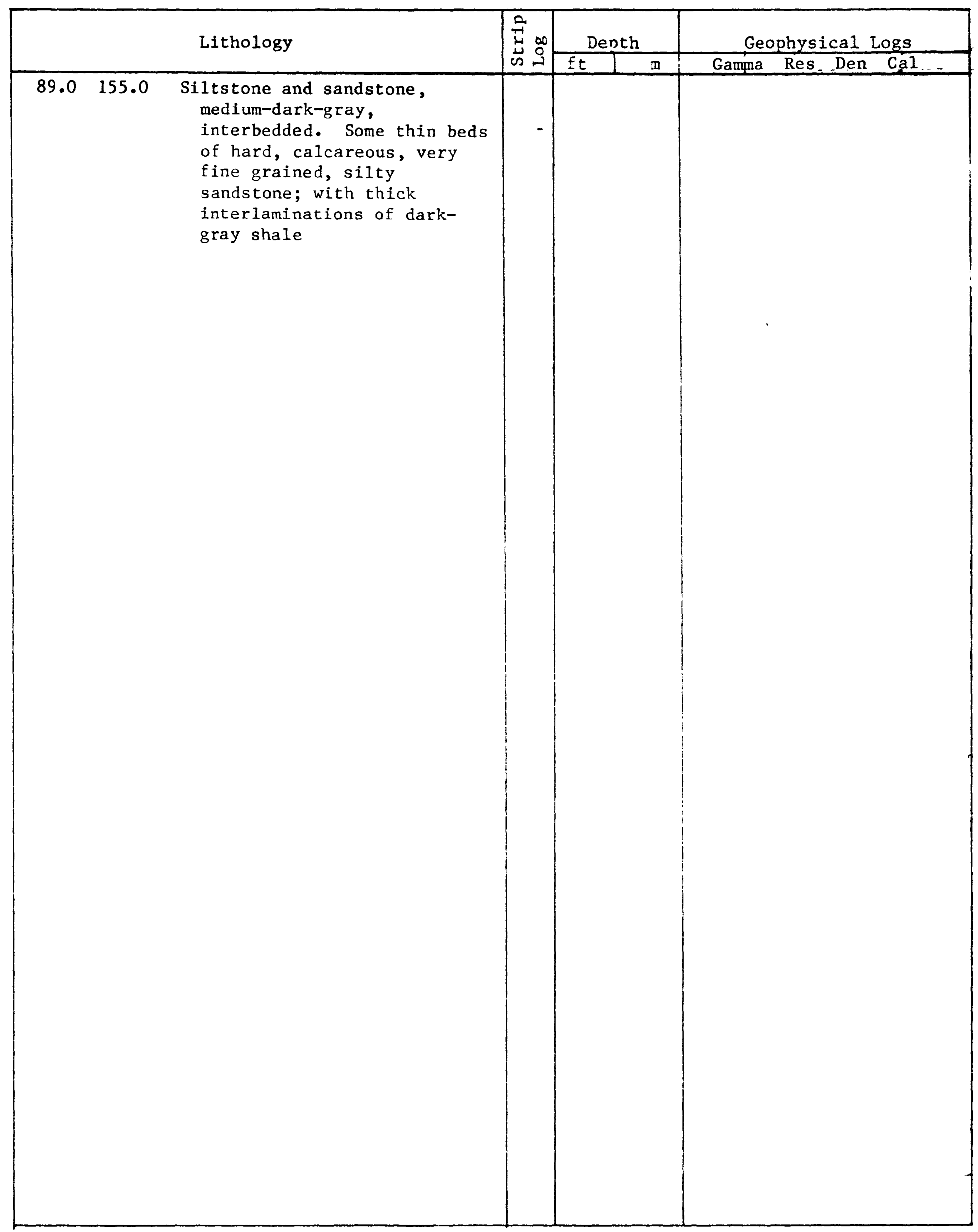

51 